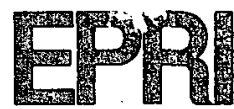

Electric Power

Research Institute
Topics:

Bacteria-Legionella

Cooling systems

Legionnaires' disease bacterium

Microbiology

Water quality

Environmental studies
EPRI EA-4017

Project 1909-1

Interim Report

April 1985

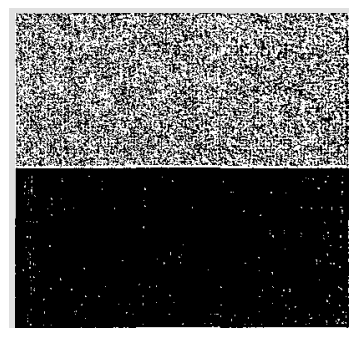

\title{
Legionnaires Disease Bacteria in Power Plant Cooling Systems: Phase 2
}

Prepared by

Oak Ridge. National Laboratory

Oak Ridge, Tennessee 


\section{DISCLAIMER}

This report was prepared as an account of work sponsored by an agency of the United States Government. Neither the United States Government nor any agency Thereof, nor any of their employees, makes any warranty, express or implied, or assumes any legal liability or responsibility for the accuracy, completeness, or usefulness of any information, apparatus, product, or process disclosed, or represents that its use would not infringe privately owned rights. Reference herein to any specific commercial product, process, or service by trade name, trademark, manufacturer, or otherwise does not necessarily constitute or imply its endorsement, recommendation, or favoring by the United States Government or any agency thereof. The views and opinions of authors expressed herein do not necessarily state or reflect those of the United States Government or any agency thereof. 


\section{DISCLAIMER}

Portions of this document may be illegible in electronic image products. Images are produced from the best available original document. 


$R$ E P O R T S U M M A R $Y$

SUBJECTS Water quality/aquatic resources / Human health studies / Water quality control

TOPICS

Bacteria-Legionella

Cooling systems

Legionnaires' disease bacterium
Microbiology

Water quality

Environmental studies

AUDIENCE Safety officers/Environmental managers

EPRI-EA--4017

DE85 011546

\section{Legionnaires' Disease Bacteria in Power Plant Cooling Systems: Phase 2}

Water temperature and quality, along with other aquatic organisms, affect the existence of infectious Legionella in power plant cooling water. However, the interaction of these factors is so complex that scientists are far from being able to predict the growth and infectivity of these bacteria.

BACKGROUND Legionnaires' disease bacteria (Legionella)-part of the normal aquatic community - can become infectious to human beings if aerosolized.

Phase 1 of this study confirmed that Legionella-at levels not usually considered a health hazard-do exist in power plant cooling systems (EPRI report EA-3153). To determine whether control procedures may be desirable at power plants required more information on what physical, chemical, and biological characteristics of cooling waters promote Legionella growth and infectivity.

OBJECTIVES To identify and quantify the components of power plant cooling waters that promote Legionella growth or infectivity.

APPROACH The work in this phase of the study consisted primarily of laboratory experiments directed toward understanding the environmental parameters affecting Legionella growth. In the experiments, researchers used both individual laboratory strains of Legionella and natural populations of mixed species and types. Preparatory studies examined the effects of storing Legionella samples on the density and infectivity of the bacteria and calibrated the experimental inoculation system. In the basic experiments, scientists investigated the effects of temperatures ranging from 32 to $45^{\circ} \mathrm{C}$ and used intake and discharge water from several power plants to evaluate the effects of different levels of water quality. In addition, they studied interactions between Legionella and associated living components in the water, such as algae, fungi, and other bacteria.

RESULTS These laboratory tests indicate that much work remains before scientists identify the factors affecting the density or infectivity of Legionella. This study showed that all three environmental factors under study do influence Legionella growth, but their effects vary by species and/or type. Some Legionella, for example, withstood water temperatures of $85^{\circ} \mathrm{C}$ for several 
EPRI PERSPECTIVE

hours. And, unexpectedly, a high incubation temperature $\left(42^{\circ} \mathrm{C}\right)$ stimu- , lated the growth of some indigenous Legionella groups but inhibited that of laboratory cultures of the same groups. It appears that the innate characteristics of certain populations sometimes determine their growth responses. A finding that bodes well for further Legionella studies is that laboratory cultures retain their infectivity over time.

It is clear that four major factors complicate the study of Legionella: (1) The composition of populations varies from place to place and over time at any one place. (2) The physical and chemical parameters affecting Legionella populations also vary over space and time. (3) No one yet knows whether the effects of other organisms on the abundance of Legionella result from direct interaction or from the effects of those organisms on the environment. (4) No studies have determined the infectivity of any one Legionella group in an environmental sample. Methodologies developed during this study show promise, but the complexity of the problem makes it unlikely that scientists will develop reliable assessment tools in the near future.

PROJECT RP1909-1

EPRI Project Manager: Jack S. Mattice

Energy Analysis and Environment Division

Contractor: Oak Ridge National Laboratory

For further information on EPRI research programs, call EPRI Technical Information Specialists (415) 855-2411. 


\title{
Legionnaires' Disease Bacteria in Power Plant Cooling Systems: Phase 2
}

\author{
EA-4017 \\ Research Project 1909-1 \\ Interim Report, April 1985
}

EPRI-EA--4017

DE85 011546

Prepared by

OAK RIDGE NATIONAL LABORATORY

Environmental Sciences Division

Post Office Box $X$

Oak Ridge, Tennessee 37831

Editor

S. W. Christensen

$$
\begin{array}{cc} 
& \text { Authors } \\
\checkmark & \text { R. L. Tyndall } \\
\checkmark & \text { S. W. Christensen } \\
\checkmark & \text { J. A. Solomon } \\
& \text { Subcontractors }
\end{array}
$$

UNIVERSITY OF TENNESSEE

Knoxville, Tennessee 37916

Author

R. L. Tyndall

ECOLOGICAL MICROBES UNLIMITED

Augusta, Georgia 30909

Author

C. B. Fliermans

Prepared for

Electric Power Research Institute

3412 Hillview Avenue

Palo Alto, California 94304

EPRI Project Manager

J. S. Mattice

Ecological Studies Program

Energy Analysis and Environment Division 


\section{ORDERING INFORMATION}

Requests for copies of this report should be directed to Research Reports Center (RRC), Box 50490, Palo Alto, CA 94303, (415) 965-4081. There is no charge for reports requested by EPRI member utilities and affiliates, U.S. utility associations, U.S. government agencies (federal, state, and local), media, and foreign organizations with which EPRI has an information exchange agreement. On request, RRC will send a catalog of EPRI reports.

\section{DISCLAIMER}

This report was prepared as an account of work sponsored by an agency of the United States Government. Neither the United States Government nor any agency thereof, nor any of their employees, makes any warranty, express or implied, or assumes any legal liability or responsibility for the accuracy, completeness, or usefulness of any information, apparatus, product, or process disclosed, or represents that its use would not infringe privately owned rights. Reference herein to any specific commercial product, process, or service by trade name, trademark, manufacturer, or otherwise does not necessarily constitute or imply its endorsement, recommendation, or favoring by the United States Government or any agency thereof. The views and opinions of authors expressed herein do not necessarily state or reflect those of the United States Government or any agency thereof.

\section{NOTICE}

This report was prepared by the organization(s) named below as an account of work sponsored by the Electric Power Research Institute, Inc. (EPRI). Neither EPRI, members of EPRI, the organization(s) named below, nor any person acting on behalf of any of them: (a) makes any warranty, express or implied, with respect to the use of any information, apparatus, method, or process disclosed in this report or that such use may not infringe privately owned rights; or (b) assumes any liabilities with respect to the use of, or for damages resulting from the use of, any information, apparatus, method, or process disclosed in this report.

Prepared by

Oak Ridge National Laboratory

Oak Ridge, Tennessee 
Legionnaires' Disease Bacteria (Legionella) are a normal component of the aquatic community. The Phase II study investigated various environmental factors that affect Legionella profiles in power plant cooling waters, and finalized the interpretation of the Phase I results. The results of Phase II experiments indicate that each of the four factors investigated (incubation temperature, water quality, the presence and type of assoclated biota, and the nature of the indigenous Legionella population) is important in determining the Legionella profile of these waters. Simple predictive relationships were not found.

Observations made during the Phase II research should be valuable in future investigations of Legionella. At incubation temperatures of $32^{\circ}$ and $37^{\circ} \mathrm{C}$, waters from a power plant where infectious Legionella were not observed stimulated the growth of stock Legionella cultures more than did waters from plants where infectious Legionella were prevalent. This observation is consistent with Phase 1 results, which showed that densities of Legionella were frequentiy reduced in closed-cycle cooling systems despite the often higher infectivity of Legionella in closed-cycle waters. In contrast, water from power plants where infectious Legionella were prevalent supported the growth of indigenous Legionella pneumophila at $42^{\circ} \mathrm{C}$, while water from a power plant where infectious Legionella were absent did not support the growth of indigenous Legionella. Some Legionella are able to withstand a water temperature of $85^{\circ} \mathrm{C}$ for several hours, thus proving more tolerant than was previously realized. Finally, the observation that water from two power plants where infectious Legionella were prevalent usually supported the growth of Group A Legionella at $45^{\circ} \mathrm{C}$ indicates the presence of soluble Legionella growth promoters in these waters. This test system could allow for future identification and control of these growth promoters and, hence, of Legionella. 


\section{ACKNOWLEDGMENTS}

This report was prepared as an interim document for Research Project 1909-1 of the Electric Power Research Institute (EPRI) of Palo Alto, California. We express our appreciation to the EPRI project manager, Jack Mattice, for his assistance and advice throughout the conducting of the research and the preparation of this report. We are also grateful to the following members of the Project Advisory Committee for their ongoing reviews and suggestions, which have been very helpful: James Bechthold, Thomas Bott, Frank Boucher, Tony Branan, John Brellenthin, Harold Eitzen, Morris French, Robert Kavet, Glen Küh1, James Lancour, and Cary Young. We thank Rebecca Jernigan and Cynthia Evans for their expert technical assistance during this project, and Anthony Palumbo and Bruce Kimmel for their thoughtful reviews of and comments on this report. Finally, we gratefully acknowledge the considerable assistance of the Environmental Sciences Division's Editorial office and Word Processing Center in the preparation of this document. Publication No. 2452, Environmental Sciences Division, Oak Ridge National Laboratory. 


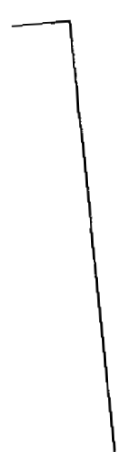


CONTENTS

Section Page

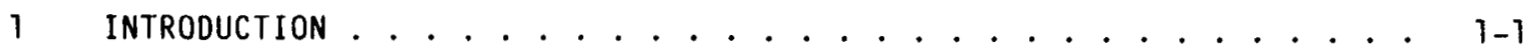

2

OVERVIEW . . . . . . . . . . . . . . . . . 2-1

Preparatory Studies................ . . 2-1

Effect of Sample Storage on Legionella Density

and Infectivity .................. 2-1

Calibration of the Guinea Pig System .......... 2-1

Development of a Test System For Defining

Environmental Influences on Growth of Legionella ....... 2-2

Growth of Environmental Isolates in Culture ....... 2-4

Growth of Mixed Natural Populations in Power Plant Water . 2 2-5

Incubation without Manipulation ......... 2-5

Pellet Exchange Experiments ........... 2-5

Separation of Components Experiments . . . . . 2-5

Growth of Mixed Natural Populations in Lake Water:

Nitrate Enrichment Experiment ........... . 2-5

Field Experiments................... 2-6

Membrane Chambers ................ 2- 2-6

Closed-Cycle Cooling System Intenstue Sampling..... 2-6

Further Investigation of a Suspected New Species . . . . . 2-7

3 MATERIALS AND METHODS ...........................

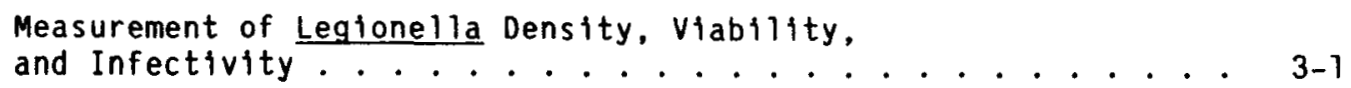

Measurement of Legionella Density ........... . . 3-1

Measurement of Legionella Viability .......... . 3-1

Measurement of Legionella Infectivity ......... 3-1

Preparatory Studies . . . . . . . . . . . . . 3-2

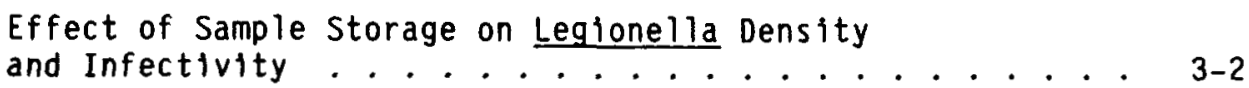

Calibration of the Guinea Pig System.......... . 3-2

Laboratory Experiments . . . . . . . . . . . . . . . 3-3

Growth of Environmental Isolates in Culture ...... 3-3 
Growth of Mixed Natural Populations in Power Plant Water . - 3-4

Incubation Without Manipulation . . . . . . . . . 3-4

Pellet Exchange Experiments . . . . . . . . . . 3-4

Separation of Components Experiments . . . . . . . 3-4

Growth of Mixed Natural Populations in Lake Water:

Nitrate Enrichment Experiment . . . . . . . . . . . 3-5

Field Studies . . . . . . . . . . . . . . . . . . 3-5

Membrane Chambers .. . . . . . . . . . . . . . 3-5

Closed-Cycle Cooling System Intensive Sampling . . . . . . 3-6

Further Investigation of a Suspected New Species . . . . . . . 3-6

RESULTS AND DISCUSSION . . . . . . . . . . . . . . . . . . . . . . 4-1

Preparatory Studies . . . . . . . . . . . . . . . . . 4-1

Effect of Sample Storage on Legionella Density

and Infectivity .................... . . . 4-1

Calibration of the Guinea Pig System . . . . . . . . . . . 4-3

Development of a Test System for Defining

Environmental Influences on Growth of Legionella . . . . . . . . 4-5

Growth of Environmental Isolates in Culture . . . . . . . 4 4-6

Growth of Mixed Natural Populations in Power Plant Water . 4-9

Incubation Without Manipulation.......... . 4-10

Pellet Exchange Experiments ... . . . . . . . . 4-14

Separation of Components Experiments . . . . . . . . 4-29

Growth of Mixed Natural Populations in Lake Water:

Nitrate Enrichment Experiment . . . . . . . . . . . . 4-32

Fleld Experiments . . . . . . . . . . . . . . . . . . . . 4-36

Membrane Chambers .. . . . . . . . . . . . . . . 4-36

Closed Cycle Cooling System Intensive Sampling . . . . . . . 4-39

Further Investigation of a Suspected New Species . . . . . . . . 4-42

5 INTEGRATION • • . . . . . . . . . . . . . . . . . . . . . . . . . 5-1

Complexity of Laboratory Work With Environmental Samples . . . . 5-1

Significance of the Persistently Infectious

Environmental Isolate . . . . . . . . . . . . . . . . 5-2

Legionella in the Power Plant Environment . . . . . . . . . . . 5-3

6 REFERENCES . . . . . . . . . . . . . . . . . . . . . . . . 6-1

7 GLOSSARY . . . . . . . . . . . . . . . . . . . . . . . . 7-1

8 APPENDIX TABLES . . . . . . . . . . . . . . . . . . . . . . . . A-1 


\section{ILLUSTRATIONS}

4-1 Calibration of guinea pig system: Isolation of Legionella pneumophila, serogroup 1 (Knoxville), from three guinea pig tissues after intraperitoneal inoculation of four animals, as a function of number $\left(\log _{10}\right)$ of low- or high-virulence cells injected ............... 4-4

4-2 ENV-2: Growth index (see glossary) of high- and low-virulence Legionella pneumophlla, serogroup 1 (Knoxville), in negative and positive plant waters at three temperatures ........ . 4-7

4-3 ENV-4: Density of Legionella spp. from plant B, incubated at three temperatures $\left[\log _{10}\right.$ (mean cell number $/ \mathrm{mL}$ ) ] . . . . . . . 4-11

4-4 ENV-4: Density of Legionella spp. from plant $F$ at three

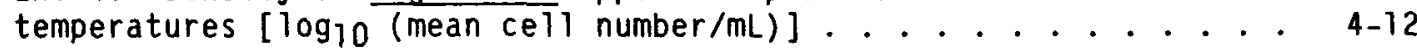

4-5 ENV-4: Density of Legionella spp. from plant $G$ at three

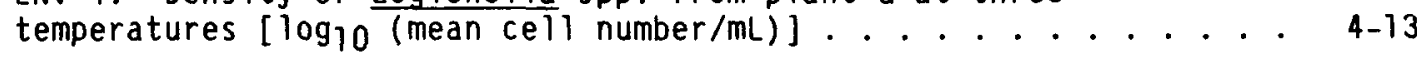

4-6 ENV-5: Density of Legionella spp. from plant B at $32^{\circ} \mathrm{C}$ in water from two power plants $\left[\log _{10}\right.$ (mean cell number $/ \mathrm{mL}$ ) \pm 1 S.E.

4-7 ENV-5: Density of Legionella spp. from plant B at $45^{\circ} \mathrm{C}$ in water from two power plants $\left[\log _{10}\right.$ (mean cell number $/ \mathrm{mL}$ ) \pm 1 S.E.

4-8 ENV-5: Density of Legionella spp. from plant $F$ at $32^{\circ} \mathrm{C}$ in water from two power plants $\left[\log _{10}\right.$ (mean cell number $/ \mathrm{mL}$ ) \pm 1 S. E

4-9 ENV-5: Density of Legionella spp. from plant $F$ at $45^{\circ} \mathrm{C}$ in water from two power plants $\left[\log _{10}\right.$ (mean cell number $/ \mathrm{mL}$ ) \pm 1 S.E.

4-10 ENV-6: Density of Legionella spp. from plant B incubated in water from two power plants [ $\log _{10}$ (mean cell number $/ \mathrm{mL}$ ) \pm 1 S.E.

4-11 ENV-6: Density of Legionella spp. from plant B incubated in water from two power plants [ $\log _{10}$ (mean cell number $/ \mathrm{mL}$ ) \pm 1 S.E.

4-12 ENV-6: Density of Leglonella spp. from plant $F$ incubated in water from two power plants $\left[\log _{10}\right.$ (mean cell number $/ \mathrm{mL}$ ) \pm 1 S.E.] 
4-13 ENV-6: Density of Legionella spp. from plant $F$ incubated in water from two power plants $\left[\log _{10}\right.$ (mean cell number $/ \mathrm{mL}$ )

4-14 ENV-7: Density of Legionella spp. from plant $B$ at $32^{\circ} \mathrm{C}$ incubated in water from two power plants $\left[\log _{10}\right.$ (mean cell number $/ \mathrm{mL}$ ) \pm 1 S.E.]

4-15 ENV-7: Density of Legionella spp. from plant B at $45^{\circ} \mathrm{C}$ incubated in water from two power plants $\left[\log _{10}\right.$ (mean cell number $/ \mathrm{mL}) \pm 1$ S.E.] .............. 4-26

4-16 ENV-7: Density of Legionella spp. from plant $F$ at $32^{\circ} \mathrm{C}$ incubated in water from two power plants $\left[\log _{10}\right.$ (mean cell number $/ \mathrm{mL}) \pm 1$ S.E.] ............... 4-27

4-17 ENV-7: Density of Legionella spp. from plant $F$ at $45^{\circ} \mathrm{C}$ incubated in water from two power plants $\left[\log _{10}\right.$ (mean cell number $/ \mathrm{mL}) \pm 1$ S.E.] ................ 4-28

4-18 ENV-8: Density of Legionella pneumophila, serogroups 1-4, from plant $F$ incubated in plant $B$ water at $45^{\circ} \mathrm{C}\left[\log _{10}\right.$ (mean cel1 number $/ \mathrm{mL}) \pm 1$ S.E.] . . . . . . . . . . . 4 4-30

4-19 ENV-8: Density of Legionella pneumophila, serogroups 1-4, from $p$ lant $F$ incubated in plant $F$ water at $45^{\circ} \mathrm{C}\left[\log _{10}\right.$ (mean cell number $/ \mathrm{mL}) \pm 1$ S.E.] ................ 4-31

4-20 ENV-9: Density of Legionella pneumophila, serogroups 1-4, from $p$ lant $H$ incubated in plant $B$ water at $45^{\circ} \mathrm{C}\left[\log _{10}\right.$ (mean cell number $/ \mathrm{mL}) \pm 1$ S.E.] ................44-33

4-21 ENV-9: Density of Legionella pneumophila, serogroups 1-4, from $p$ lant $H$ incubated in plant $H$ water at $45^{\circ} \mathrm{C}\left[\log _{10}\right.$ (mean cel1 number $/ \mathrm{mL}) \pm 1$ S.E.] . . . . . . . . . . . . . 4-34

4-22 ENV-10: Density of Legionella spp. from the epilimnion of Normandy Lake, Tennessee, incubated at $32^{\circ} \mathrm{C}$ with nitrate enrichment $\left[\log _{10}\right.$ (mean cell number $\left./ \mathrm{mL}\right) \pm 1$ S.E.] . . . . . . 4-37

4-23 ENV-10: Density of Legionella spp. from the metalimnion of Normandy Lake, Tennessee, incubated at $32^{\circ} \mathrm{C}$ with nitrate enrichment $\left[\log _{10}\right.$ (mean cell number $\left./ \mathrm{mL}\right) \pm 1$ S.E. $] \ldots . . . .4$ 4-38 
TABLES

Table

Page

1-1 Legionella Detected Using Polyvalent Antisera . . . . . . . . . 1-2

1-2 Cooling System Characteristics and Geographic Location of Power Plants in the Phase II Study............... 1-3

1-3 Summary of Laboratory Experiments ............... 1-5

4-1 Effect of Storage on Densities (Cells/mL) of Legionella...... . 4-2

4-2 Effect of Storage on Infectivity of Legionella ......... 4-2

4-3 Quantity of L. pneumophila (no. of cells $\times 10^{-3}$ ) from Phase I Environmental samples Injected into Guinea Pigs from which

L. pneumophila were Subsequently Isolated ............4-6

4-4 ENV-3: Effects of Temperature and Water Quality on Percentage of Legionella pneumophila Viable in Culture........... 4-10

4-5 Infectivity Tests of Samples from Experiment Env-9......... 4-35

4-6 Densities of Legionella Relative to the Type of Associated Biota at Plant G............... . 4-40

4-7 Characteristics of Untypeable Legionella Isolated from Plant D . . 4-42 


\section{SUMMARY}

In Phase I of this study (Christensen et al. 1983) the density, viability, and infectivity of Legionnaires' Disease Bacteria (Legionella) in the cooling systems of nine power plants, identifled as A through I, were determined. The Phase II studies had two major objectives. The first was to develop an exploitable test system which could be used to identify those components of power plant cooling waters which promote the growth and/or infectivity of Legionella populations. The second major objective was to elucidate further and expand the interpretation of Phase I results. The Phase II studies consisted of four elements designed to meet these objectives: preparatory studies, laboratory experiments, field studies, and characterization of the second new species discovered during Phase I.

A preparatory study examined the effects of sample storage on Legionella, density and infectivity. This was important for validating the use of Phase I results in designing Phase II experiments. Sample storage of up to $8 \mathrm{~d}$ at room temperature had no marked effects on elther the density or infectivity of Legionella, and therefore did not change our interpretation of the results obtained in the Phase I study.

A second preparatory study calibrated the guinea pig system for evaluating the infectivity of Legionella. Preliminary observations indicated that different environmental isolates of $\underline{L}$. pneumophila, serogroup 1, varied in their infectivity to guinea pigs. One such isolate (low-virulence) required injection of greater numbers of Legionella to establish infection than did another isolate (high-virulence). The calibration study demonstrated that an inoculation of about a thousandfold more low-virulence Legionella than high-virulence Legionella were required to infect guinea pigs. This was important in defining the scale of subsequent laboratory experiments. In addition, assuming that the infectious potential of Legionella in nature is similar to that of the stock cultures used in Phase II tests, the results show that the numbers of Legionella injected into guinea pigs in the Phase I studies were generally sufficient to enable high- but not low-virulence Legionella to cause infection. Therefore, samples designated as being infectious in Phase I probably contained 
high-virulence Legionella rather than simply overwheiming numbers of low-virulence Legionella.

The main series of laboratory experiments was aimed at understanding the environmental parameters affecting Legionella growth, which would form the basis for an exploitable test system for defining growth promoters of Legionella. Initial experiments tested the effects of water quality at several power plants on the growth and viability of laboratory (stock) cultures of high- and low-virulence Legionella isolates. The results indicated a very complex interaction between the test organisms, incubation temperature, and water-quality differences. Both temperature and water quality affected Legionella growth. Filtered water from plants $F$ and $G$, where infectious Legionella had been repeatedly isolated (denoted as "positive plant water"), inhibited the growth of both high- and low-virulence stock $\underline{L}$. pneumophila cultures. From a hundredfold to a thousandfold more bacteria were needed to initiate growth at $37^{\circ} \mathrm{C}$ in yeast extract media containing those waters than were needed in media containing distilled water or "negative plant water" from plant $B$, where infectious Legionella could not be isolated. Growth of both high-and low-virulence $L$. pneumophila was markedly inhibited at $42^{\circ} \mathrm{C}$ in media containing all test waters. In the viability tests, the lag time (delay before rapid growth) of the high-virulence strain was longer than that of the low-virulence strain. In addition, viability levels on the first day of visible growth were higher for bacteria growing in negative plant water than for those growing in positive piant water. Overall, these results demonstrate that water source and temperature did affect these laboratory Legionella cultures.

Subsequent experiments used indigenous Legionella (populations collected from power plant cooling systems) rather than the stock cultures. These were grown in media composed entirely of power plant water. The results confirmed the previous observation of water-quality and temperature effects but also indicated the occurrence of complex interactions between Legionella, associated biota, temperature, and water-quality factors. Perhaps the most unexpected difference with the indigenous populations was the observation that a high $\left(42^{\circ} \mathrm{C}\right)$ incubation temperature stimulated the growth of some of the indigenous Legionella groups, in contrast to the inhibitory high-temperature effect observed in laboratory cultures of the same groups. This high-temperature stimulation effect was found for two different groups of Legionella, group $C$ Legionella in plant $B$ water and group $A$ Legionella in plant $F$ water. 
These results confirmed the importance of temperature and water source to Legionella growth, but did not resolve the question of whether the observed responses reflected differences in the Legionella populations or differences in water quality. To address this question, we conducted experiments in which indigenous Legionella populations were resuspended either in the water from which they were removed or in water from another site. Results indicated that, in addition to water temperature, water quality, and particulate material, the innate characteristics of the indigenous Legionella populations sometimes determine growth responses.

A further set of experiments separated the indigenous population into components using density-gradient centrifugation, and examined growth of group A Legionella in unfiltered and filtered (particle-free) positive and negative plant waters. The positive waters, from plants $F$ and $H$, usually sustained the growth of indigenous group $A$ Legionella at $45^{\circ} \mathrm{C}$, while the negative waters did not. This finding was significant because it suggested an exploitable test system which might lead to strategies for controlling Legionella growth. Technologies exist for isolating and identifying filterable (i.e. soluble) aquatic moleties. If the entities supporting Legionella growth were isolated and identified, means for the control or eradication of the Legionella they support could be considered.

The effects of nitrate, a soluble component of water, on Legionella growth were examined in a laboratory experiment using water from a nitrate-limited reservoir. This experiment tested whether, as the Phase I study suggested, nitrate concentrations may be positively related to population densities of Legionella. Initial counts showed that levels of groups $A$ and $B$ Legionella in the nitrate-iimited lake were significantly higher in the metalimnetic (5-m depth) water than in the epilimnetic (2-m depth) water. During incubation, however, added nitrate did not stimulate the growth of groups $A$ and $B$ Legionella populations. Considering the laboratory experiments as a whole, temperature, water quality, particulate material, and the initial composition of the Legionella population were the parameters suggested as influencing the Legionella profile of power plant waters.

Field studies were aimed at extending the laboratory results. These consisted of studies using membrane chambers as a possible means of investigating growth-related factors in the field and sampling Legionella in conjunction with other blota at numerous locations within a closed-cycle cooling system. The 
membrane chambers were found to need further development for use in the context of this study; such development was not pursued. Results of the intensive field sampling were consistent with results obtained from other work in that they implicated foam, nearby excavation, and certain protozoans as factors associated with higher densities of Legionella, although the associations may not be causal.

The characterization studies defined the second new species of Legionella (Legionella cherrii) and confirmed the Phase I hypothesis that the serologically untypeable Legionella isolated from plant $D$ may have been a new species. Unlike Legionella oakridgensis, also isolated in the Phase I study, L. cherrii are more typical of other members of the genus. The fatty acid profile and the ONA relatedness of $\underline{L}$. cherrij are not as distinctive as those of $\underline{L}$. oakridgensis. While $L$. cherrii was infectious to guinea pigs, as indicated by its isolation from moribund test animals, the possible involvement of $\underline{L}$. cherrif in human disease is unknown. 
Section 1

INTRODUCTION

Legionnaires' Disease Bacteria (Legionella) are a component of the normal aquatic community (Fliermans et al. 1979) that, when aerosolized, can be pathogenic to man (McDade et a1. 1977). Studies on the source of infection in various outbreaks of Legionella have implicated cooling towers used in air conditioning systems (Deubner and Gilliam 1977; CDC 1978; Fraser et al. 1979). Power plant cooling towers and cooling lakes typically contain heated water, and Legionella are known to tolerate elevated temperatures (Fliermans et a1. 1981a). Electric energy production also increases the temperature of once-through cooling waters. These considerations, coupled with the observation that infectious Legionella are present in heated waters from industrial plants (Fliermans et al. 1981a), indicated that further studies were needed to evaluate the current extent of and options for control of Legionella populations in cooling waters. Accordingly, the Electric Power Research Institute (EPRI) judged it desirable to support a study of Legionella in power plant cooling systems.

Phase I of this study (Christensen et al. 1983) involved a seasonal survey of ambient and plant-affected water at nine power plant sites located in the eastern half of the United States. Legionella were detected in $98 \%$ of all samples. Water from closed-cycle cooling systems frequently had lower densities of Legionella than did the ambient water. However, infectious Legionella, as defined by their isolation from sick guinea pigs after inoculation, were found more frequently in plant-exposed water of closed-cycle plants than in water from once-through plants or amblent samples. Analyses indicated a number of physical and chemical variables that may be related to Legionella density, viability, and infectivity, but cause and effect relationships could not be established from Phase I data. A new species (Legionella oakridgensis) was initially isolated from three of the sites, and its distribution has since been found to be widespread (Orrison et a1. 1983; Tyndall et al. 1983). Another organism found to cause 171 ness in guinea pigs was considered to be a potentially new species. 
Phase II had two major objectives: to develop an exploitable test system which could be used in the identification of those components of power plant cooling waters which promote the growth or infectivity of Legionella populations, and to elucidate further and expand the interpretation of Phase I results. The Phase II studies consisted of four elements designed to meet these objectives: preparatory studies, laboratory experiments, field studies, and characterization of the second new species discovered during Phase I.

A preparatory study examined the effects of sample storage, which was sometimes unavoldable in Phase $I$, on Legionella density and infectivity. This validated conclusions which formed the basis of the Phase II design. An additional preparatory study calibrated the guinea pig inoculation system for evaluating the infectivity of Legionella, as a further basis for Phase II design.

The majority of the Phase II study, however, consisted of laboratory experiments directed toward understanding the environmental parameters affecting Legionella growth, which would form the basis for an exploitable test system for defining Legionella growth parameters. The three major environmental parameters investigated were temperature, water quality, and the associated biota. These were selected based on their relevance to power plant cooling systems and the implication of their being important factors in Phase $I$ or other studies of Legionella. In addition, the experiments used either individual laboratory strains of Legionella or natural populations containing a mixture of species and serogroups (Table 1-1).

Table 1-1

Legione 11a DETECTED USING POLYVALENT ANTISERA

Group A: Legionella pneumophila, serogroups 1 through 4 (Knoxville, Togus, Bloomington, and Los Angeles).

Group B: L. pneumophila, serogroups 5 and 6 (Dallas and Chicago); L. dumoffii, serogroup 1 ; and $\underline{L}$. longbeachae, serogroup 1 .

Group C: ㄴ. micdadei, serogroup 1; L. bozemani i, serogroup 1; ㄴ. gormanii. serogroup 1 ; and $\underline{L}$. longbeachae, serogroup 2 . 
Temperature was included because elevated temperatures had already been implicated as positively affecting Legionella growth or infectivity. In addition, the environment under study was the power plant cooling system, an inherent component of which is warmed water. Temperatures used ranged from a low of $32^{\circ} \mathrm{C}$ to a high of $45^{\circ} \mathrm{C}$, with one inadvertent $85^{\circ} \mathrm{C}$ exposure.

From the Phase I study it was known that there were wide and changing variations in water quality between the different plants. Water quality is a broad term that includes a range of unmeasured parameters associated with soluble components (e.g., pH, conductivity, sulfate, nitrate, dissolved oxygen, organic compounds, etc.). Water from different power plants (Table 1-2), as well as Oak Ridge National Laboratory (ORNL) laboratory-distilled water, was used to provide different levels of water quality.

The associated blota includes all other living components of the system potentially affecting Legionella--primarily algae, fungi, and other sacteria--but also some viruses, small invertebrates, and protozoans. Various

Table $1-2$

COOLING SYSTEM CHARACTERISTICS AND GEOGRAPHIC LOCATION

OF POWER PLANTS IN THE PHASE II STUDY

\begin{tabular}{|c|c|c|}
\hline Plant Code & $\begin{array}{l}\text { Cooling System } \\
\text { Characteristics }\end{array}$ & $\begin{array}{l}\text { Geographic } \\
\text { Location }\end{array}$ \\
\hline B & $\begin{array}{l}\text { Once-through, } \\
\text { reservoir. } \\
\text { no towers }\end{array}$ & Southern \\
\hline$D$ & $\begin{array}{l}\text { Once-through, } \\
\text { lake, no towers }\end{array}$ & Northern \\
\hline $\mathrm{F}$ & $\begin{array}{l}\text { Variable mode, } \\
\text { river, mechanical- } \\
\text { draft towers }\end{array}$ & Northern \\
\hline G & $\begin{array}{l}\text { Closed-cycle, river, } \\
\text { natural-draft towers }\end{array}$ & Northern \\
\hline$H$ & $\begin{array}{l}\text { Closed-cycle, river } \\
\text { mechanical-draft } \\
\text { towers }\end{array}$ & Northern \\
\hline
\end{tabular}


studies (Tison et a1. 1980; Tyndall and Domingue 1982) have indicated significant interactions between Legionella and other organisms.

The series of laboratory environmental experiments (Table 1-3) was begun using laboratory-maintained environmental isolates of individual strains of Legionella. In the power plant environment, however, a natural Legionella population is composed of a variety of different Legionella species (23 had been described by June 1983) as well as different serogroups of each species ( 8 serogroups of L. pneumophila were identified by June 1983). It is from a mixed natural population that an infectious serogroup is either selected (e.g., by elevated temperature) or produced (e.g., by mutation or transfer of a plasmid). To allow these mechanisms to operate, we decided early in the studies to work with the complexities of a natural mixed population.

Overal1, the laboratory regime consisted of initial experiments in which we attempted to rule out one or more of the factors of interest. The design of the next group of experiments depended on the outcome of this first group. By conducting these studies sequentialiy, we attempted to develop an exploitable test system from which the biologic or organic compounds stimulatory to Legionella growth or infectivity could be isolated and identified.

Field studies were aimed at extending the laboratory results. Membrane chambers were examined as a potential means of investigating growth-related factors in the field, and an intensive sampling survey of Legionella in relation to other biota in a closed-cycle system was undertaken.

Finally, characterization studies were performed on a serologically untypeable Legionella isolated from plant $D$ during Phase I (Christensen et al. 1983). The isolate proved to be a new species, now named Legionella cherrii.

Section 2 provides an overview of the Phase II studies. This overview is intended to clarify the logic underlying this rather complex experimental program. The Glossary, which constitutes Section 7 , also explains terms that may be unfamiliar or specialized. 
Table 1-3

SUMMARY OF LABORATORY EXPERIMENTS

\begin{tabular}{|c|c|c|c|c|c|}
\hline \multirow[b]{2}{*}{10 No. } & \multirow[b]{2}{*}{ Procedure } & \multirow{2}{*}{$\begin{array}{l}\text { Temp. } \\
\left(^{\circ} \mathrm{C}\right)\end{array}$} & \multirow{2}{*}{$\begin{array}{l}\text { Organism } \\
\text { Source } \\
\end{array}$} & \multicolumn{2}{|c|}{ Growth Medium } \\
\hline & & & & Water Source & Supplements \\
\hline ENV - 1 & $\begin{array}{l}\text { Titration } \\
\text { (incubation of } \\
\text { serial dilutions) } \\
\text { in algal extract }\end{array}$ & 37 & $\begin{array}{l}\text { L. pneumophila sg la } \\
\text { low- + hlgh. } \\
\text { virulence } \\
\text { lab cultures } \\
\text { (environmental } \\
\text { isolates) }\end{array}$ & $\begin{array}{l}\text { Diluted power } \\
\text { plant (B, F, G) } \\
\text { and distilled }\end{array}$ & $\begin{array}{l}\text { Algal } \\
\text { extract }\end{array}$ \\
\hline ENV - 2 & $\begin{array}{l}\text { Titration in } \\
\text { yeast extract }\end{array}$ & 42,37 & $\begin{array}{l}\text { L. } \frac{\text { pneumophlla }}{\text { low-thlgh-vir. }} \\
\text { lab cultures } \\
\text { (environmental } \\
\text { isolates) }\end{array}$ & $\begin{array}{l}\text { Diluted power } \\
\text { plant ( } B, F, G) \\
\text { and distilled }\end{array}$ & $\begin{array}{l}\text { Yeast } \\
\text { extract }\end{array}$ \\
\hline ENV-3 & $\begin{array}{l}\text { Determination } \\
\text { of Leglonella } \\
\text { viability levels } \\
\text { at titration } \\
\text { endpoints }\end{array}$ & ${ }_{42}^{32,} 37$ & $\begin{array}{l}\text { L. pneumophila sg } 1 \\
\text { low-thigh-vir. } \\
\text { lab cultures } \\
\text { (environmental } \\
\text { isolates) }\end{array}$ & $\begin{array}{l}\text { Diluted power } \\
\text { plant ( } B, F, G) \\
\text { and distilled }\end{array}$ & $\begin{array}{l}\text { Yeast } \\
\text { extract }\end{array}$ \\
\hline ENV-4 & $\begin{array}{l}\text { Incubation of } \\
\text { untreated power } \\
\text { plant waters }\end{array}$ & 42,37 & $\begin{array}{l}\text { Indigenous bacterial } \\
\text { population t } \\
\text { assoclated biota }\end{array}$ & Plants $B, F, G$ & None \\
\hline ENV-5 & $\begin{array}{l}\text { "Pellet exchange" } \\
\text { [ incubate: } \\
\text { (1) uncentrifuged } \\
\text { water } \\
\text { (2) centrifuged } \\
\text { Legionella } \\
\text { (a) in own water } \\
\text { (b) in other wate }\end{array}$ & 32,45 & $\begin{array}{l}\text { Indigenous } \\
\text { bactertal } \\
\text { population } \\
\text { associated } \\
\text { blota }\end{array}$ & Plants $B+F$ & None \\
\hline ENV -6 & "Pe'llet exchange" & $\begin{array}{l}32-45 \\
45-85-37\end{array}$ & $\begin{array}{l}\text { Indigenous } \\
\text { population } \\
\text { assoclated } \\
\text { blota }\end{array}$ & Plants $B+F$ & None \\
\hline ENV-7 & "Pellet exchange" & 32,45 & $\begin{array}{l}\text { Indigenous } \\
\text { population } \\
\text { assoclated } \\
\text { blota }\end{array}$ & Plants $B+F$ & None \\
\hline ENV- 8 & $\begin{array}{l}\text { Separation of } \\
\text { component effects } \\
\text { (bacteria. } \\
\text { associated blota, } \\
\text { tiny particulates) }\end{array}$ & 45 & $\begin{array}{l}\text { Natural bacterial } \\
\text { population from } \\
\text { plant f only } \\
\text { separated by } \\
\text { centrifugation }\end{array}$ & $\begin{array}{l}\text { Plants } B+F \\
\text { (+f } 11 \text { ter } \\
\text { ster } 111 z e d)\end{array}$ & $\begin{array}{l} \pm \text { Pellet } \\
\text { containing } \\
\text { large } \\
\text { particulates } \\
+ \text { assoclated } \\
\text { blota from } \\
\text { plant } F\end{array}$ \\
\hline ENV-9 & $\begin{array}{l}\text { Separation of } \\
\text { component effects }\end{array}$ & 45 & $\begin{array}{l}\text { Natural bacterlal } \\
\text { population from } \\
\text { plant } H \text {, banded } \\
\text { or pelleted } \\
\text { through density } \\
\text { gradlent }\end{array}$ & $\begin{array}{l}\text { Plants } B+H, \\
(+f i l \text { ter- } \\
\text { stertlized })\end{array}$ & $\begin{array}{c}\text { Other assoclated } \\
\text { microbes }\end{array}$ \\
\hline ENV - 10 & Nitrate enrichment & 32 & $\begin{array}{l}\text { Natural bacterial } \\
\text { population from } \\
\text { Normandy Lake }\end{array}$ & $\begin{array}{l}\text { Normandy Lake, } \\
\text { epi-and meta- } \\
1 \text { imnion }\end{array}$ & $\begin{array}{l}\mathrm{NaNO}_{3} \\
50 \mathrm{mg} / \mathrm{L}\end{array}$ \\
\hline
\end{tabular}

$\overline{a_{\text {sg }}} \bar{l}=$ serogroup 1. 
Section 2

OVERVIEW

This overview section is provided because the Phase II studies are unusually diverse and complex. Unlike phase I, which was a field sampling study, the activities undertaken in Phase II were not predetermined, but rather followed a sequence that was in part determined by the results of previous phase II work. This section presents the logic which guided the design of this study.

The Phase II studies consisted of four elements. First, preparatory studies were undertaken as a basis for further work. Second, laboratory experiments involving the growth of Legionella in power plant waters were performed, these representing the largest part of the Phase II effort. Third, field studies aimed at extending the laboratory results were undertaken. Fourth, another new species, discovered during Phase $I$, was characterized. Some of the effort in each of these elements was concurrent with efforts in other elements, but it is helpful to think in terms of this conceptual sequence.

\section{PREPARATORY STUDIES}

Effect of Sample Storage on Legionella Density and Infectivity

Samples in Phase I were usually enumerated and injected into guinea pigs within 1 to $2 \mathrm{~d}$ after collection, but longer delays were sometimes unavoidable. If sample storage had been found to affect these profile characteristics, doubt would have been cast on the ability of the phase I analyses to serve as a beginning point for Phase II experiments. Storage for as long as 1 week was found not to affect Legionella density or infectivity substantially. Therefore, using Phase I as a beginning point for Phase II was reasonable, and the validity of the Phase I analyses was supported.

\section{Calibration of the Guinea Pig System}

Legionella have the ability to cause infections in certain mammals, including man and guinea pigs. Whether or not an infection will occur in a particular animal is thought to depend on the type and condition of the animal, the route of exposure, and the number and virulence of the Legionella to which the animal 
is exposed. In both Phase I and Phase II, intraperitoneal inoculation of guinea pigs was used to assess infectivity.

In Phase I, the assessment of infectivity was considered part of the process of characterizing water from a particular location. A test animal was inoculated with a fixed volume of concentrated water, and the result was related to that particular sample. The number of Legionella used in inoculations varied from sample to sample because Legionella density varied. In Phase II, however, attention was to be focused on the characteristics of specific groups of Legionella being cultured. It was therefore necessary to establish the relationship between the number of Legionella in an inoculum, the virulence, and the infectivity. Establishing this relationship is referred to as calibrating the guinea pig system.

A calibrated system for determining infectivity was important to the Phase II research for two main reasons. First, the number of organisms needed to test for infectivity would be known. This meant that the scale of the culture system and the measure of success for experimental conditions designed to promote growth would also be known. Second, guinea pigs could be used to determine reliably whether conversion of avirulent to virulent Legionella had occurred.

The guinea pig system was successfully calibrated. As expected, even the low-virulence Legionella were able to cause infection if injected in sufficiently high numbers. The high-virulence strain was, however, approximately a thousandfold more virulent.

An added benefit of calibrating the guinea pig system was the capability for additional interpretation of the Phase I infectivity results (Christensen et al. 1983) this allowed. By examining the numbers of organisms used in inoculations during Phase I in conjunction with the calibration work, it was possible to determine that most of the positive results in Phase I quite likely reflected a virulent population rather than simply an overwhelming of the guinea pigs with an excessive number of low-virulence Legionella.

DEVELOPMENT OF A TEST SYSTEM FOR DEFINING ENVIRONMENTAL INFLUENCES ON GROWTH OF Legionella

The laboratory experiments in Phase II had as their primary objective developing an understanding of the environmental parameters affecting legionella growth, which would form the basis of an exploitable system for studying factors that 
determine or control the abundance and virulence of Legionella. Once such a system was found, it would be possible to use it to study the phenomenon of virulence in detail.

To be exploitable, the sought-after system needed to be able, under laboratory conditions, to consistentiy produce growth (increase the density) of Legionella. The bacteria's growth was important for three reasons. First, the study of factors promoting or inhibiting the growth of Legionella requires a population which is growing rather than one which is more or less stationary. Second, the process by which a nonvirulent population becomes virulent may involve conversion of individuals from one state to the other, or alternatively it may involve selection (increased reproduction) of particular strains of Legionella. Selection is recognizable only in a growing system. Third, a system producing consistent growth would be needed to produce sufficient numbers of Legionella for inoculation into guinea pigs. The inoculation procedure is necessary to determine whether Legionella are infectious; there is, unfortunateiy, no simpler method avallable at present. With respect to control of the organism, both growth and virulence are relevant, because the two attributes are known to work together in determining infectivity.

The search for an exploitable system involved examining the effects of (1) temperature, (2) water quality, and (3) associated biota on the growth of Legionella populations. Temperature was included because elevated temperatures had already been implicated as having a positive effect on Legionella growth and infectivity (fliermans et al. 1981a) and because power plants unavoidably affect water temperature. Water quality was found to vary considerably among the power plants studied in Phase I, and there were indications of water-quality effects on abundance (Christensen et al. 1983). Interactions between Legionella and other organisms may be important determinants of Legionella abundance (Tison et al. 1980; Tyndall and Domingue 1982).

In addition to varying these factors in our study, different types of Legionella populations were also examined. Low-virulence and high-virulence environmental isolates were available as laboratory strains, and these were used in early experiments. Intermediate experiments utilized mixed natural populations of Legionella, but to preserve at least the potential for differences in virulence, these were taken from both "negative" and "positive" plant waters . "Positive" water was obtained from the cooling systems of two power plants identified during Phase $I$ as often yielding infectious samples (plants $F$ and $G$, Table 1-2, 
and Christensen et a1. 1983). "Negative" water was either ORNL laboratory-distilled water or discharge from plant $B$ (Table 1-2). In these experiments, groups $A, B$, and $C$ Legionella were enumerated. In later experiments, when it was not possible to eliminate environmental factors and reduction of variables was required, enumeration was restricted to group $A$ Legionella, the main group implicated in human health problems.

\section{Growth of Environmental I solates in Culture}

Low-virulence and high-virulence environmental isolates of Legionella pneumophila, serogroup 1, were avallable as laboratory strains. These were used in a series of three experiments (Table 1-3, ENV-1, 2, and 3) investigating the effects of temperature and power plant water quality on growth (ENV-1 and 2) and viability (ENV-3). The algal extract used in experiment ENV-1 as a supplement proved to be contaminated and could not be purified even when filtered through a 0.45- $\mu \mathrm{m}$-pore-sized filter. Yeast extract was therefore used as the supplement in ENV-2 and 3. If an exploitable system had looked very promising in these experiments, it would have been pursued and effort would have focused on two areas: identifying growth promoters and/or inhibitors, and attempting to convert the low-virulence strain to a high-virulence strain by manipulating the system. Although such a system was not evident, two main results were found. The power plant waters were found to differ in their growth-inducing characteristics. Also, unsupplemented power plant waters were capable of supporting Legionella growth. The ability to dispense with supplements was significant because yeast extract contains so many substances that it would make identifying influential power plant factors virtually impossible. The use of unsupplemented power plant water might implicate a factor as being important that could be controlled in the power plant environment. Subsequent laboratory experiments were therefore conducted using unsupplemented power plant water.

In addition, the use of the laboratory strains of Legionella was discontinued in favor of using mixed natural populations taken from these power plant waters. This had several potential benefits. First, such indigenous populations are more relevant to the power plant environment and therefore are of greater inherent interest to the power industry. Second, whether the development of a virulent population is a matter of selection of a particular strain or of conversion of individuals from nonvirulent to virulent status, the use of a natural population would provide much more diverse starting material and, hence, a greater opportunity for studying the question of virulence. 
Growth of Mixed Natural Populations in Power Plant Water

Incubation without Manipulation. In the first of this series of experiments (ENV-4), indigenous populations from three power plants were incubated, without prior manipulation, at three temperatures. This enabled the responses of the populations to the laboratory conditions and the consistency of response among groups $A, B$, and $C$, to be examined.

Pellet Exchange Experiments. The results from experiment ENV-4 did not enable determination of whether differences in growth patterns between groups $A, B$, and $C$ were due to properties associated with the indigenous populations or to factors associated with water quality. Experiments ENV-5, 6, and 7 were designed to separate these factors by comparing the growth of indigenous Legionella in their own water with the growth of Legionella centrifuged and resuspended in their own or different water with or without other microblota. Suggestive growth patterns were found. Because the universality of any consistent patterns observed would need confirmation, we attempted to replicate the experiment to examine consistency. Experiment ENV-6 was not a proper replicate because our equipment falled. In ENV-7, substantial growth of non-Legionella biota in many of the flasks interfered with interpretation. This growth of associated biota in ENV-7 but not in ENV-5 very likely resulted from seasonal changes in the source water and/or biota and indicated a need to control associated biota further in the experiments.

Separation of Components Experiments. In experiments ENV-8 and 9, the indigenous populations were fractionated using density-gradient centrifugation, rather than simple pelleting. In a manner similar to ENV-5, 6, and 7, the fractions were then resuspended in their own or in different water with or without associated biota. The fractionation procedure established greater control over the presence or absence of associated biota by isolating the Legionella better prior to resuspension. The effects of positive waters [waters from plants $F(E N V-8)$ and $H(E N V-9)$ ] were compared with those of negative waters from plant $B$. The results suggested an exploitable system involving incubation of group A Legionella in water from closed-cycle power plants.

Growth of Mixed Natural Populations in Lake Water: Nitrate Enrichment Experiment

A final laboratory experiment examined the effect of a single water-quality factor (nitrate) on indigenous Legionella populations in lake water. Nitrate was chosen because in further analyses of the Phase I results (unpublished) it 
consistently predicted Legionella densities. The experiment used water from Normandy Lake, a reservoir in Tennessee, because the natural nitrate limitation of this lake enabled the effect of nitrate enrichment to be compared with a control situation in which nitrate was virtually absent. No effect of nitrate enrichment could be discerned.

\section{FIELD EXPERIMENTS}

The field experiments were intended to provide a means of extending the laboratory results to more realistic field situations. Two approaches were used: membrane chambers and intensive sampling in a power plant closed-cycle system.

\section{Membrane Chambers}

Membrane chambers (Fliermans et al. 1979) have been successfully used to study water-quality effects on microbes held within the chamber. A study was therefore undertaken to test the applicability of the method to the Phase II studies. Depending on the success of this study, a number of potential uses of membrane chambers were foreseen. They could be located in power plant situations difficult to duplicate in the laboratory, such as in proximity to aquatic macrophytes in a cooling lake. Legionella from negative plant waters (e.g., plant B) could have been enclosed in chambers suspended in positive plant water (e.g., plant F) to see whether conversion from avirulent to virulent status occurred. Virulent Legionella, if found in a cooling system, could have been inoculated into a chamber to see if removal from the temperature fluctuations associated with closed-cycle operations resulted in conversion from virulent to avirulent status.

The limited study of the membrane chambers revealed difficulties that would need to be overcome before the chambers could be usefully deployed in such situations. A decision was made not to pursue development of the membrane chamber system in this study.

\section{Closed-Cycle Cooling System Intensive Sampling}

The use of closed-cycle cooling water in the laboratory experiments was an attempt to bring the field situation into the laboratory. This could not be completely successful, however, because the closed-cycle power plant environment is so diverse. It is to be expected that spatial variation in Legionella abundance would exist there, because of both the physical and, especially, the 
biotic factors. Legionella are known to be strongly influenced by at least some types of associated biota, such as blue-green algae (Tison et al. 1980), and amoebae (Tyndall and Domingue 1982). To test this expectation, an intensive field sampling was conducted at plant $G$. Legionella densities were related semiquantitatively to physical conditions and to the presence and abundance of other organisms.

FURTHER INVESTIGATION OF A SUSPECTED NEW SPECIES

The final element of the Phase II studies involved characterization of an unknown Legionella isolated from plant D (Table 1-2) during the Phase I study. As hypothesized in Phase I, the isolate proved to be another new species, now named Legionella cherril. 


\section{Section 3}

MATERIALS AND METHODS

MEASUREMENT OF Legionella DENSITY, VIABILITY, AND INFECTIVITY

Specialized laboratory procedures were used routinely to determine Legionella density, viability, and infectivity. These are described here.

Measurement of Legionella Density

The direct fluorescent antibody (DFA) procedure was used to determine Legionella density. The sample was concentrated by centrifugation. A $0.010-\mathrm{mL}$ subsample of the concentrate was pipetted into 6 -mm-diam wells on toxoplasmosis slides (Cel-Line Associates, Minotola, New Jersey). These slides were air dried, heat fixed, and treated with polyvalent antisera containing fluorescent antibodies against various serogroups of $\underline{L}$. pneumophila and other Legionella species (Table 1-1). These antisera were prepared according to protocols established by the Centers for Disease Control in Atlanta ( $C O C$ ) as previously described (Cherry et al. 1978) and obtained from CDC, Zeuss, or BioDx laboratories. Samples were viewed by epifluorescence microscopy at 1000x, using a Zeiss Universal microscope, and the number of Legionella, as indicated by fluorescing cells having the appropriate morphology, was determined in 50 fields. These counts were then used to estimate the number of organisms present per unit volume of original sample.

\section{Measurement of Legionella Viabllity}

When viability was measured in experiment ENV-3, evidence of an active election transport system was sought using the INT test. The samples were treated for 30 min using 2-p-iodophenyl-3-p-nitropheny 1-5-phenyl tetrazolium chloride (INT) prior to centrifugation and DFA analys is (Fliermans et a1. 1981b). The DFA slides were then viewed using a combination of epifluorescence and bright-field microscopy to determine the proportion of fluorescing organisms containing formazan crystals.

Measurement of Legionella Infectivity

The infectivity of Legionella was assessed using guinea pigs. Uncompromised 
guinea pigs (Abyssinia, Hartley, or American breed, 2 to 3 months old) whose base-line body temperatures had been established were injected intraperitoneally with the test samples and were observed over a 4-d period for fever and overt signs of 111 ness (e.g., lethargy, ruffled fur, watery eyes, etc.). All animals were sacrificed and necropsied on the fourth day after inoculation. Samples from peritoneal swabs and tissues were cultured on CYE agar plates at $35^{\circ} \mathrm{C}$. The resultant Legionella isolates were then identified using the DFA test. Pure cultures of Legionella isolated from tissues of inoculated animals were considered presumptively infectious. It is not possible to directly relate such infectivity results to human risk. This is so because the quantity of material, the route of exposure, and the size and species of the host animal all differ greatly.

\section{PREPARATORY STUDIES}

\section{Effect of Sample Storage on Legionella Density and Infectivity}

The effect of sample storage (i.e., keeping the sample at room temperature for 1 to $8 \mathrm{~d}$ ) on the density and infectivity of Legionella populations was tested using cooling tower water collected from plants $B$ and $F(T a b l e ~ 1-2)$. The density of Legionella was determined within 24-h of collection and again after 8-d of storage at room temperature, using the DFA procedure.

The infectivity of the samples was determined by intraperitoneal inoculations of guinea pigs with the 500-fold concentrates. The animals were monitored for signs of 111 ness and for rises in body temperature. When temperature rises or signs of 11 lness occurred, the animals were sacrificed and peritoneal fluid, spleen, and liver tissues were tested for viable Legionella by plating on charcoal yeast extract (CYE) agar.

\section{Calibration of the Guinea Pig System}

To determine the minimal infectious densities of two laboratory cultures of Legionella, the high-and low-virulence Legionella cultures were serially diluted and injected into guinea pigs. These calibrations utilized environmental isolates of $\underline{L}$. pneumophila, serogroup 1 (Knoxville). The low-virulence strain was obtained from Dr. Carl fliermans. The high-virulence strain was isolated in our laboratory from water from the clinch River in conjunction with a related study. Both isolates were cultured in yeast extract broth. The 48-h cultures were centrifuged to concentrate the bacteria, and the resultant pellets were resuspended in phosphate-buffered saline. Tenfold 
dilutions of the Legionella suspensions were made. One-milliliter aliquots of these dilutions were injected intraperitoneally into guinea pigs. Also, $1-\mathrm{mL}$ aliquots were plated on CYE agar and inoculated into tubes of yeast extract broth to determine the number of viable Legionella. Total numbers of high-virulence Legionella inoculated into guinea pigs ranged from $10^{3}$ to $10^{8}$ organisms. The low-virulence Legionella were inoculated in quantities ranging from $10^{6}$ to $10^{10}$ organisms.

To examine animal-to-animal variability, eight animals were injected with $10^{6}$ high-virulence Legionella and another eight were injected with $10^{6}$ low-virulence Legionella. The animals were observed for signs of 111 iness and were sacrificed on the fourth day following injection. Tissues were plated as previously described, and the number in each group yielding viable Legionella was determined.

\section{LABORATORY EXPERIMENTS}

\section{Growth of Environmental Isolates in Culture}

In experiment ENV-1 (Table 1-3), fisherella sp. (a blue-green alga) was grown in a minimal salts medium. The algal extract used in this experiment was prepared by sterile filtration (0.45-um-pore-sized) of this algal culture. Serial, tenfold dilutions of $48-h$ broth cultures of the previously described high- and low-virulence isolates of $\underline{L}$. pneumophila were incubated at $37^{\circ} \mathrm{C}$ in $50 \%$ algal extract broth and $50 \%$ sterile-filtered $(0.45$-um-pore sized) power plant water from plants $B, F$, and $G$. [Throughout this Phase II study, power plant water denotes water from the circulating water system of closed-cycle plants or from the discharge of once-through plants (see Table 1-2). In the Phase I study, these waters were termed "plant-exposed."] The cultures were incubated for $7 d$, and the mean growth index was defined as the negative logarithm of the smallest inoculum (serial dilution) from which cells grew. Experiment ENV-2 was conducted similarly, except that a $50 \%$ yeast extract (DIFCO) was substituted for the algal extract. Yeast extract experiments were incubated at 32,37 , and $42^{\circ} \mathrm{C}$ (Table 1-3, ENV-2).

To examine changes in viability of early cultures (ENV-3) high-and low-virulence $\underline{L}$. pneumophila cultures were centrifuged to pellet the bacteria. The pellets were resuspended in distilled water and inoculated into replicate flasks containing $50 \%$ yeast extract and $50 \%$ of either distilled water or filter-sterilized power plant water. The cultures were incubated at 32,37 , and $42^{\circ} \mathrm{C}$ for $2 \mathrm{~d}$ to allow assessment of the early effects of the test water on 
electron transport system activity of the Legionella. On days one and two, aliquots of the cultures were analyzed for concentrations of Legionella, using the DFA procedure, and for evidence of an active electron transport system, using the INT test.

Growth of Mixed Natural Populations in Power Plant Water

Incubation Without Manipulation. In the first of these experiments (Table 1-3, ENV-4), cooling waters from plants $B, F$, and $G$ were incubated at 32,37 , and $42^{\circ} \mathrm{C}$ without any prior manipulations. Densities of groups $\mathrm{A}, \mathrm{B}$, and $\mathrm{C}$ Legionella were determined by the DFA procedure as previously described.

Pellet Exchange Experiments. In these experiments (Table 1-3, ENV-5, 6, and 7), the water samples were centrifuged to pellet the microbial populations. The supernatant water was collected and recombined with either its own microbial pellet or a pellet derived from water from a different site. These various combinations of microbial pellets resuspended in supernatant waters were incubated at either 32 or $45^{\circ} \mathrm{C}$. Deviation from this planned temperature regime in experiment ENV-6, however, resulted from equipment failure. All treatments were performed in replicate. In all of these experiments, the indigenous Legionella (Table 1-3) were quantified by the DFA procedure.

Separation of Components Experiments. Experiments ENV-8 and 9 (Table 1-3) focused on the growth of group A Legionella, but with greater control over the presence or absence of assoclated biota. These experiments involved fractionating water from $p l a n t s ~ B$ and $F$ or $B$ and $H$, recombining certain fractions (according to a replicated factorial design), incubating, and enumerating group $A$ Legionella, using the DFA technique. In ENV-8, power plant water from plants $B$ and $F$ was centrifuged and half of the supernatant from each plant was filter sterilized. Because centrifugation does not remove all of the particulate matter, the filtered vs unfiltered supernatants represented two levels of water purity from each of two plants. The pellet from centrifugation of the plant $F$ water was subsequently subjected to Percoll (Pharmacia Fine Chemicals) density-gradient centrifugation to separate bacterial bands from the pellet containing associated biota and other particulate matter. Bacteria retrieved from this gradient centrifugation of the plant $F$ pellet were then added, either with or without the pellet, to the supernatant waters from both plants and incubated. All three groups of Legionella were counted at days zero and three; in addition, group A Legionella were also counted on day seven. In the ENV-9 
experiments either the banded or the pelleted Legionella from the density-gradient preparations of the plant $H$ microbial population were incubated at $45^{\circ} \mathrm{C}$ in filter-sterilized water from plant B or $H$. Group A Legionella were counted at days zero, one, three, four, five, and seven. Infectivity of the test material was tested by inoculating guinea pigs on days zero, three, and seven.

Growth of Mixed Natural Populations in Lake Water: Nitrate Enrichment Experiment

Water was collected from Normandy Lake at 2- and 5-m, representing the epilimnetic and upper metalimnetic strata of the lake. Natural levels of nitrate were extremely low $(<0.005 \mathrm{mg} / \mathrm{L})$. Replicate, unfiltered aliquots from each depth were enriched with sodium nitrate at a level of $50 \mathrm{mg}$ of nitrate per liter of water and incubated on shaker platforms in a growth chamber (12:12-h photoperiod) at $32^{\circ} \mathrm{C}$. The densities of groups $A, B$, and $C$ Legionella (Table 1-3, ENV-10) were determined initlally and on days three and seven of incubation. Unenriched samples served as controls.

\section{FIELD STUDIES}

\section{Membrane Chambers}

An ORNL air conditioning cooling tower with a history of higher-than-average Legionella densities was selected for a trial deployment of the membrane chambers. Water from the tower was separated into $50-\mathrm{mL}$ aliquots. Four of these were centrifuged and the supernatants were filter sterllized. The pellets were subjected to density-gradient centrifugation to separate bacterial bands from the pellets containing associated blota and other particulate matter. Sterile environmental chambers equipped with membrane filters of 0.22-um pore size were filled with $50 \mathrm{~mL}$ of one of the following: (1) filter-sterilized water, (2) raw water, (3) banded bacteria with the filtered supernatant, or (4) banded bacteria with the pellet and the filter-sterilized supernatant. These membrane chambers were suspended in the cooling tower basin at a depth of about $10 \mathrm{~cm}$. At intervals over an $11-d$ period, $0.7-\mathrm{mL}$ samples were withdrawn. The samples were diluted to $230 \mathrm{~mL}$, using filter-sterilized water, to enable processing for DFA analysis. Whole-water samples were also collected and preserved with Lugol's solution, for subsequent analysis of associated biota. Groups $A, B$, and $C$ Legionella were enumerated using the DFA technique, and viability was evaluated using the INT method, already described. 


\section{Closed-Cycle Cooling System Intensive Sampling}

Duplicate samples were taken from a variety of locations at plant $G$ during normal operation of both units and also during downtime of one of the units while the other unit continued to operate. One of each sample pair was treated for subsequent enumeration of Legionella density and viability, and the other was preserved using Lugol's solution for later examination of associated biota.

Sampling included as many aquatic areas associated with the power plant as could practicably be reached. Several source waters, various locations with in the cooling tower, the condenser water, the runoff pond, detention basins, and the final discharge point were sampled. Legionella were enumerated in all samples; the most abundant associated biota were identified to the family or genus level, and they were assigned an index of relative abundance.

FURTHER INVESTIGATION OF A SUSPECTED NEW SPECIES

Characterization of the unknown Legionel1a isolated from plant-exposed water at plant 0 (Table 1-2) during the Phase I study was continued. Isolates were cultured for $48 \mathrm{~h}$ in yeast extract broth and then subcultured both on blood agar and on brain heart infusion (DifCo) agar. In addition, the cultures were tested for catalase activity by adding the bacteria to hydrogen peroxide. Cultures were also analyzed by the DFA test for reactivity with antibodies specific for known species of Legionella. These various tests were carried out on three isolates, designated $B, W$, and $Z$. These isolates were also sent to Dr. D. Brenner at the COC in Atlanta, Georgia, to be tested for their degree of relatedness with the DNA of other known Legionella species (Brenner et al. 1979). 


\section{Section 4}

RESULTS AND OISCUSSION

There were two main objectives in the Phase II study. The first was to develop an exploitable test system which could be used to identify those components of power plant cooling waters which promote the growth and/or infectivity of Legianella populations. The second ma in objective was to elucidate further and expand the interpretation of Phase I results.

Several preparatory studies, directed both toward clarifying Phase I results and developing the methodology necessary for the main Phase II study, were undertaken first. These included an assessment of the effect of storage on Legionella and calibration of Legionella infectivity in guinea pigs.

\section{PREPARATORY STUDIES}

Effect of Sample Storage on Legionella Density and Infectivity

Storage does not appear to affect Legionella density or infectivity. Because of some concern that differences in shipment duration or a delay before processing samples in the laboratory might result in undetected changes in population levels, Legionella densities and infectivity in water from plants $B$ and $F$ were determined on their arrival at our laboratory and after 7-d of storage at room temperature.

No significant effect of this treatment was seen (Tables 4-1 and 4-2). While Legionella densities did not decrease over the 7-d storage period at room temperature, neither did they increase by as much as an order of magnitude. As was often seen in the Phase I study, water samples from plant $F$ were infectious to guinea pigs when first acquired. This infectivity remained demonstrable after $7 \mathrm{~d}$ of storage [1.e., L. pneumophila (serogroup 1) was isolated from the tissues of guinea pigs inoculated with the samples both before and after storage (Table 4-2)]. Conversely, water from plant $B$ was not infectious on either the first or eighth day of storage. This experiment does not rule out possible changes in density or infectivity occurring during the 1-d shipment period, but the lack of change from day one to day eight suggests that our protocol provides 
Table 4-1

EFFECT OF STORAGE ON DENSITIES (CELLS/mL) OF Legionella

\begin{tabular}{|c|c|c|c|c|c|}
\hline \multirow{2}{*}{$\begin{array}{l}\text { Day of } \\
\text { Experiment }\end{array}$} & \multirow{2}{*}{$\begin{array}{c}\text { Source of } \\
\text { Water }\end{array}$} & \multirow[b]{2}{*}{ Test No. } & \multicolumn{3}{|c|}{ Serogroup ${ }^{b}$} \\
\hline & & & A & B & C \\
\hline \multirow[t]{4}{*}{1} & $\mathrm{~F}^{\mathrm{C}}$ & 1 & 350 & $-d$ & - \\
\hline & $\mathrm{F}$ & 2 & 2600 & $<10$ & 320 \\
\hline & $\mathrm{F}$ & 3 & 2300 & $<10$ & 310 \\
\hline & B & 4 & $<10$ & $<10$ & $<10$ \\
\hline \multirow[t]{4}{*}{4} & $F$ & 1 & - & - & - \\
\hline & $\mathrm{F}$ & 2 & 2800 & $<10$ & 910 \\
\hline & $F$ & 3 & 2200 & $<10$ & 560 \\
\hline & B & 4 & - & - & - \\
\hline \multirow[t]{4}{*}{8} & $\mathrm{~F}$ & 1 & 310 & - & - \\
\hline & $\mathrm{F}$ & 2 & 5900 & 80 & 320 \\
\hline & $\mathbf{F}$ & 3 & 4700 & 120 & 430 \\
\hline & B & 4 & 67 & 270 & $<10$ \\
\hline
\end{tabular}

$\overline{\text { Water }}$ was collected and shipped via air express on day 0 from the indicated power plant. Day 1 is the day on which the first count was made at ORNL.

bsee Table 1-1.

${ }^{C}$ Circulating water from power plant $F$ or discharge water from power plant $B$ (see Table 1-2).

dCounts not made.

Table 4-2

EFFECT OF STORAGE ON INFECTIVITY OF Legionella

\begin{tabular}{|c|c|c|c|c|}
\hline \multirow[b]{2}{*}{$\begin{array}{c}\text { Source of } \\
\text { Water }\end{array}$} & \multirow[b]{2}{*}{$\begin{array}{c}\text { Incubation Period } \\
\text { of Water (d) }\end{array}$} & \multicolumn{3}{|c|}{ Number of Guinea Pigs } \\
\hline & & Inoculated & $\begin{array}{l}\text { Becoming } \\
\text { sick }\end{array}$ & $\begin{array}{l}\text { Positive for } \\
\text { Legionella }\end{array}$ \\
\hline Plant $F$ & $\begin{array}{l}1 \\
8\end{array}$ & $\begin{array}{l}2 \\
2\end{array}$ & $\begin{array}{l}2 \\
2\end{array}$ & $\begin{array}{l}2 \\
2\end{array}$ \\
\hline Plant B & $\begin{array}{l}1 \\
8\end{array}$ & $\begin{array}{l}2 \\
2\end{array}$ & $\begin{array}{l}0 \\
0\end{array}$ & $\begin{array}{l}0 \\
0\end{array}$ \\
\hline
\end{tabular}

a Isolation of $L$.pneumophila, serogroup 1 , from tissues of inoculated guinea pigs. 
an accurate picture of the Legionella populations in natural water bodies and power plant cooling systems. It should be noted that lack of storage effect is uncharacteristic of many other aquatic microbes, for which storage at room temperature often causes marked changes. In fact, the standard protocol for counting water-borne bacteria is to chill the sample and conduct counting procedures within $24 \mathrm{~h}$ after sampling (Standard Methods 1976). Legionella differ in many ways from other aquatic bacteria, and this lack of marked storage effects appears to be yet another difference.

\section{Calibration of the Guinea Pig System}

Results of the serial dilutions (Fig. 4-1) indicated a thousandfold difference in infectivity between the high-and low-virulence strains of $\underline{L}$. pneumophila, serogroup 1 (Knoxville). Four days after injection, Legionella were recovered from tissues of all guinea pigs inoculated with as few as $10^{6}$ high-virulence bacteria. Approximately one-half of the animals sacrificed 4 d after inoculation with $10^{4}$ high-virulence cells yielded viable Legionella from their tissues. In contrast, inoculation with 1000 times as many $\left(10^{7}\right)$ organisms of the low-virulence strain was required before viable Legionella could be isolated from approximately one-half of the guinea pigs. A density of $10^{6}$ low-virulence cells was insufficient to provide evidence of infection. From these results we concluded that an inoculum of $10^{6}$ cells was optimal for distinguishing a high-virulence strain of Legionella from a low-virulence one.

The next study -. in which guinea pigs were injected intraperitoneally with $10^{6}$ L. pneumophila, serogroup 1, of either low- or high-virulence cells--revealed no animal-to-animal variability. None of the eight animals injected with the low-virulence strain was positive for demonstrable Legionella, but all eight animals injected with the high-virulence strain yielded Legionella, a response consistent for all three tissues sampled. Since the animals used for this study were random-bred rather than inbred, and since they were injected at different times (over a 3-month period), we concluded that animal-to-animal variability at this inoculum size was insignificant.

The results of these animal calibration experiments were similar to those reported by wong et al. (1981), where inoculation of guinea pigs with $10^{5}$ or more of high-virulence serogroup 1 of $\underline{L}$. pneumophlla resulted in overt infection. Conversely, inoculation of more than $10^{8}$ low-virulence organisms was required to produce overt infection. Thus, the existence of two discrete L. pneumophila subpopulations of the same serotype, differing in level of virulence, is confirmed 


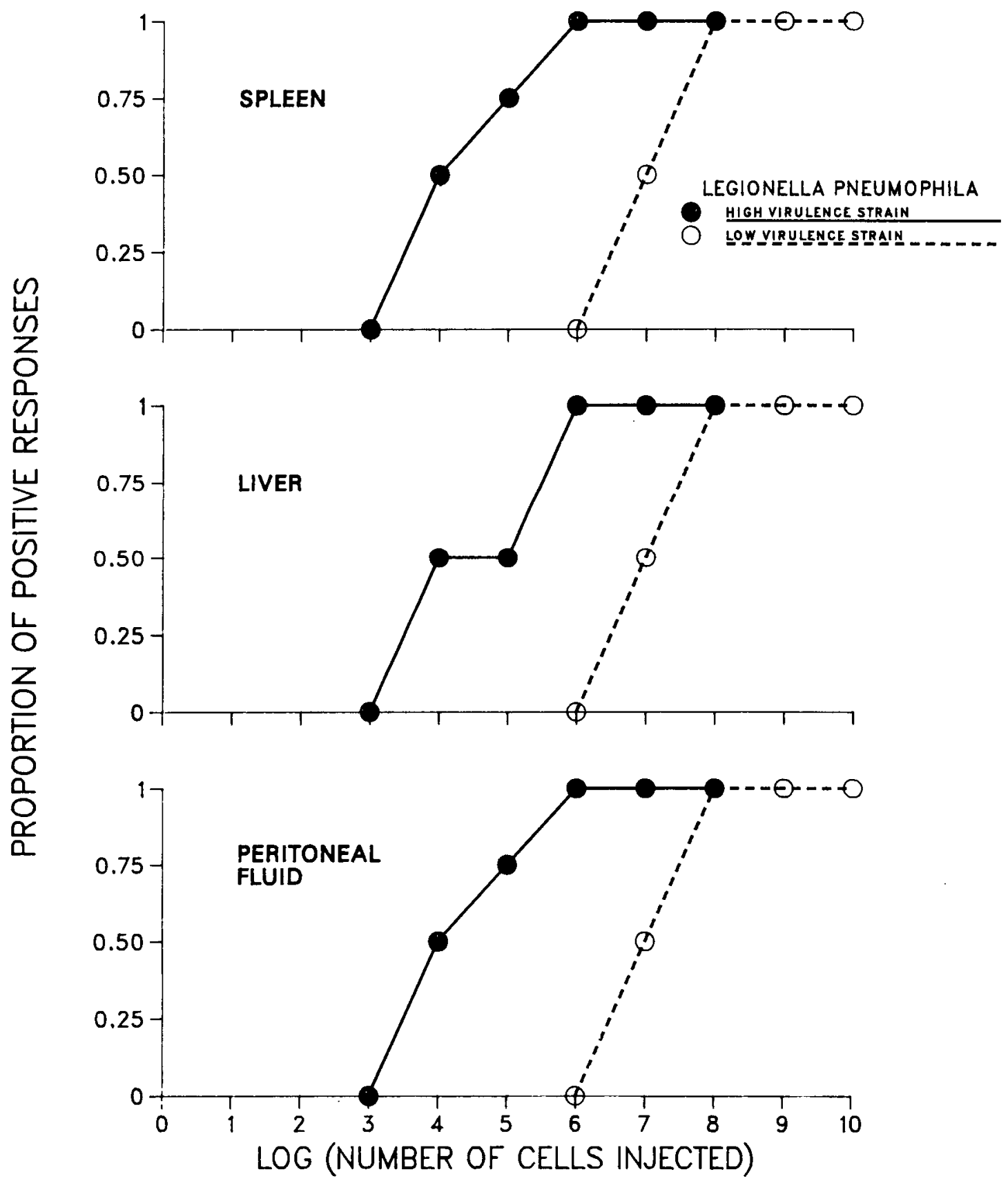

Figure 4-1. Calibration of guinea pig system: Isolation of Legionella pneumophila, serogroup 1 (Knoxville), from three guinea pig tissues after intraperitoneal inoculation of four animals, as a function of number $\left(\log _{10}\right)$ of low- or high-virulence cells injected. 
for our environmental isolates, as well as for the clinical isolates of wong et a1. (1981). Moreover, the level of virulence, as indicated by inoculum size, is similar for both.

These results heip clarify our interpretation of Phase I results (Christensen et a 1. 1983). In the Phase I study, infectivity of a sample was determined by injecting the centrifugate from a standard quantity of raw water into test animals. No effort was made to control the size of the Legionella inoculum, because the infectivity of the entire sample (i.,e., bacteria plus any contaminants which might, for example, increase the susceptibility of the host), not the virulence of Legionella per se, was being measured. Having identified the inoculum size of high-and low-virulence Legionella needed for isolation, it became possible to retrospectively compare these levels with the numbers of Leglonella actually injected during the Phase I study, and thus to determine the virulence level of the injected Legionella. Inoculation of $10^{8} \mathrm{high}$ - or low-virulence cells would have caused infection in guinea pigs.

The results show that in $94 \%$ of the cases, the numbers of Legionella injected in the Phase I studies were sufficient to enable high-but not low-virulence Legionella to infect guinea pigs, assuming that the infectious potential of Legionella spp. in nature is similar to that of the high-and low-virulence environmental isolates used in Phase II tests. In 21 of 27 samples yielding L. pneumophila from tissues of inoculated guinea pigs, the inoculum contained $10^{6}$ or fewer $\underline{L}$. pneumophila (Table 4-3). Five of the remaining six samples contained $>10^{6}$ Legionella in the inoculum, and only one infectious sample had $>10^{7}$ Legionella. Thus, the inadvertent isolation of low-virulence Legionella in Phase I was improbable in that only 4 of the 71 samples injected contained in excess of $10^{7}$ L. pneumophila (unpublished analysis).

DEVELOPMENT OF A TEST SYSTEM FOR DEFINING ENVIRONMENTAL INFLUENCES ON GROWTH OF Legionella

The purpose of the next sequence of experiments was to develop an understanding of the environmental parameters affecting Legionella growth. This in turn would form the basis for an exploitable test system -- an experimental regime by which differential effects of various environmental parameters on the growth of Legionella would be demonstrable. A similar approach had been used for previous studies with the pathogenic amoeba Naegleria fowleri, and a differential effect of thermally altered water on the growth of the amoeba was demonstrated (Tyndall 
Table 4-3

QUANTITY OF L. pneumophila (NO. OF CELLS $\times 10^{-3}$ ) FROM PHASE I ENVIRONMENTAL SAMPLES INJECTED INTO GUINEA PIGS FROM WHICH L. pneumophila WERE SUBSEQUENTLY ISOLATED

\begin{tabular}{|c|c|c|c|c|c|c|c|c|c|c|}
\hline \multirow[b]{2}{*}{ Season } & \multirow{2}{*}{$\begin{array}{l}\text { Water } \\
\text { Source } \\
\end{array}$} & \multicolumn{9}{|c|}{ Plant site } \\
\hline & & A & $B$ & C & $D$ & $E$ & $F$ & $G$ & $\mathrm{H}$ & $\bar{I}$ \\
\hline \multirow[t]{2}{*}{ Spring } & Ambient & $-a$ & - & - & - & - & - & - & - & - \\
\hline & Plant & - & - & - & - & 343 & - & 19,400 & - & 248 \\
\hline \multirow[t]{2}{*}{ Summer } & Ambient & 520 & - & 71 & - & - & - & 183 & - & - \\
\hline & Plant & 235 & - & - & 128 & - & 4,081 & - & 146 & 95 \\
\hline \multirow[t]{2}{*}{ Fall } & Ambient & 63 & - & - & 21 & - & 40 & - & 49 & - \\
\hline & Plant & - & - & - & - & - & 36 & 112 & 30 & 55 \\
\hline \multirow[t]{2}{*}{ Winter } & Ambient & - & - & 320 & - & - & - & - & 4,450 & 45 \\
\hline & Plant & - & - & - & 158 & 1,070 & 2,050 & 1,640 & 315 & - \\
\hline
\end{tabular}

a. pneumophila not isolated.

1984). A series of ten experiments (ENV-1 through ENV-10; Table 1-3) was carried out to investigate factors accounting for growth or decline of Legionella populations.

\section{Growth of Environmental I solates in Culture}

The first efforts to culture environmental isolates of Legionella in a medium consisting of algal extract and power plant or distilled water were not successful due to contamination by Pseudomonas-like bacteria. This problem had not been encountered previously in this laboratory when filter-sterilized (0.45-um sterile membranes) media were used, and repeated filtration did not solve the problem. Since algal extract apparently supports the growth of Legionella by providing low molecular weight organic compounds (most likely amino acids) rather than entities peculiar to algal metabolism (Pope, unpublished observation), subsequent experiments used yeast extract (a standard bacteriological medium) as a source of such compounds.

In experiments ENV-2 and 3 (Table 1-3), in which low- and high-virulence Legionella strains were grown in power plant water enriched with yeast extract, growth varied both with temperature and with water source (Fig. 4-2). Overall, 


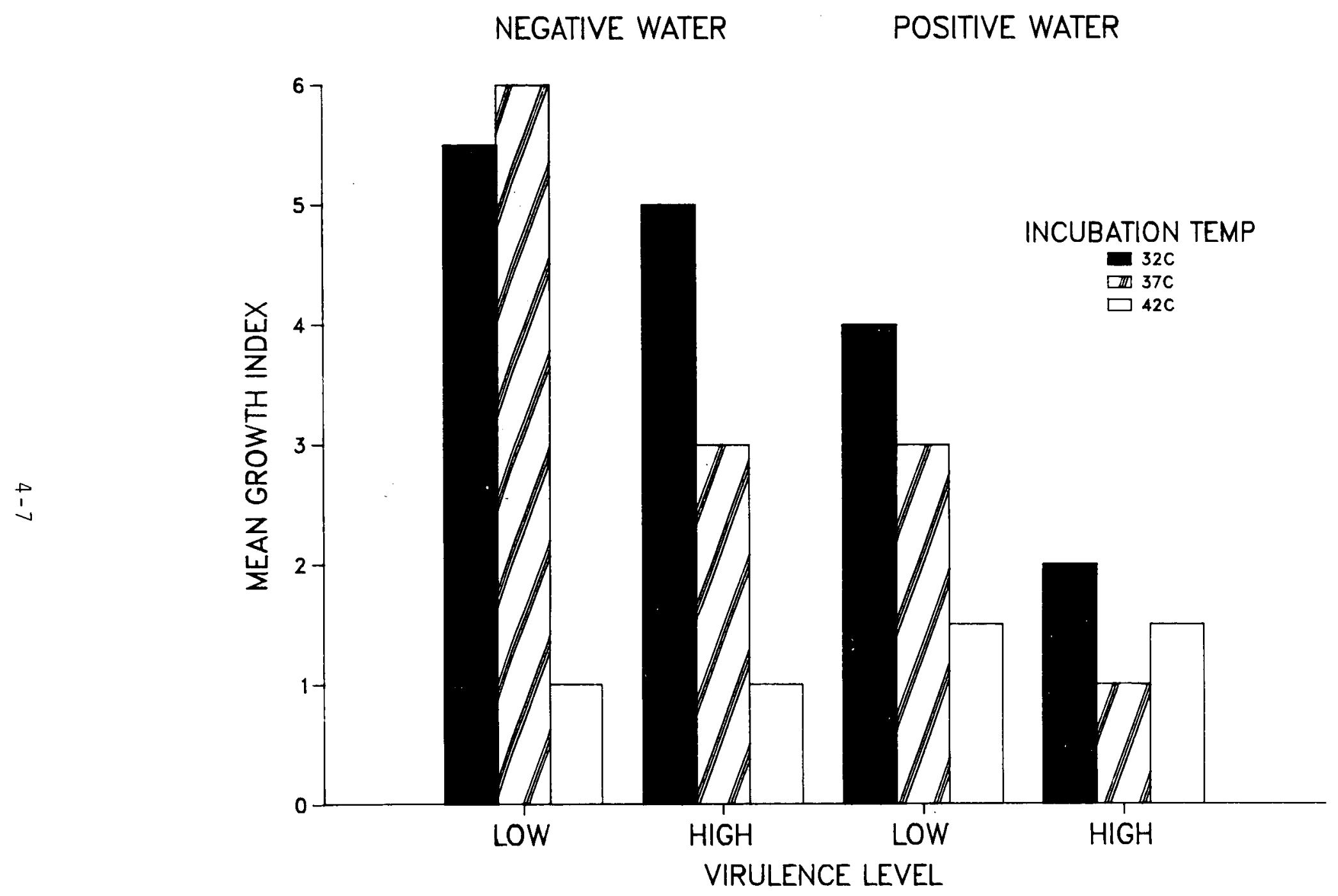

Figure 4-2. ENV-2: Growth index (see glossary) of high-and low-virulence Legionella pneumophlla, serogroup 1 (Knoxville), in negative and positive plant waters at three temperatures. 
negative plant water at 32 and $37^{\circ} \mathrm{C}$ produced the best growth, with the low-virulence strain growing more readily than the high-virulence one. Examination of the interaction of these factors (temperature, water source, virulence level) reveals deviation from this pattern, however.

At the two lower temperatures, distinct differences in the growth potential of the two strains were seen, with the low-virulence strain producing sustained growth from much lower inoculum levels than the high-virulence strain $\left(P=0.0003\right.$, analysis of variance). At $42^{\circ} \mathrm{C}$, however, the growth of the two strains was indistinguishable, one from the other.

Differences in the source waters were also apparent at $32^{\circ}$ and $37^{\circ} \mathrm{C}$. The negative plant water produced considerably greater growth of both strains, compared with the water from power plants where infectious Legionella had often been found $(P=0.0001)$. However, this relationship was not consistent at the higher temperature, for at $42^{\circ} \mathrm{C}$ growth was actually better $(P=0.015$, interaction term in analysis of variance) for both strains in the positive plant water than in the negative.

The consistency of the response to the variation in water quality is notable (see Appendix, Results of ENV-2). Distilled water and plant $B$ water represented two types of negative water from which infectious Legionella had not been isolated, while waters from plants $F$ and $G$ were positive. In only three cases did the results of the two representative types differ, and then by only one growth-index unit (see Glossary) on a scale of 6 . Legionella did, in fact, respond to some difference in water quality between the positive and negative plant water types.

This experiment provides evidence that the high- and low-virulence strains occupy different ecological niches. Both the high-and low-virulence strains were initially isolated from the natural aquatic environment. As previousiy described, both belong to the same species and both are of Knoxville serogroup, the only obvious difference between them being their ability or inability to cause infection in guinea pigs at a given inoculum level. Yet, the high-virulence strain grew less well in both positive and negative plant water at $32^{\circ}$ and $37^{\circ} \mathrm{C}$, compared with the low-virulence strain. 
One source of the observed differences between the high- and low-virulence Legionella strains may be in their differing growth proflies. When viability was measured in ENV-3 (1dentical in design to ENV-2), it appeared that the lag time of the high-virulence strain was longer than that of the low-virulence strain (Table 4-4). High viability levels, expected in exponential (log phase) growth, were found on day one for the low-virulence strain but not until day two for the high-virulence strain.

Viability level was also related to water source. Viability levels on the first day of visible growth (day one for low-virulence, day two for high-virulence) were significantly higher $(P=0.023)$ for bacteria growing in negative plant water compared with those growing in positive plant water.

\section{Growth of Mixed Natural Populations in Power Plant Water}

Having demonstrated that differences in water sources could affect the growth of stock laboratory Legionella cultures, we next carried out a series of experiments to refine the test system. Our goal was to identify specific components of the power plant environment that affected Legionella growth predictably. For this reason, mixed natural populations of Legionella were studied, in contrast to the pure strains of one species used previously. In mixed populations, conversion and selection mechanisms would be free to operate on population components of power plant water in a manner not possible in an isolated bacterial strain. Also, dependency on the added nutrients from yeast extract was eliminated; the natural Legionella were grown in unsupplemented power plant water. Since we wanted to identify individual factors influencing Legionella growth, the elimination of this highiy complex organic supplement was very desirable. The feasibility of this approach was suggested by results of Yee and Wadowsky (1982), indicating that natural Legionella populations could grow in heated tap water.

The decision as to which organisms to count represented a necessary compromise, because it was not feasible to follow all 23 Legionella species. Limiting the study to only one or two serograups was undesirable, for many different serogroups are implicated in disease. The solution, to use three combinations of individual antisera (Table 1-1), provided maximum coverage (12 serogroups and species) but had the disadvantage of obscuring details within each polyserum group. 
Table 4-4

ENV-3: EFFECTS OF TEMPERATURE AND WATER QUALITY ON PERCENTAGE OF Legionella pneumophila VIABLE IN CULTUREa

Water Source

\begin{tabular}{|c|c|c|c|c|c|c|c|c|c|}
\hline \multirow{3}{*}{$\begin{array}{l}\text { Temperature, } \\
{ }^{\circ} \mathrm{C} \\
\end{array}$} & \multirow{3}{*}{$\begin{array}{c}\begin{array}{c}\text { Virulence } \\
\text { Level }\end{array} \\
\end{array}$} & \multicolumn{4}{|c|}{ Negative } & \multicolumn{4}{|c|}{ Positive } \\
\hline & & \multicolumn{2}{|c|}{ Distilled } & \multicolumn{2}{|c|}{ Plant B } & \multicolumn{2}{|c|}{ Plant $\mathrm{F}$} & \multicolumn{2}{|c|}{ Plant $G$} \\
\hline & & Day 1 & Day 2 & Day 1 & Day 2 & Day 1 & Day 2 & Day 1 & Day 2 \\
\hline 32 & Low & 77 & 29 & 41 & 17 & 36 & 10 & 58 & $<1$ \\
\hline 37 & Low & 55 & 7 & 65 & 5 & 39 & 2 & 42 & $<1$ \\
\hline 42 & Low & 49 & 4 & 66 & $<1$ & 30 & $<1$ & 34 & $<1$ \\
\hline 32 & High & $-^{b}$ & 15 & - & 60 & - & 42 & - & 2 \\
\hline 37 & High & - & 70 & - & 36 & - & 37 & - & 13 \\
\hline 42 & High & - & - & - & - & - & - & - & - \\
\hline
\end{tabular}

$\overline{a v i a b i l i t y ~ l e v e l ~ m e a s u r e d ~ i n ~ t h e ~ m o s t ~ d i l u t e ~ c u l t u r e ~ i n ~ w h i c h ~ g r o w t h ~ c o u l d ~ b e ~}$ visually detected.

b Dash indicates that Legionella populations were not detectable by visual examination; therefore, the viability was not measured.

Incubation without Manipulation. The fact that Legionella from power plant waters could in fact grow without added nutrients was shown in experiment ENV-4 (Table 1-3). Initial densities of the three Legionella groups varied among the three power plant waters used in ENV-4 (Figs. 4-3, 4-4, and 4-5). Plant G (a plant generally positive for infectious Legionella) had the highest initial densities of all three groups of Legionella, with groups $A$ and $B$ being the most abundant. Plant $B$, a negative plant, had the lowest initial densities of groups $A$ and $B$ Legionella.

As shown in Figs. 4-3, 4-4, and 4-5, all three groups of Legionella were at least able to maintain initial population levels in unsupplemented power plant water for periods of up to $30 \mathrm{~d}$. Hundredfold increases (two orders of magnitude) in cell density, representing more than six doublings from the lowest level, were common. Such increases were seen in group $A$ from plant $F$ at $42^{\circ} \mathrm{C}$, in group $C$ from $p l a n t ~ B$ at $42^{\circ} \mathrm{C}$, and in group $B$ at all temperatures at 

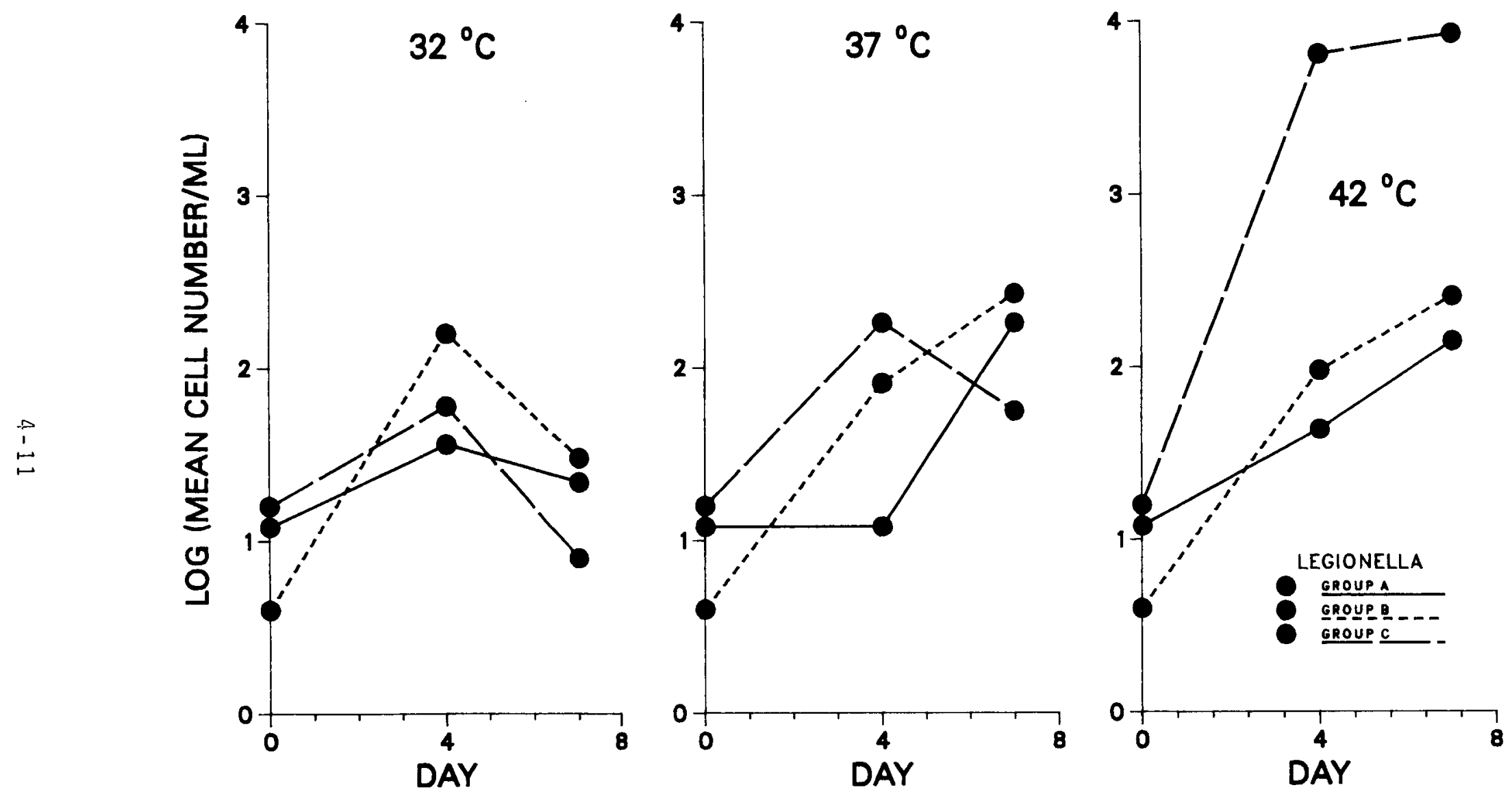

Figure 4-3. ENV-4: Density of Legionella spp. from Plant $B$, incubated at three temperatures
$\left[\log _{10}\right.$ (mean cell number $\left.\left./ \mathrm{mL}\right)\right]$. 

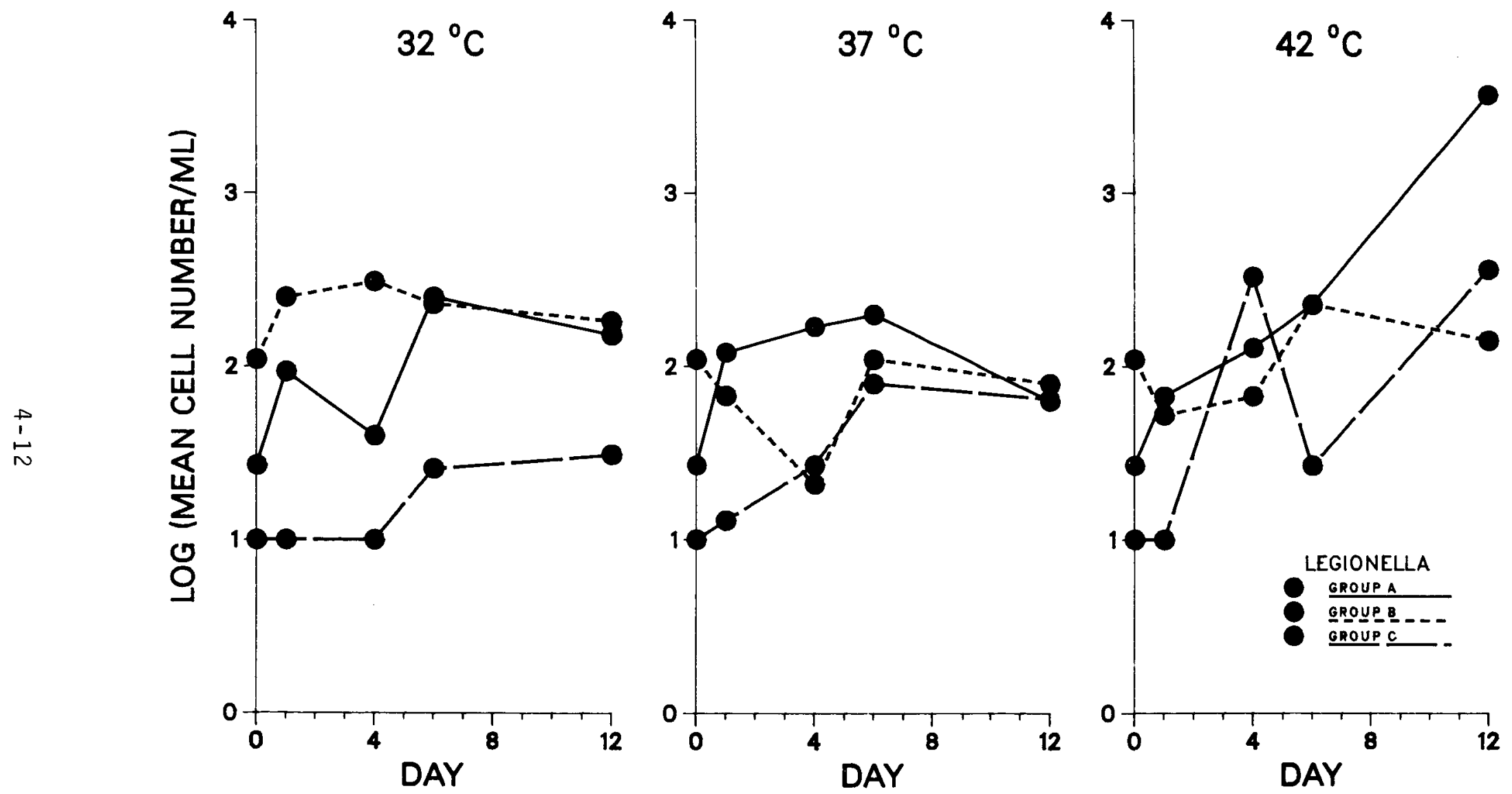

Figure 4-4. ENV-4: Density of Legionella spp. from plant $F$ at three temperatures $\left[\log _{10}\right.$ (mean cell number $/ \mathrm{mL}$ )]. 


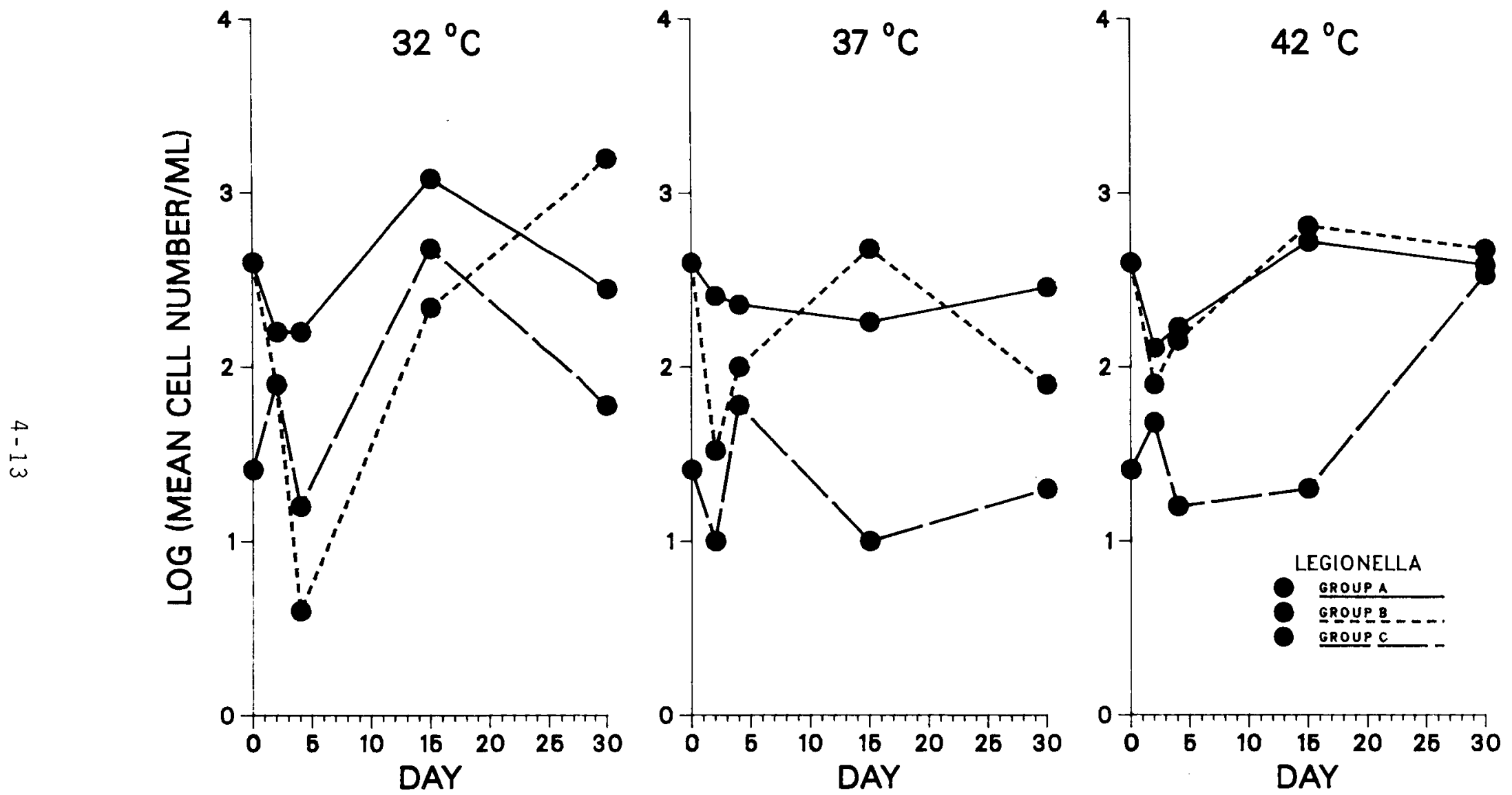
Figure 4-5. ENV-4: Density of Legionella spp. from plant $G$ at three temperatures
$\left[\log _{10}\right.$ (mean cell number/mL)]. 
plant $B$ and at $32^{\circ} \mathrm{C}$ in plant $G$. The first of these cases was especially noteworthy for several reasons: (1) group A contains many of the known pathogenic forms; (2) plant $F$ is often a source of infectious Legionella: and (3) elevated temperature is associated with all cooling tower environments, which environments have been implicated in Legionellosis episodes.

Other differences between waters from the three plants were apparent in the initial population responses (i.e., in the first 4 d). At plant $B$, eight of the nine cultures showed an initial density rise, at plant $F$ six of nine rose, and at plant $G$ only two of nine showed an initial increase. This agrees with the results of ENV-2, where both laboratory strains of Legionella grew better in the negative plant water ( $p$ lant $B$ ) than in the positive plant water ( $p$ lants $F$ and $G$ ).

These results were meaningful from several standpoints. First, they demonstrated the capability for growth at $42^{\circ} \mathrm{C}$ of Legionella populations from power plants. This property is generally not demonstrable in laboratory Legionella cultures. In addition, the results show a site dependency for Legionella growth indicating that the composition of the Legionella populations themselves, water quality differences, or the interaction of these variables may determine the temperature at which growth occurs or whether it occurs at all.

This complexity is not present, or at least is not demonstrated, in the usual laboratory cultures of Legionella because, in general, the growth media and incubation temperatures do not vary. Also, a laboratory culture of Legionella normally consists of only one strain of the bacteria, while natural Legionella populations are composed of a mixture of species and strains, each of which responds to the environment in its own manner. However, while it is easier to interpret the growth of Legionella under typical laboratory conditions, these conditions do not necessarily allow us to address the important question of which parameters in nature affect the growth of natural Legionella populations, such as those found in power plant waters. The results of ENV-4 suggest that some parameters affecting the growth of natural Legionella populations might be definable.

Pellet Exchange Experiments. The goal of ENV-5 through ENV-7 was to separate the effects of water quality and temperature from possible variations between the composition of the naturally occurring Legionella populations at the positive versus the negative power plants. In ENV-4, growth of group $A$ Legionella in plant $F$ water at $42^{\circ} \mathrm{C}$ increased by more than a hundredfold. Such 
strong growth of group A Legionella was not seen at the other piants, nor at 32 or $37^{\circ} \mathrm{C}$ at plant $\mathrm{F}$. We wanted to replicate this selective enhancement of growth and, if successful, to determine whether water-quality differences among the plants had interacted with temperature to produce this effect. Complicating the picture was the question of whether the composition of the mixed Legionella populations at the two plants was comparable [1.e., was the strain(s) of Legionella growing at plant $F$ at a high temperature even present at plant $B$ ?].

To address this question the bacterial flora from plant $F$ (a positive plant) was incubated in plant $B$ (negative) water, and the flora from the negative plant was incubated in positive plant water (the pellet exchange experiments). Because Wadowsky and Yee (1983) had shown that aquatic bacteria other than Legionella could grow at $42^{\circ} \mathrm{C}$ but not at $45^{\circ} \mathrm{C}$, an incubation temperature of $45^{\circ} \mathrm{C}$ was used in these experiments to discourage the growth of non-Legionella bacteria.

In the first of the three pellet exchange experiments (ENV-5, Figs. 4-6 through 4-9) the plant $B$ Legionella grew better at $32^{\circ} \mathrm{C}$ than they did at $45^{\circ} \mathrm{C}$ $(P<0.025$, Fisher's exact test; Siegel 1956). In eight out of nine cases, all three plant $B$ Legionella groups showed an increase in cell density at $32^{\circ} \mathrm{C}$, regardless of which water source was used for the incubation.

Results for plant $F$ Legionella indicated a contrasting but less consistent response to temperature (compare the corresponding frames in Figs. 4-8 and 4-9). Better growth at $45^{\circ} \mathrm{C}$ than at $32^{\circ} \mathrm{C}$ was evident for plant $F$, group $A$ Legionella in plant $F$ water and plant $F$, group $C$ Legionella in plant $B$ water.

The next pellet exchange experiment (ENV-6, Figs. 4-10 through 4-13) revealed a thermotolerant component of the Legionella population, particularly at plant $F$. Although ENV-6 was designed to replicate ENV-5, equipment failure after $2 \mathrm{~d}$ resulted in half of the cultures being incubated at $85^{\circ} \mathrm{C}\left(185^{\circ} \mathrm{F}\right)$ for about 18 $h$. While most of the organisms in these cultures showed a precipitate decrease in density during the first $3 d$ (Figs. 4-11 and 4-13), groups $A$ and $B$ from plant $F$ increased in plant $B$ water (Fig. 4-13). In addition, the unprocessed plant $F$ water apparently contained enough viable cells of all three groups to produce a definite increase in cell density on its return to less extreme conditions (Fig. 4-13, first frame). Similar recoveries also occurred in a few other cases. The microbial flora from plant $F$ (and perhaps also from plant $B$ ) appears to contain a Legionella subpopulation tolerant of very high temperatures for about $18 \mathrm{~h}$. 
Water souroe: Plent B (unprooeseed)
Water souroe: Plent B (centrifuged)
Water souros: Plent F (centrifuged)
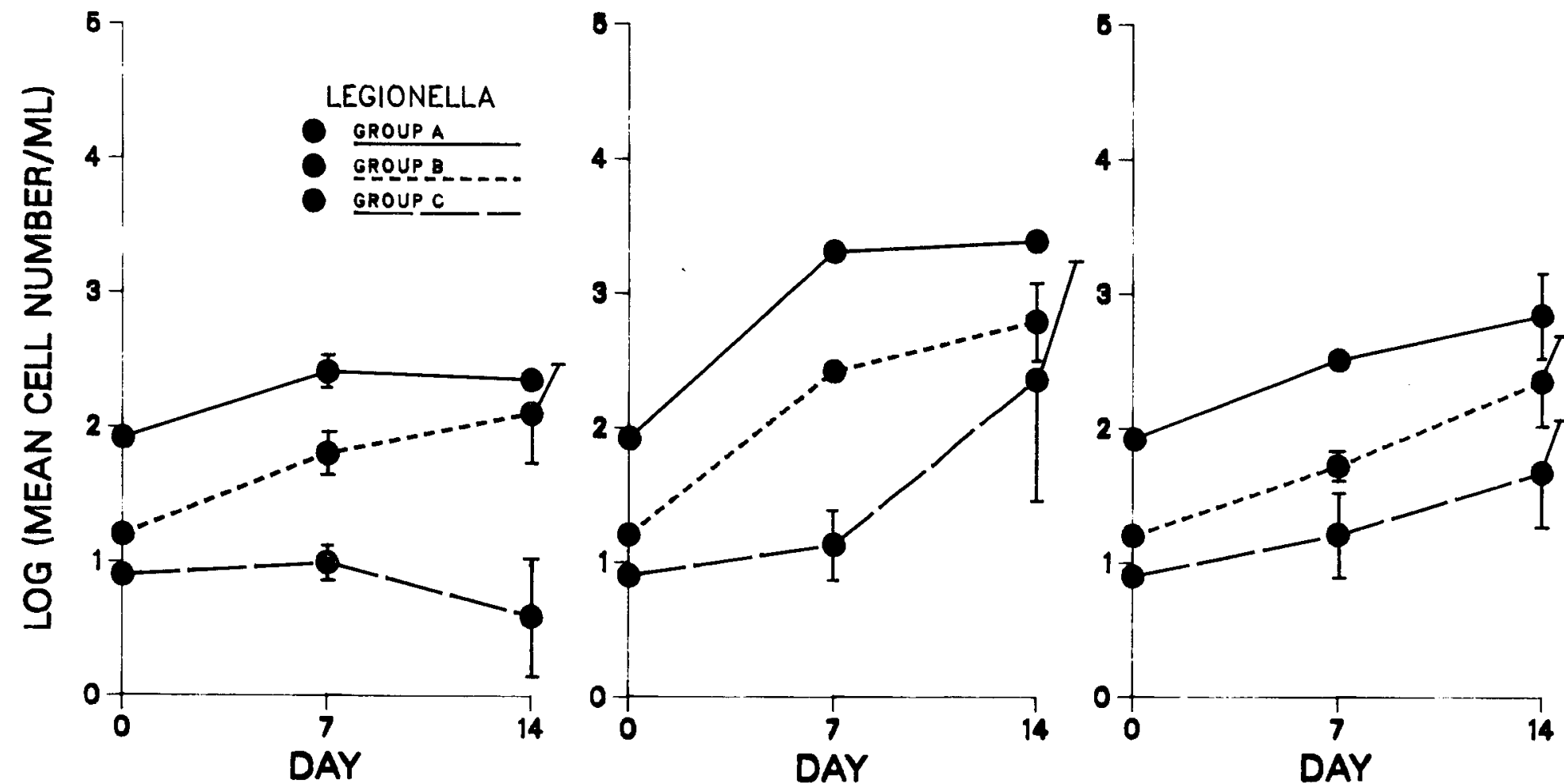

Figure 4-6. ENV-5: Density of Legionella spp. from plant $B$ at $32^{\circ} \mathrm{C}$ in water from two power plants $\left[\log _{10}\right.$ (mean cel1 number/mL) \pm 1 S.E.]. Where error bars are not shown, they are smaller than the diameter of the circle representing the mean. 
Water souroe: Plant B

(unprocessed)
Water souroe: Plent B (oentrifuged)
Water souroe: Plant F (oontrifuged)
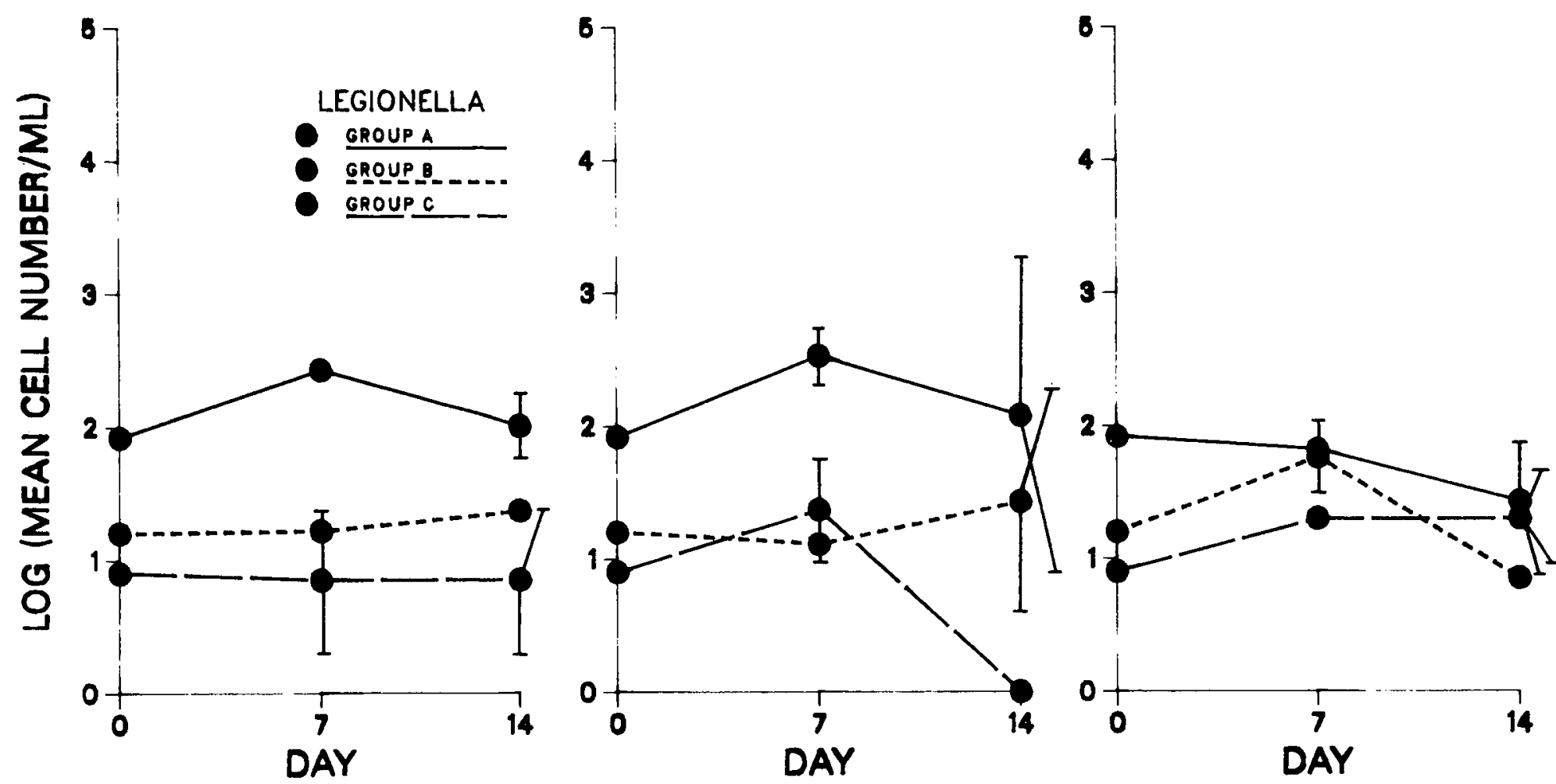

Figure 4-7. ENV-5: Density of Legionella spp. from plant $B$ at $45^{\circ} \mathrm{C}$ in water from two power plants $\left[\log _{10}\right.$ (mean cell number $/ \mathrm{mL}$ ) \pm 1 S.E.]. Where error bars are not shown, they are smaller than the diameter of the circle representing the mean. 


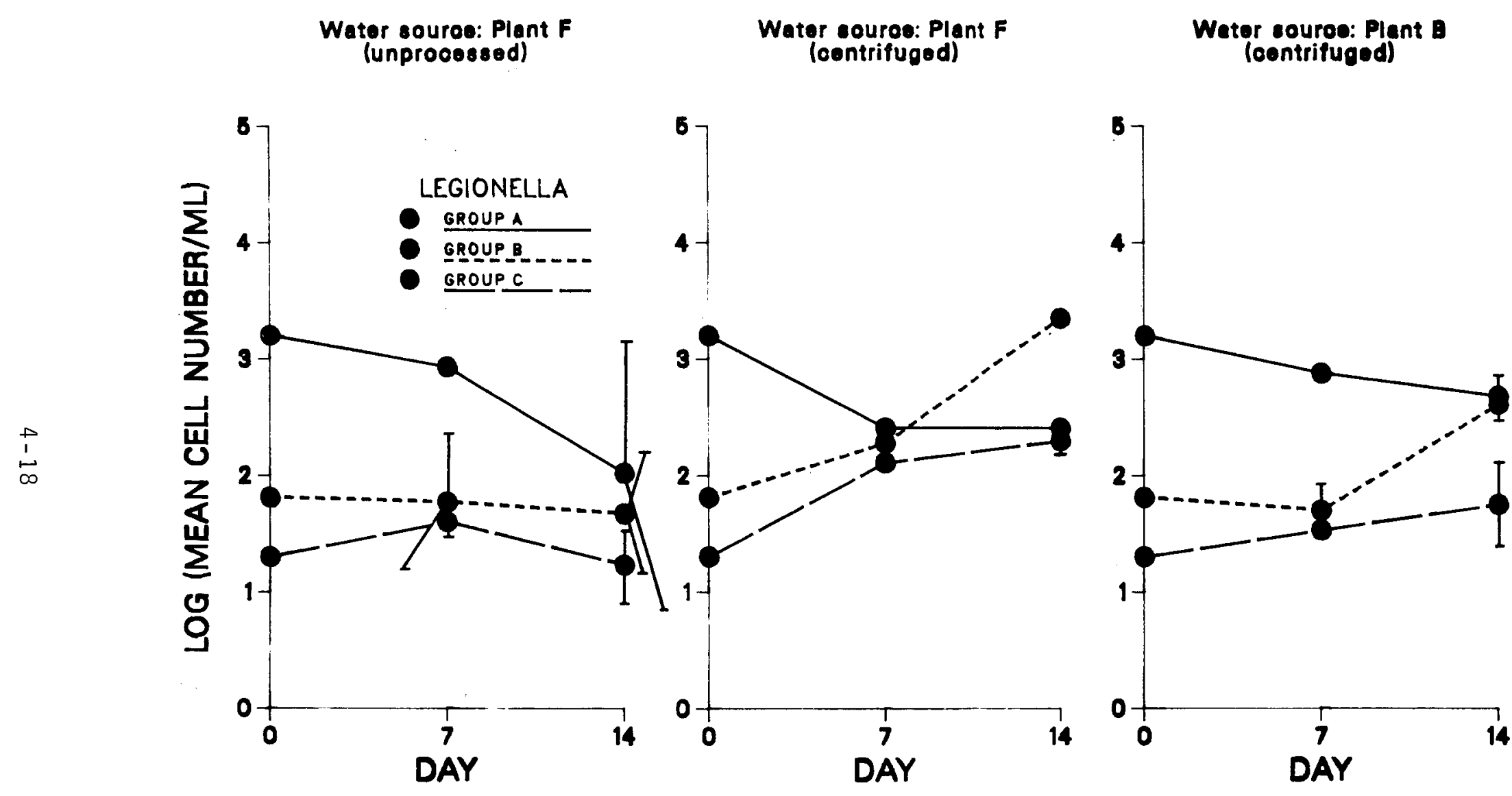

Figure 4-8. ENV-5: Density of Legionella spp. from plant $F$ at $32^{\circ} \mathrm{C}$ in water from two power plants $\left[\log _{10}\right.$ (mean cell number $/ \mathrm{mL}$ ) \pm 1 S.E.]. Where error bars are not shown, they are smaller than the diameter of the circle representing the mean. 


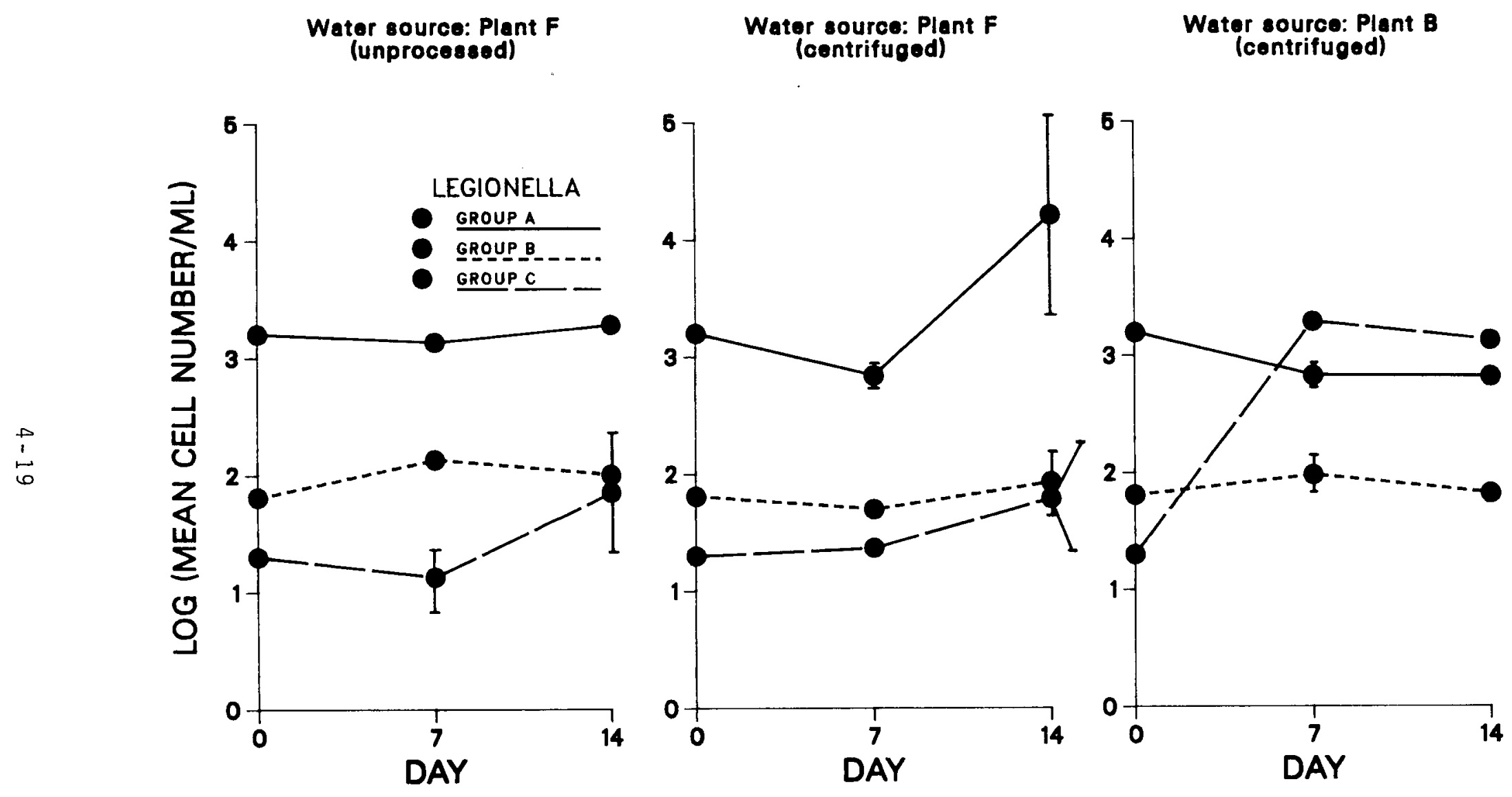

Figure 4-9. ENV-5: Density of Legionella spp. from plant $F$ at $45^{\circ} \mathrm{C}$ in water from two power plants $\left[\log _{10}\right.$ (mean cell number $/ \mathrm{mL}$ ) $\left.\pm 1 \mathrm{~S} . \mathrm{E}.\right]$. Where error bars are not shown, they are smalier than the diameter of the circle representing the mean. 

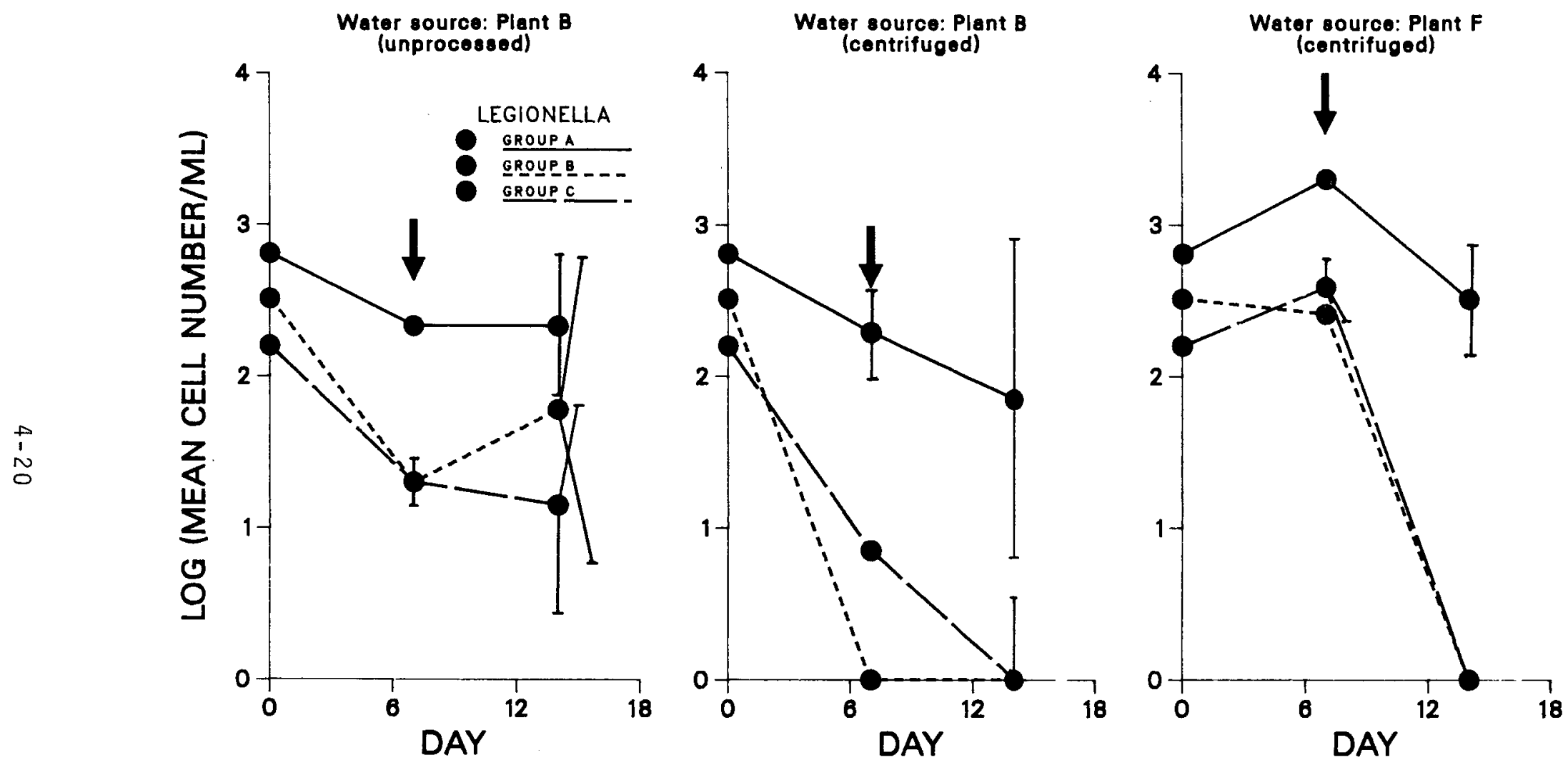

Figure 4-10. ENV-6: Density of Legionella spp. from plant B incubated in water from two power plants $\left[\log _{10}\right.$ (mean cell number $/ \mathrm{mL}$ ) \pm 1 S.E.]. Incubation temperature was $32^{\circ} \mathrm{C}$ for the first $7 \mathrm{~d}$ and $45^{\circ} \mathrm{C}$ subsequently (arrow marks time of temperature change). Where error bars are not shown, they are smaller than the diameter of the circle representing the mean. 

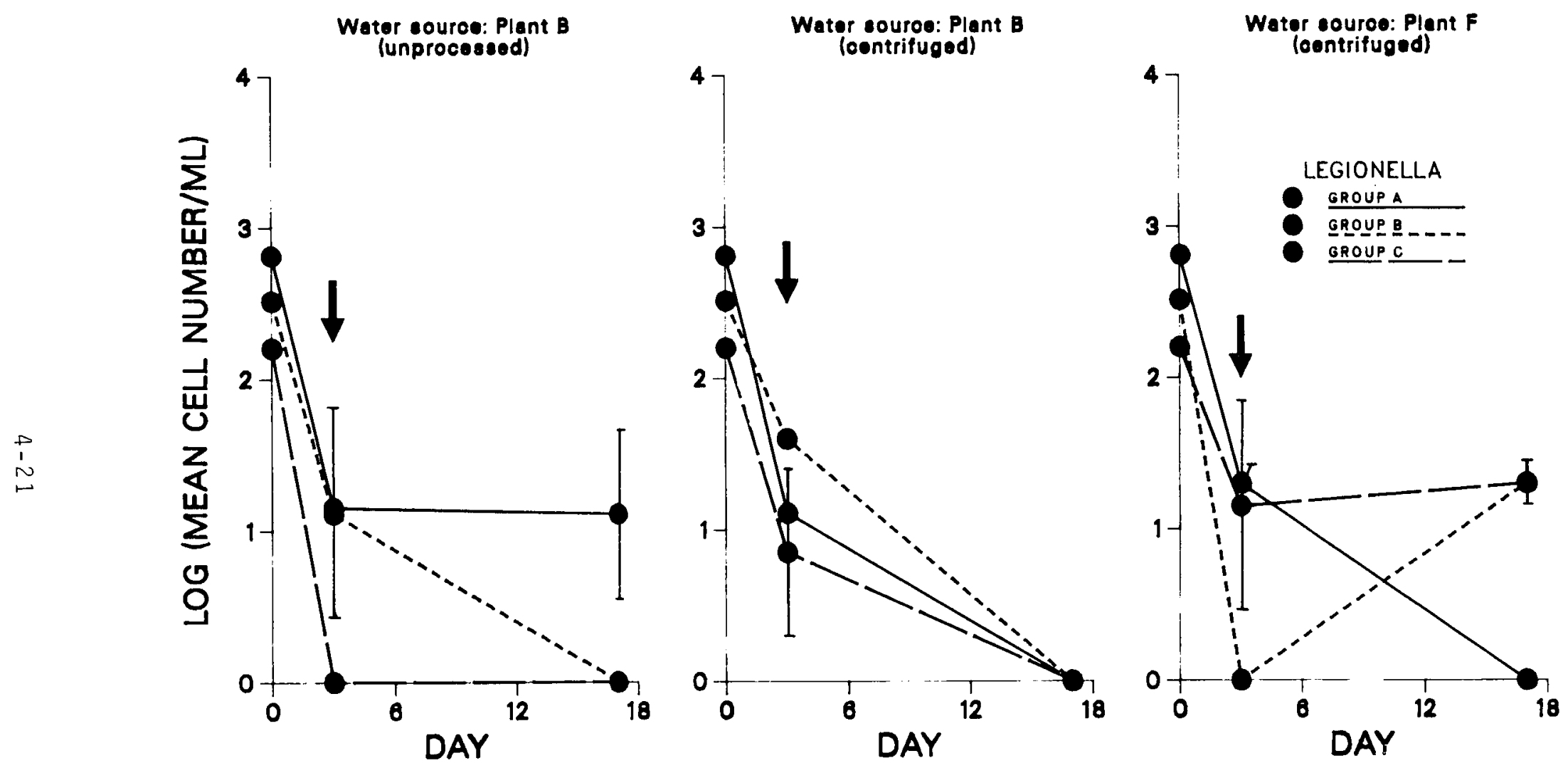

Figure 4-11. ENV-6: Density of Legionella spp. from plant B incubated in water from two power plants [ $\log _{10}$ (mean ce 11 number $/ \mathrm{mL}$ ) \pm 1 S.E.]. Incubation temperature was $45^{\circ} \mathrm{C}$ for $2 \mathrm{~d}$, $85^{\circ} \mathrm{C}$ for $18 \mathrm{~h}$, and $37^{\circ} \mathrm{C}$ subsequently (arrow marks time of final temperature change). Where error bars are not shown, they are smaller than the diameter of the circle representing the mean. 

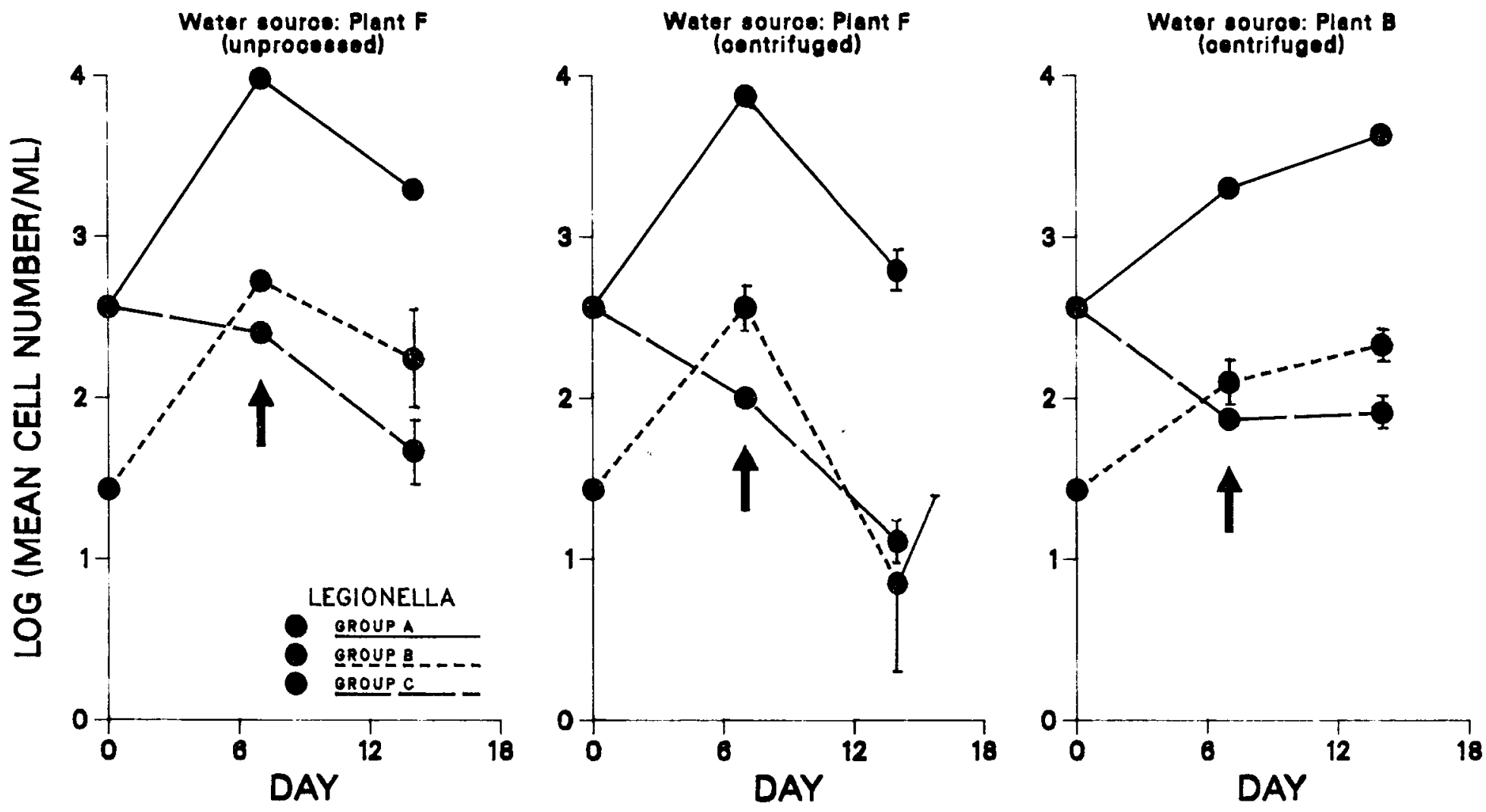

Figure 4-12. ENV-6: Density of Legionella spp. from plant $F$ incubated in water from two power plants $\left[\log _{10}\right.$ (mean cell number $/ \mathrm{mL}$ ) $\left.\pm 1 \mathrm{~S} . \mathrm{E}.\right]$. Incubation temperature was $32^{\circ} \mathrm{C}$ for the first $7 \mathrm{~d}$ and $45^{\circ} \mathrm{C}$ subsequently (arrow marks time of temperature change). Where error bars are not shown, they are smaller than the diameter of the circle representing the mean. 

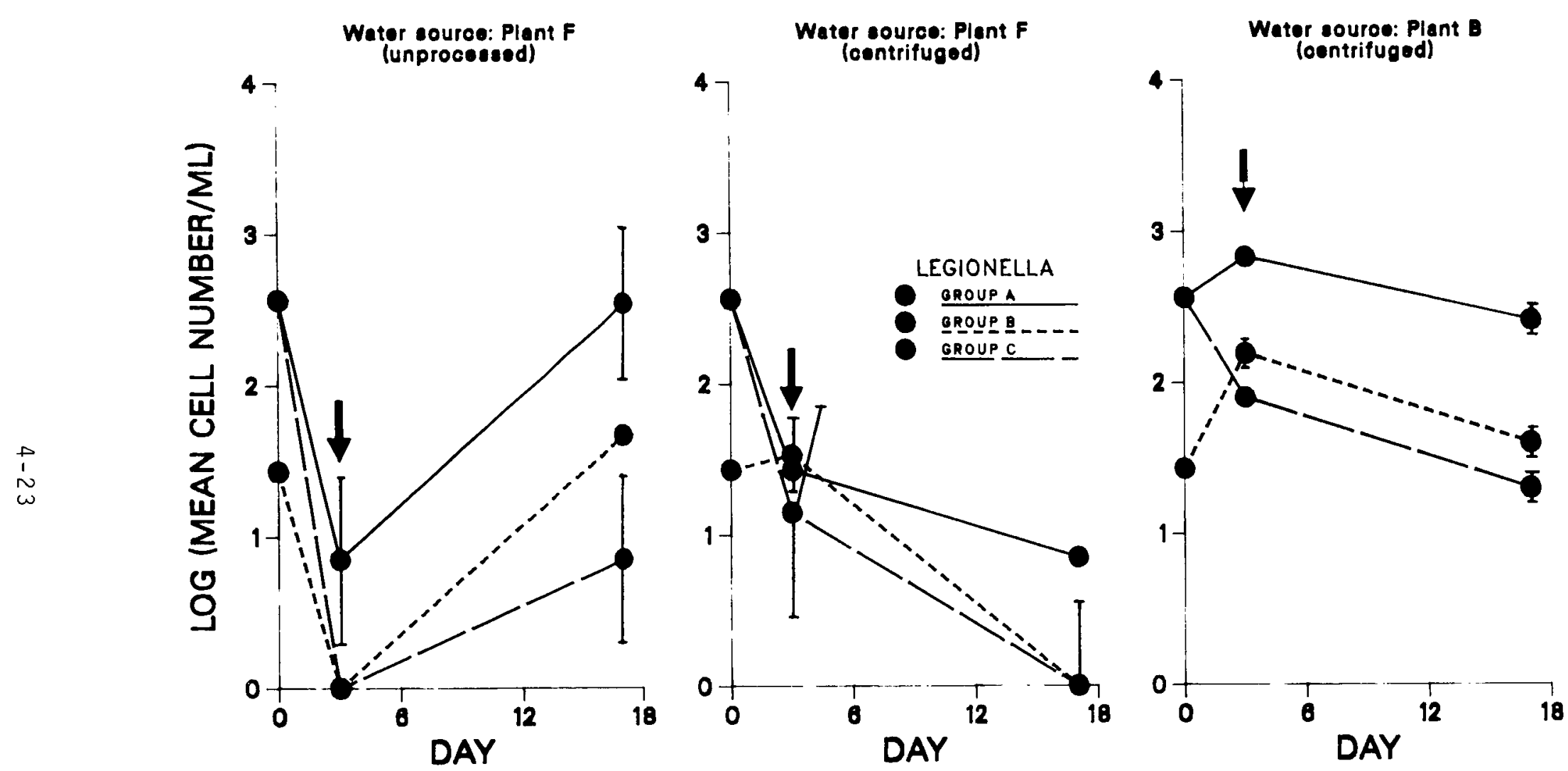

Figure 4-73. ENV-6: Density of Leglonella spp. from plant $F$ incubated in water from two power plants [ $\log _{10}$ (mean cell number $/ \mathrm{mL}$ ) \pm 1 S.E.]. Incubation temperature was $45^{\circ} \mathrm{C}$ for $2 \mathrm{~d}$, $85^{\circ} \mathrm{C}$ for $18 \mathrm{~h}$, and $37^{\circ} \mathrm{C}$ subsequently (arrow marks time of final temperature change). Where error bars are not shown, they are smaller than the diameter of the circle representing the mean. 
The portion of ENV-6 which still could have served as a replicate for ENV-5 (the first $7 \mathrm{~d}$ at $32^{\circ} \mathrm{C}$ ) produced decidedly contradictory results. Plant $B$ Legionella in plant B water grew or did not decline in a 11 six cases in ENV-5 (frames 1 and 2, Fig. 4-6), while in ENV-6, every corresponding case declined (frames 1 and 2, Fig. 4-10). The responses of plant $B$ Legionella incubated in plant $F$ water were more similar (third frame, Figs. 4-6 and 4-10). This pattern would be consistent with a marked change in the water quality of plant $B$ and not plant $F$.

Plant $F$ Legionella at $32^{\circ} \mathrm{C}$ (Figs. 4-8 and 4-12) also showed dissimilar behavior in these experiments performed one month apart. In ENV-6, however, the plant $F$ Legionella have similar growth patterns at $32^{\circ} \mathrm{C}$ in the two water sources, indicating a lack of effect of water-quality differences. Such lack of water-quality differences is both unlikely and contradictory to the response of plant $B$ Legionella, described above.

A probable explanation is that the plant $B$ Legionella population also changed in composition between ENV-5 and ENV-6. Comparison of initial cell densities at plant $B$ supports this. The similar responses of plant $F$ Legionella to plants $B$ and $F$ waters may indicate that the plant $F$ population can adapt more easily to changing conditions.

In the third pellet exchange experiment (ENV-7; Figs. 4-14 through 4-17), all cultures from both plants, without exception, showed population declines by the seventh day. At the same time, considerable growth of the associated biota, not observed in any previous experiment, was noted in many of the flasks, particularly in those cultures from plant $F$. Microscopic examination revealed a variety of algae in the $32^{\circ} \mathrm{C}$ flasks, primarily diatoms and colonial green algae. The non-Legionella population at $45^{\circ} \mathrm{C}$ was totally different in that no recognizable algae were seen, but there was a great deal of unidentifiable debris, probably fungal in origin. Attempts to culture the debris were unsuccessful.

In spite of the incubator fallure in ENV- 6 and the overgrowth of associated biota in ENV-7, experiments ENV-5, 6, and 7 yielded valuable results. The experiments confirmed the results of ENV-4 in demonstrating the growth of indigenous power plant Legionella populations at elevated temperatures. These pellet exchange experiments also indicated that differences in growth patterns at $32^{\circ}$ and $45^{\circ} \mathrm{C}$ were partly dependent both on the water quality effects and on inherent differences in the Legionella populations themselves. Overall, the plant $F$ 

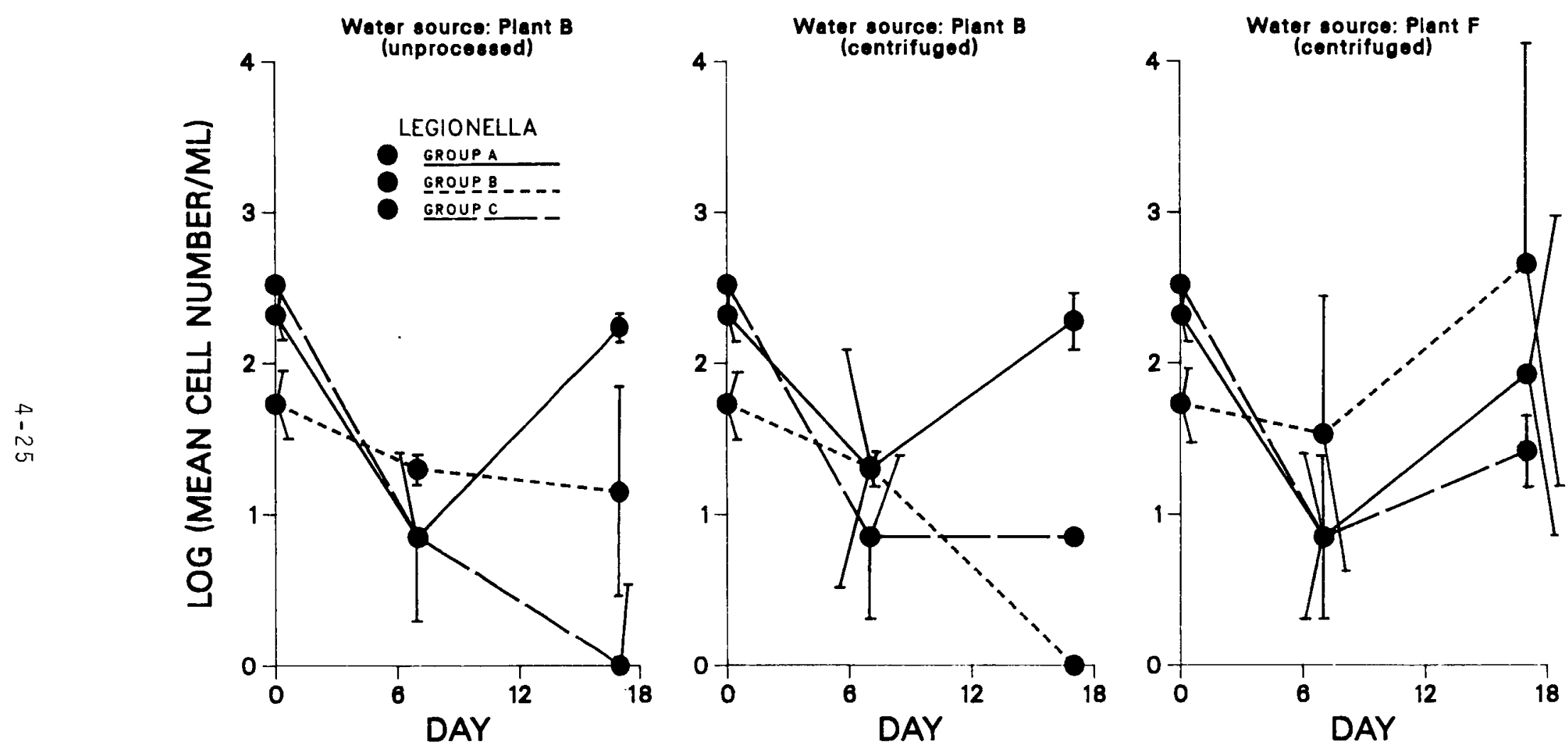

Figure 4-14. ENV-7: Density of Legionella spp. from plant $B$ at $32^{\circ} \mathrm{C}$ incubated in water from two power plants $\left[\log _{10}\right.$ (mean cel1 number $/ \mathrm{mL}$ ) $\pm>$ S.E. $]$. Where error bars are not shown, they are smaller than the diameter of the circle representing the mean. 

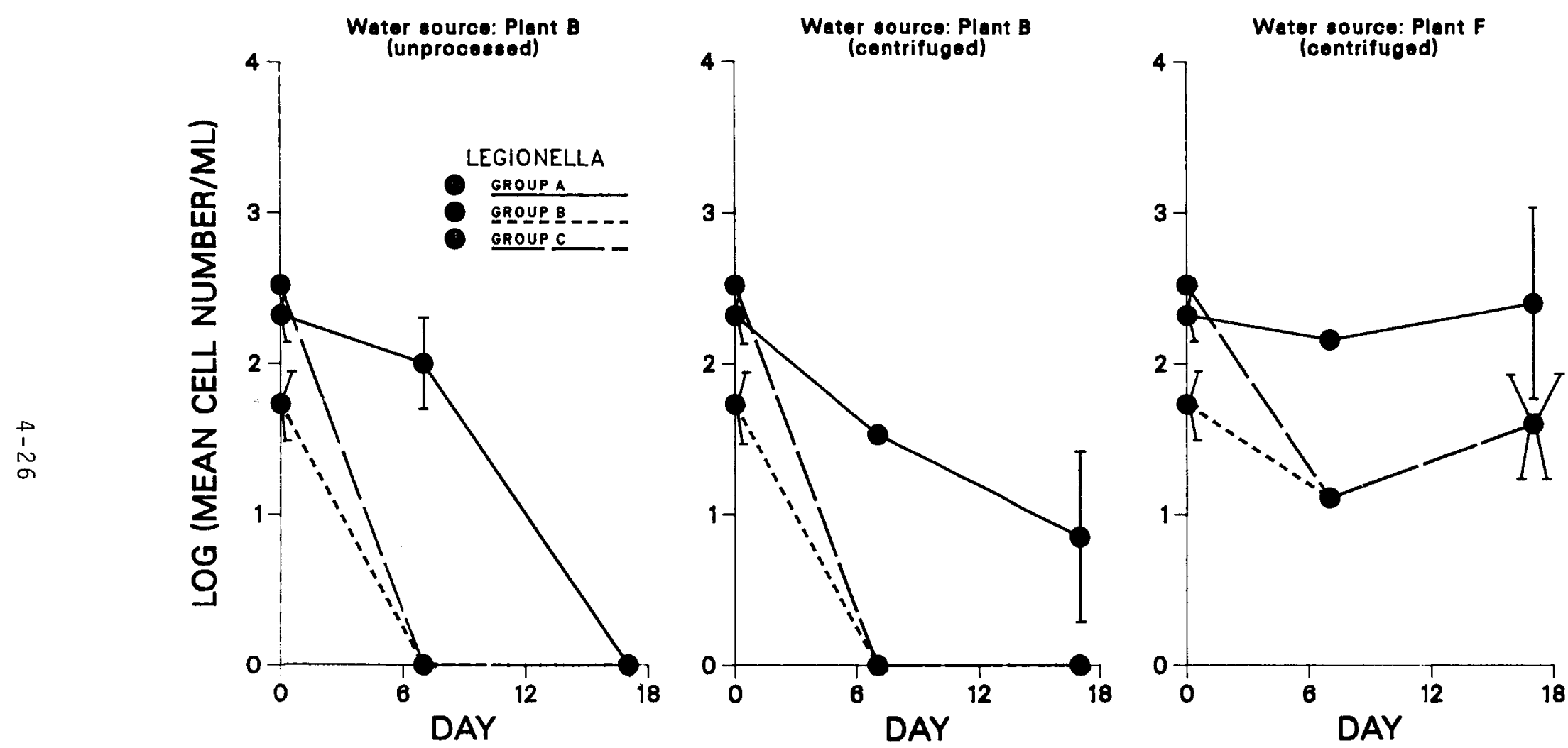

Figure 4-15. ENV-7: Denstty of Legionella spp. from plant $B$ at $45^{\circ} \mathrm{C}$ incubated in water from two power plants $\left[\log _{10}\right.$ (mean ce11 number $\left./ \mathrm{mL}\right) \pm 1$ S.E.]. Where error bars are not shown, they are smaller than the diameter of the circle representing the mean. 

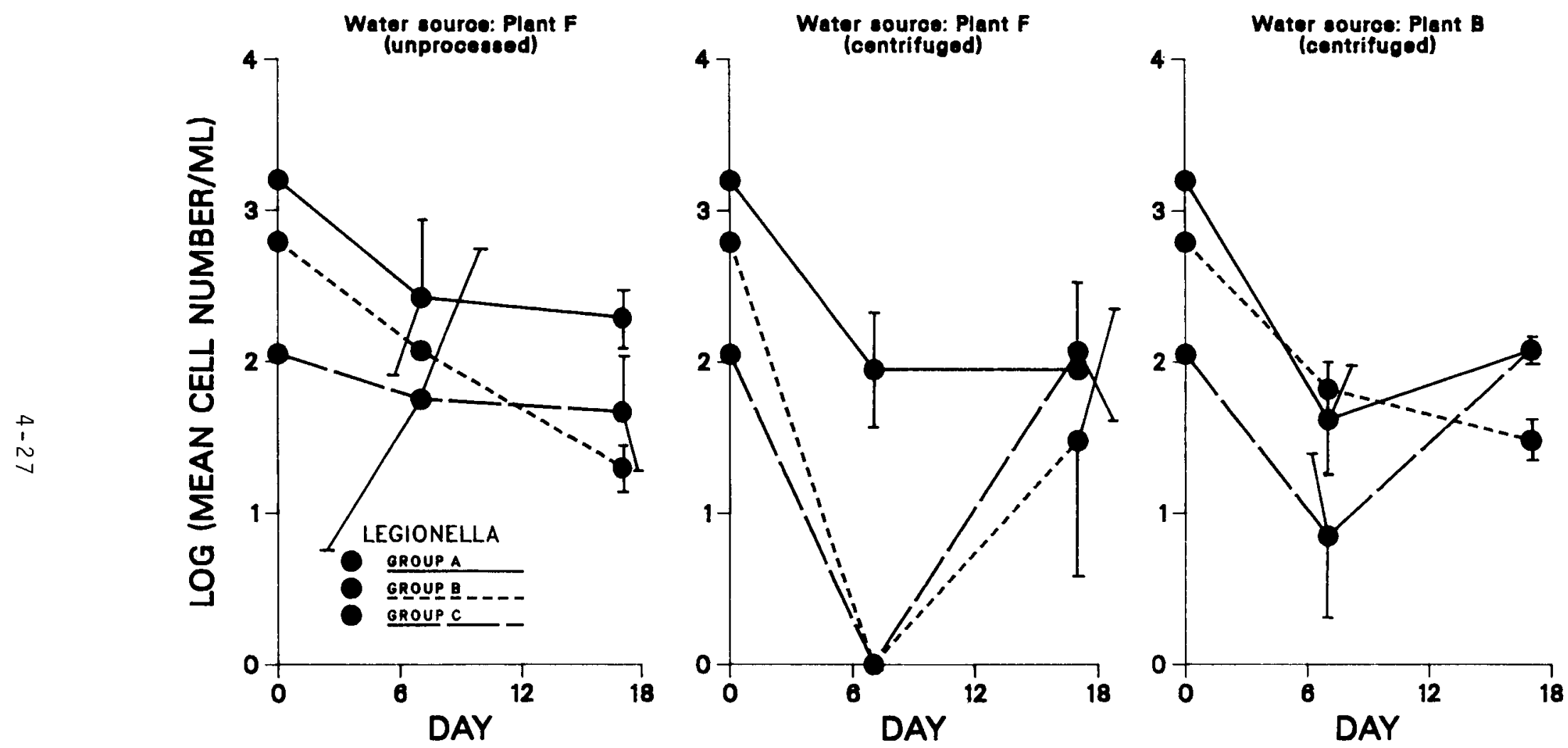

Figure 4-16. ENV-7: Density of Legionella spp. from plant $F$ at $32^{\circ} \mathrm{C}$ incubated in water from two power plants $\left[\log _{10}\right.$ (mean cell number $/ \mathrm{mL}$ ) $\left.\pm 1 \mathrm{~S} . \mathrm{E}.\right]$. Where error bars are not shown, they are smaller than the diameter of the circle representing the mean. 

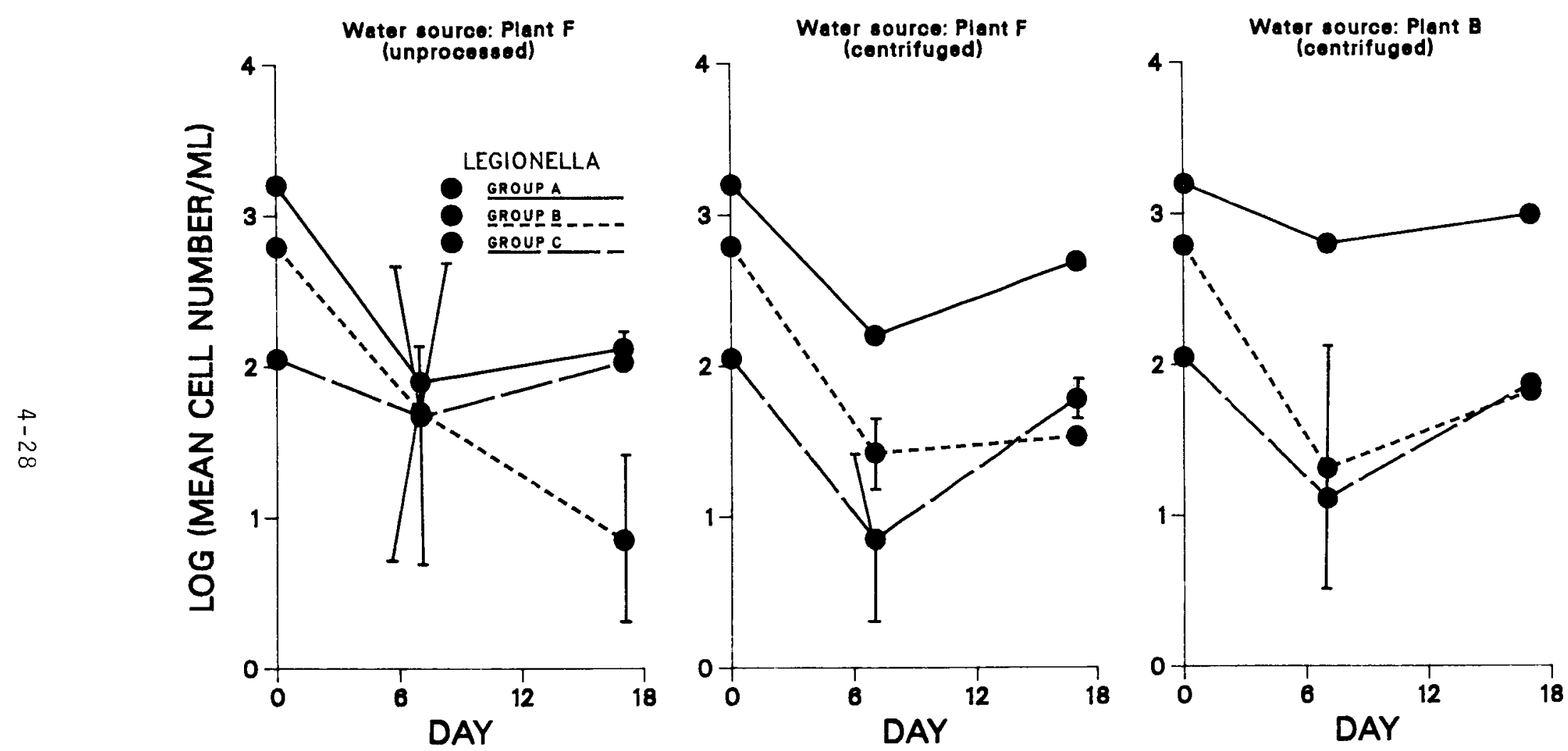

Figure 4-17. ENV-7: Density of Legionella spp. from plant $F$ at $45^{\circ} \mathrm{C}$ incubated in water from two power plants $\left[\log _{70}\right.$ (mean cell number $/ \mathrm{mL}$ ) \pm 1 S.E.]. Where error bars are not shown, they are smaller than the diameter of the circle representing the mean. 
Legionella population showed signs of being better adapted to elevated temperatures than did the plant B population. This is not surprising since plant $F$ usually operated in a recirculating mode and plant $B$ has a once-through cooling system.

Separation of Components Experiments. Indications from the previous experiments that water quality parameters affected group A Legionella growth or survival were encouraging. However, many difficulties of interpretation arose because of the complexity of the experimental components. Each time the experiment was repeated, a new supply of water with associated organisms was obtained, so that both water quality and the biotic component varied. Also, the bacterial pellet contained not only the mixed natural Legionella population but also the associated biota (other bacteria, algae, fungi, etc.) and nonbiotic particulates (e.g., ENV-7).

Several steps were taken in ENV-8 and 9 (Table 1-3) to simplify the composition of the experimental system. If soluble components of power plant water could be implicated as promoting or inhibiting the growth of group A Legionella then, theoretically, these components could be identified. Because in the previous experiments the water for incubation had been prepared by centrifugation rather than filtration, not all particulates were removed; hence, we were not dealing with soluble water-quality factors only. Consequently, the water in ENV-8 and 9 was centrifuged and an aliquot of the supernatant was filtered through sterile 0.45- $\mu \mathrm{m}$-pore-sized membranes to remove small particulate matter. An unfiltered aliquot was tested for comparison. As in the pellet exchange experiments, centrifuged pellets were used as the source of Legionella and associated blota. Unlike the protocol in the previous experiments, however, the pellet was fractionated further through a Percoll density gradient. This resulted in a less dense subpopulation of Legionella banding together in the gradient with other bacteria, while the more dense Legionella, and those associated with large particles, collected at the bottom of the gradient. Only bacterial populations from positive plants ( $p$ lant $F$ for ENV-8 and plant $H$ for ENV-9) were used, and only group A Legionella were consistently counted.

During the first 3 d of ENV-8, mean densities increased under all conditions (Figs. 4-18 and 4-19). The initial rise was most pronounced for the banded group $A$ Legionella in filtered plant $B$ water and in nonfiltered plant $F$ water. These results would be consistent with the presence of a particulate-associated inhibitor of Legionella growth in the plant $B$ water. The high variation in 

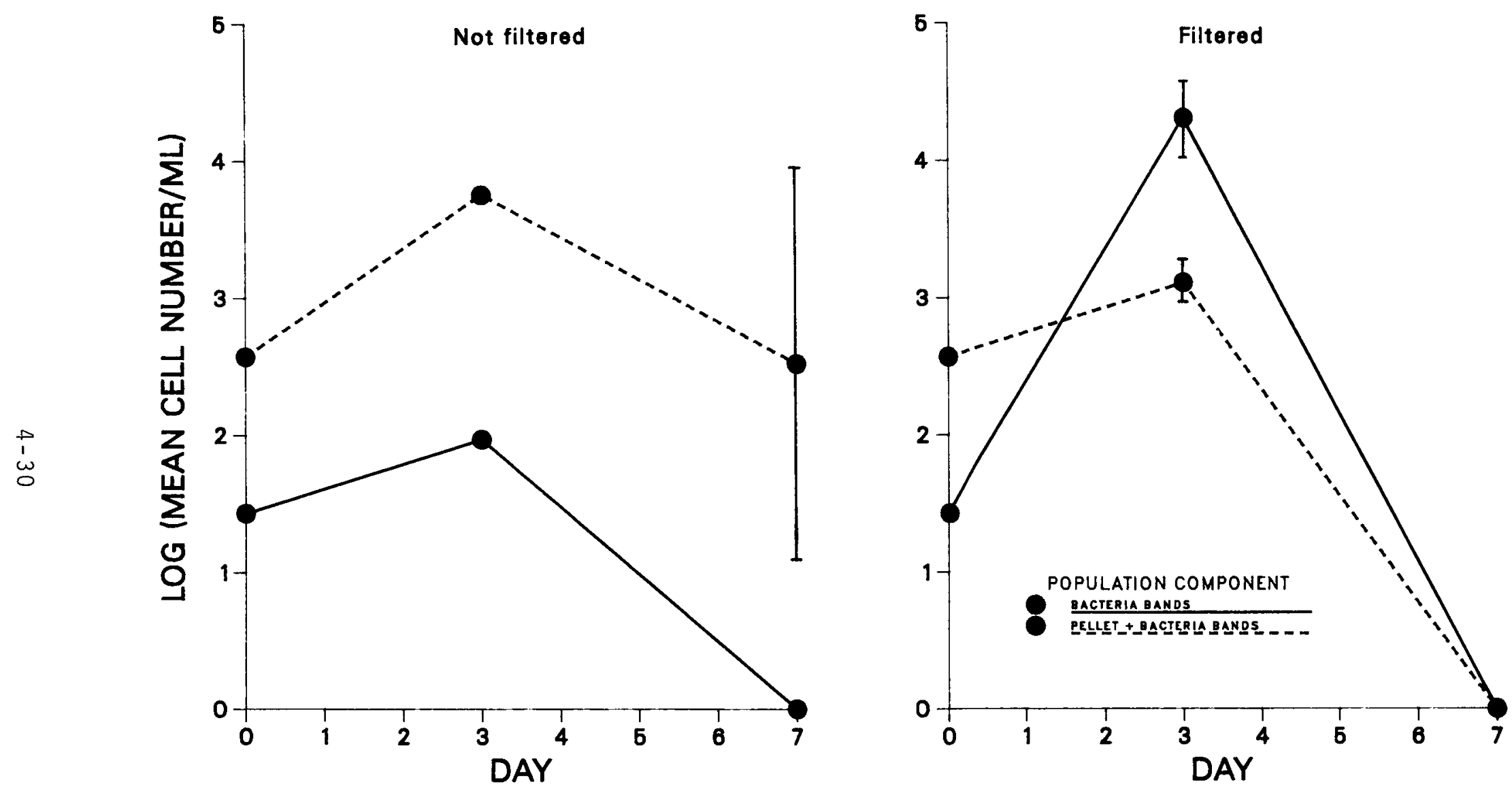

Figure 4-18. ENV-8: Density of Legionella pneumophila, serogroups 1-4, from plant $F$ incubated in plant $B$ water at $45^{\circ} \mathrm{C}\left[\log _{10}\right.$ (mean cell number $/ \mathrm{mL}$ ) $\left.\pm 1 \mathrm{~S} . \mathrm{E}.\right]$. Where error bars are not shown, they are smaller than the diameter of the circle representing the mean. 

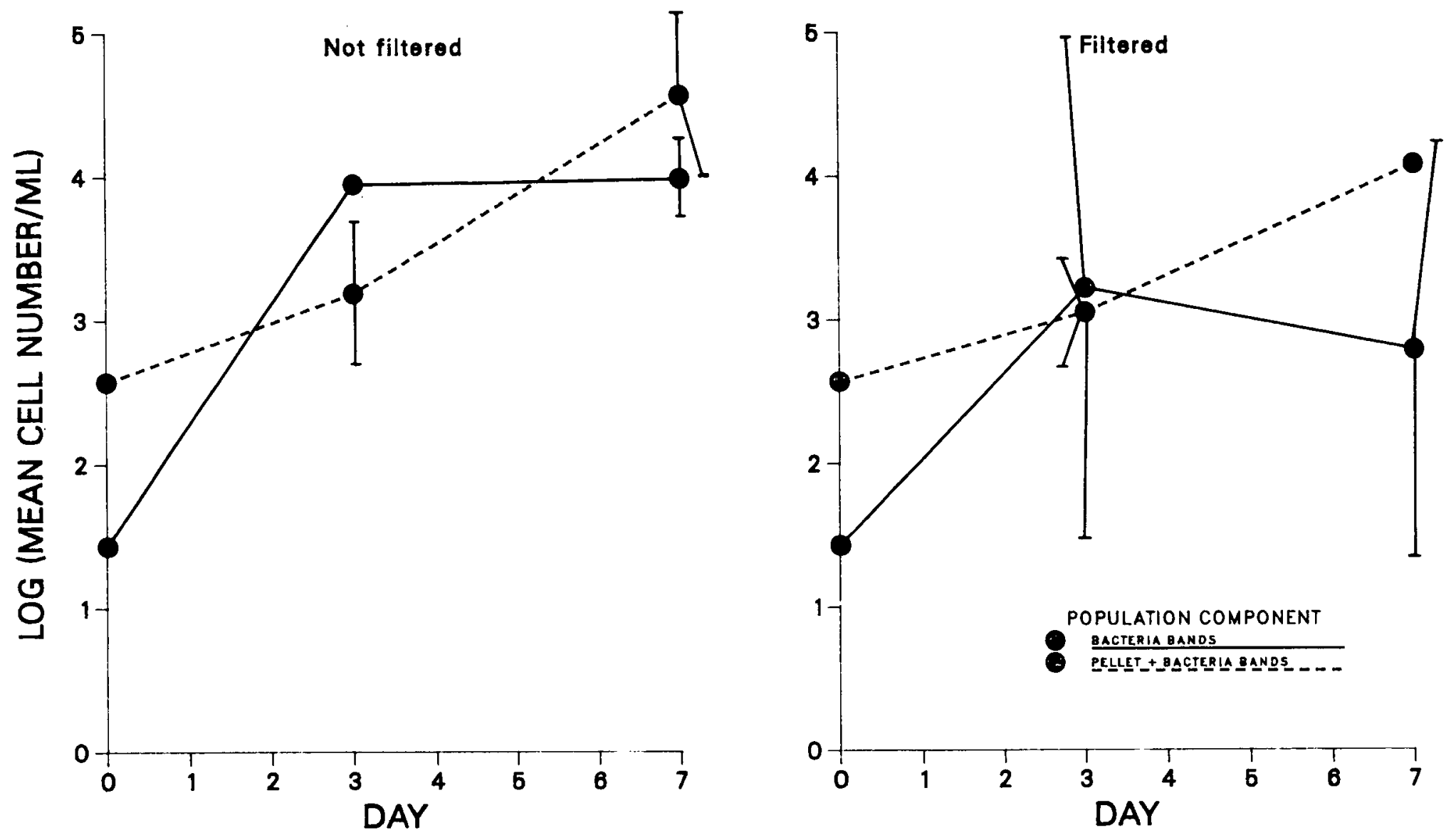

Figure 4-19. ENV-8: Density of Legionella pneumophila, serogroups 1-4, from plant $F$ incubated in plant $\mathrm{F}$ water at $45^{\circ} \mathrm{C}\left[\log _{10}\right.$ (mean cell number $/ \mathrm{mL}$ ) \pm 1 S.E.]. Where error bars are not shown, they are smaller than the diameter of the circle representing the mean. 
densities of the replicate banded bacteria cultures in filtered plant $F$ water precludes such comparisons there.

Plant $F$ water was able to support continued growth of Legionella throughout the $7 \mathrm{~d}$ of the experiment, whereas plant $B$ water was not. In three of the four cases, the plant $F$ populations grown in plant $B$ water stopped growing and then declined markedly. In contrast, all cultures in plant $f$ water (with one possible exception, indeterminate very likely because of measurement variability) continued growing throughout the 7-d period.

In ENV-9 (Figs. 4-20 and 4-21), a partial replication of ENV-8, the banded Legionella from plant $H$ (a positive plant, see Table 1-2) placed in filtered plant $H$ water increased more than two orders of magnitude on the first day and then maintained that level for four more days. Maintenance of the banded Legionella, but no marked population increase, was seen in plant $B$ water. The plant $H$ pellets, containing associated biota, particulates, and heavier Legionella, also maintained but did not increase their numbers.

Comparing ENV-9 with ENV-8, we see that filtered water from two different positive power plants supported the extended growth of banded Legionella obtained from those plants. Plant B water did not support such growth. In two cases, there was distinctiy less growth of the pelleted fraction compared with the bands, perhaps indicating the existence of an inhibitor in this particulate fraction. Since both the water and the Legionella populations were different in each experiment, however, these variations could be due to changes in the Legionella population itself or to changes in water quality.

In experiment ENV-9 the microbial pellets from the test waters were inoculated into guinea pigs before and after incubation (Table 4-5). Infectious (1.e., high-virulence) Legionella were not found in the microbial pellets from plants $B$ and $H$ waters before or after incubation. The number of Legionella injected from the actively growing population in plant $H$ water was suffictent for detection of infectious Legionella (Fig. 4-1).

Growth of Mixed Natural Populations in Lake Water: Nitrate Enrichment Experiment

Water samples from a nitrogen-limited reservoir, not associated with a power plant, were collected from two depths and incubated after being enriched with nitrate, but no consistent response to nitrate enrichment was found. Results 


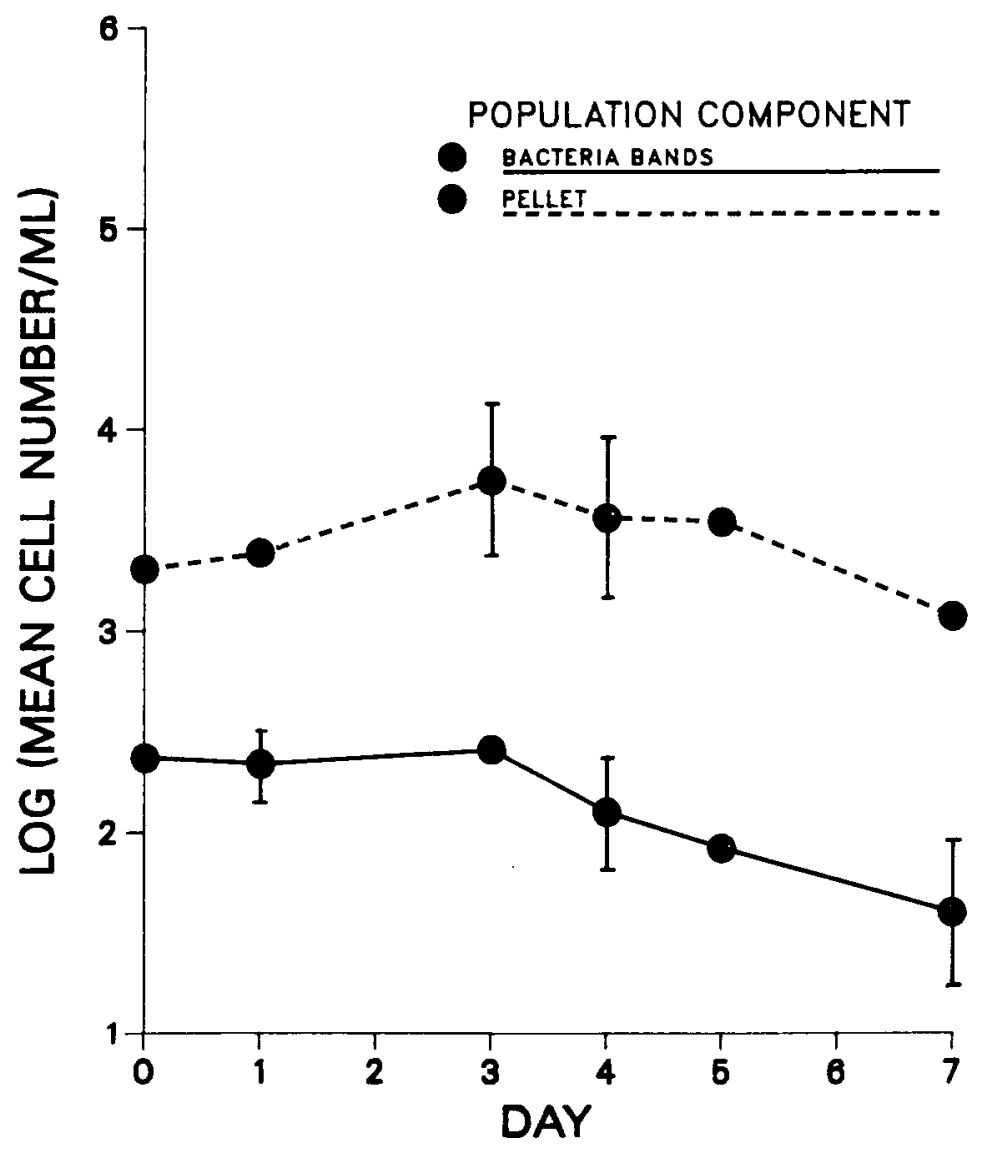

Figure 4-20. ENV-9: Density of Legionella pneumophila, serogroups 1-4, from plant $H$ incubated in plant $B$ water at $45^{\circ} \mathrm{C}\left[\log _{10}\right.$ (mean cell number $/ \mathrm{mL}$ ) \pm 1 S.E.]. Where error bars are not shown, they are smaller than the diameter of the circle representing the mean. 


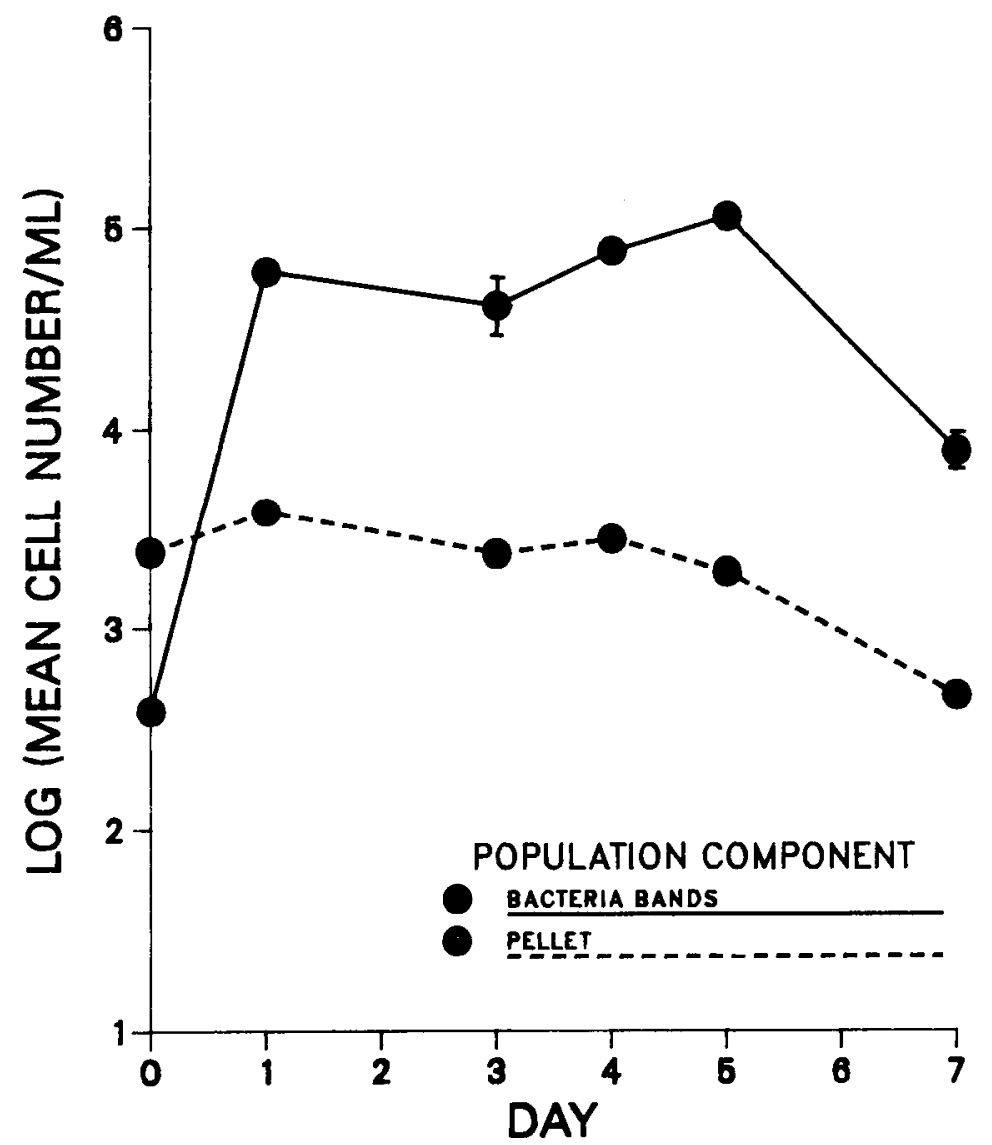

Figure 4-21. ENV-9: Density of Legionella pneumophila, serogroups 1-4, from plant $H$ incubated in plant $H$ water at $45^{\circ} \mathrm{C}\left[\log _{10}\right.$ (mean cell number $/ \mathrm{mL}$ ) \pm 1 S.E.]. Where error bars are not shown, they are smaller than the diameter of the circle representing the mean. 
Table 4-5

INFECTIVITY TESTS OF SAMPLES FROM EXPERIMENT ENV-9

\begin{tabular}{|c|c|c|c|}
\hline $\begin{array}{c}\text { Test } \\
\text { Sample }\end{array}$ & $\begin{array}{c}\text { Days of } \\
\text { Incubation }\end{array}$ & $\begin{array}{l}\text { Quantity of Legionella } \\
\text { Cells Injected } \\
\text { (No. of cells } \times 10^{-3} \text { ) }\end{array}$ & $\begin{array}{l}\text { Results of } \\
\text { Guinea Pig Test }\end{array}$ \\
\hline$\underset{\text { plant }}{\text { Banded }} \frac{\text { Legionella }}{H \text { water }}$ in & $\begin{array}{l}0 \\
3 \\
7\end{array}$ & $\begin{array}{r}120 \\
31,000 \\
31,000\end{array}$ & $\begin{array}{l}\text { Negative } \\
\text { Negative } \\
\text { Negative }\end{array}$ \\
\hline $\begin{array}{l}\text { Banded Legtonella in } \\
\text { plant } B \text { water }\end{array}$ & $\begin{array}{l}0 \\
4 \\
7\end{array}$ & $\begin{array}{r}120 \\
38 \\
12\end{array}$ & $\begin{array}{l}\text { Negative } \\
\text { Negative } \\
\text { Negative }\end{array}$ \\
\hline $\begin{array}{l}\text { Pelleted Legionellad in } \\
\text { plant } H \text { water }\end{array}$ & $\begin{array}{l}0 \\
3\end{array}$ & $\begin{array}{r}900 \\
1.100\end{array}$ & $\begin{array}{l}\text { Toxic/cont.e } \\
\text { Toxic/cont. }\end{array}$ \\
\hline $\begin{array}{l}\text { Pelleted Legionella in } \\
\text { plant } \mathrm{B} \text { water }\end{array}$ & $\begin{array}{l}0 \\
3\end{array}$ & $\begin{array}{r}900 \\
1,200\end{array}$ & $\begin{array}{l}\text { Toxic/cont. } \\
\text { Toxic/cont. }\end{array}$ \\
\hline
\end{tabular}

$\overline{\operatorname{aAt}} 45^{\circ} \mathrm{C}$.

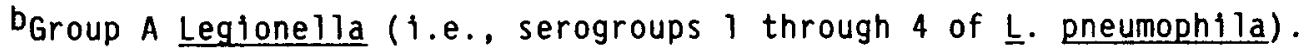

${ }^{C}$ Legionella from $p l a n t ~ H$ water that were recovered after banding by density-gradient centrifugation of a microbial concentrate.

degionella recovered from the bottom of the density gradient and in association with other biota.

eThe guinea pigs became 111 within $24 \mathrm{~h}$ of inoculation and died within $3 \mathrm{~d}$ from toxicity or from an overwhelming bacterial infection. 
are shown in Figs. 4-22 and 4-23. Legionella taken from a depth of $2 \mathrm{~m}$ grew markedly during the first $3 \mathrm{~d}$, regardless of whether nitrate was added. The same Legionella groups in water taken from a depth of $5 \mathrm{~m}$ either grew little throughout the $7 \mathrm{~d}$ of incubation (group A) or may have been suppressed by the added nitrate.

Perhaps the most interesting aspect of this experiment is the difference in the initial cell densities; group $A$ and $B$ Legionella were ten times more abundant in the deeper metalimnetic water than they were at $2 \mathrm{~m}$. In the metalimnion are found higher concentrations of both dissolved and particulate organic compounds, as well as a larger quantity of associated biota, than are present at the shallower depth. It may be, as was noted by fliermans (unpublished observation), that these dissolved organic compounds, probably released by other living or decaying organisms, are supporting larger populations of Legionella in nature.

\section{FIELD EXPERIMENTS}

\section{Membrane Chambers}

Initial results from the membrane chamber study at an ORNL cooling tower revealed two problem areas, leading us to conclude that further development work on this approach was not indicated at this time. First, the cell counts obtained were too near the level of detection to be meaningful. This occurred because of the small sample volume and, consequently, the low numbers of Legionella avallable for enumeration. This limitation could be overcome by constructing larger chambers and withdrawing larger samples less frequentiy. A second limitation, necessitated by safety considerations, was that in some field settings, the chambers can be inoculated only with Legionella removed from the same environment into which the chambers are to be placed.

Initial counts, made by withdrawing a single $0.7-\mathrm{mL}$ sample from each chamber a few minutes after inoculation, showed detectable levels of Legionella in all samples except the one containing bacterial bands retrieved from density-gradient centrifugation. Group A Legionella (Table 1-1) were predominant. As expected, based on previous experience with this tower in an unrelated study, densities in the raw (unprocessed) water were on the order of $10^{4}$ Legionella cells per milliliter. Densities in the samples derived from bands or bands combined with pellets after density-gradient centrifugation were lower $(P<0.05)$ than densities in the raw water by approximately tenfold. Actual counts in samples derived from density-gradient centrifugation were 0 to 2 cells in approximately 30 

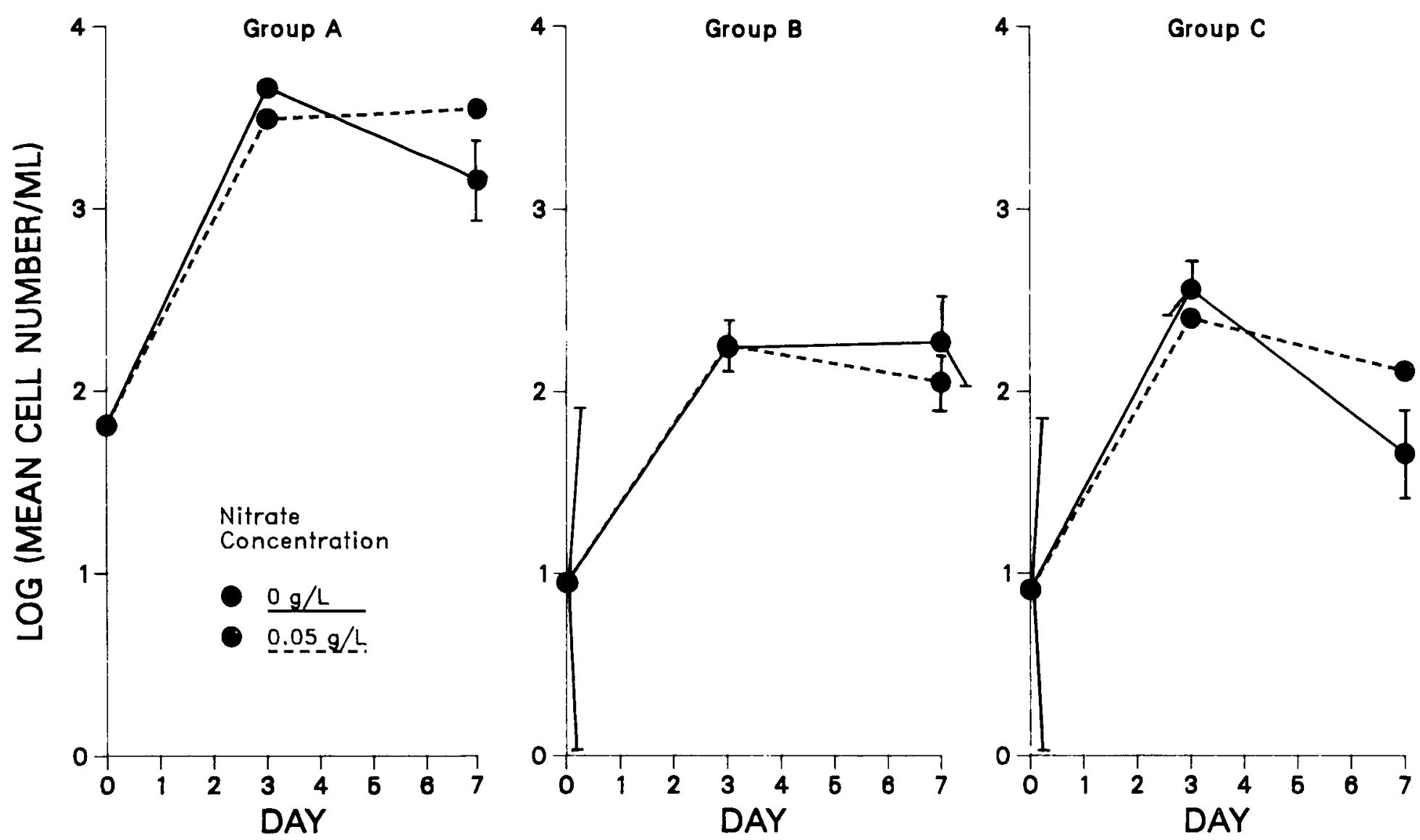

Figure 4-22. ENV-10: Density of Legionella spp. from the epilimnion of Normandy Lake, Tennessee, incubated at $32^{\circ} \mathrm{C}$ with nitrate enrichment $\left[\log _{10}\right.$ (mean cell number $/ \mathrm{mL}$ ) \pm 1 S.E.]. Where error bars are not shown, they are smaller than the diameter of the circle representing the mean. 

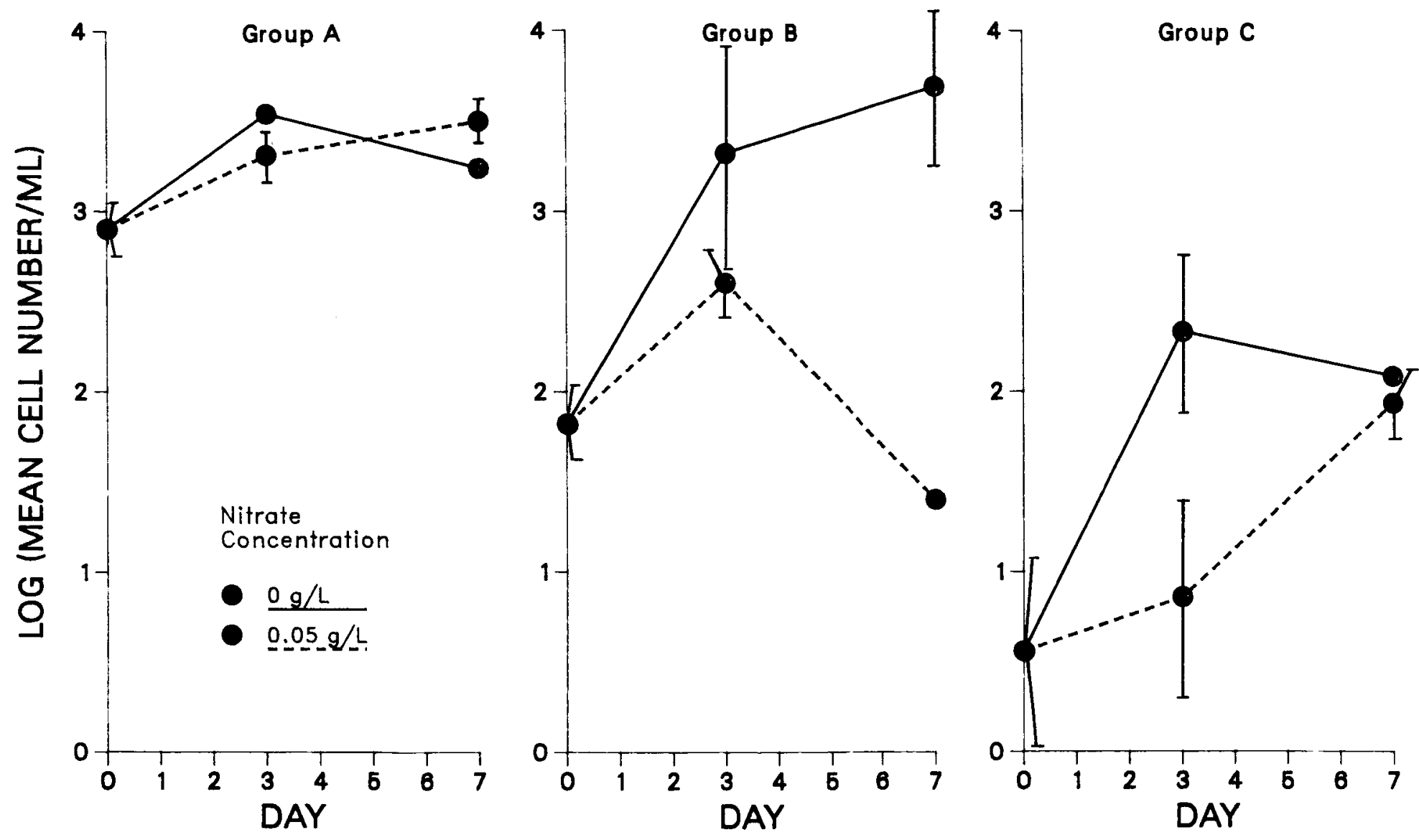

Figure 4-23. ENV-10: Density of Legionella spp. from the metalimnion of Normandy Lake, Tennessee, incubated at $32^{\circ} \mathrm{C}$ with nitrate enrichment $\left[\log _{10}\right.$ (mean cell number $/ \mathrm{mL}$ ) $\left.\pm 1 \mathrm{~S} . \mathrm{E}.\right]$. Where error bars are not shown, they are smaller than the diameter of the circle representing the mean. 
fields examined per sample, which is at the threshold of detection for this procedure.

The chamber inoculated with sterile water was initially noted to be seeping water, indicating a leak. The presence of group A Legionella in the initial sample from this "sterile water" control chamber is consistent with this observation. With one exception (16 Legionella in a raw water sample after $1 \mathrm{~d}$ of incubation), cell counts after incubation of the chambers were too near the level of detection to be useful. Fourteen of these samples, including all seven of the final (day 11) samples, showed no Legionella in the 30 fields per sample examined. These counts were too low to allow statistical interpretation, but it is clear that Legionella growth was not supported in these experimental conditions.

The regular use of various biocides in the test tower at the 0ak Ridge site undoubtedly compromised the usefulness of the technique here. Use of the chambers at power plant sites where less severe blocide treatments are used might have been more successful. Although the levels of chlorine used at the power plant sites do not appear to affect Legionella growth, implementing the studies at these sites would have been more difficult because of logistical considerations.

\section{closed Cycle Cooling System Intensive Sampling}

Due to several previous indications of the role of associated biota in Legionella growth (Tison et a1. 1980; Tyndall and Domingue 1982; ENV-7, this study), field studies at plant $G$ comparing Legionella concentrations with types of associated biota were undertaken. Results of these studies are shown in Table 4-6. The highest Legionella densities were found in the foam on the water surface at the top of the cooling tower apron. The next highest Legionella density was found in the detention pond, where a dense population of amoebae was also found. All other samples had Legionella densities of less than $10^{3} / \mathrm{mL}$.

It has only recently been recognized that bacteria in general and Legionella in particular can concentrate on bubble surfaces (Parker et al. 1983). Thus, it was of interest to find in our studies of plant $G$ that the samples having the highest densities of group A Legionella were from the foam collected from the natural-draft cooling tower. These high densities may also have been associated with the concomitant excavations under way near this sampling site. Indeed, the foam contained much dust-like material. Increased densities of airborne 
Table 4-6

DENSITIES OF Legione 1la RELATIVE TO THE TYPE OF ASSOCIATED BIOTA AT PLANT G

\begin{tabular}{|c|c|c|c|c|c|c|c|}
\hline \multirow[b]{2}{*}{$\begin{array}{l}\text { Sample } \\
\text { Number }\end{array}$} & \multirow[b]{2}{*}{ Location } & \multirow[b]{2}{*}{$\begin{array}{l}\text { Temp. } \\
\left({ }^{\circ} \mathrm{C}\right)\end{array}$} & \multicolumn{4}{|c|}{$\frac{\text { Legionella Densities }}{(\mathrm{ce} 11 \mathrm{~s} / \mathrm{mL})}$} & \multirow[b]{2}{*}{$\begin{array}{l}\text { Associated } \\
\text { Biota } \\
\end{array}$} \\
\hline & & & A & $\frac{\text { Legionella }}{\frac{B}{B}}$ & Group & $\mathrm{C}$ & \\
\hline P2-1 & $\begin{array}{l}\text { Water puddle } \\
\text { near cooling } \\
\text { tower }\end{array}$ & 17 & $-a$ & - & & - & Spirogyra \\
\hline P2-2 & $\begin{array}{l}\text { Top of cooling } \\
\text { tower apron, } \\
\text { beneath algal } \\
\text { material }\end{array}$ & 26 & - & - & & - & $\begin{array}{l}\text { I. P. }{ }^{b} \\
\text { (blue-greens, } \\
\text { diatoms) }\end{array}$ \\
\hline P2-3 & $\begin{array}{l}\text { Black rubber } \\
\text { drip nozzle, } \\
\text { top of cooling } \\
\text { tower apron }\end{array}$ & 43 & - & - & & 40 & - \\
\hline$P 2-4$ & $\begin{array}{l}\text { Foam, top of } \\
\text { cooling tower } \\
\text { apron }\end{array}$ & 43 & 2600 & 67 & & 870 & $\begin{array}{l}\text { Pennate } \\
\text { diatoms \& } \\
\text { coccoid } \\
\text { greens }\end{array}$ \\
\hline$P 2-5$ & $\begin{array}{l}\text { Algal mats } \\
\text { from header } \\
\text { pipes }\end{array}$ & 43 & 67 & - & & - & $\begin{array}{l}\text { I. P. } \\
\text { (blue- } \\
\text { greens, } \\
\text { diatoms) }\end{array}$ \\
\hline$P 2-6$ & $\begin{array}{l}\text { Amertap balls } \\
\text { clogging drip- } \\
\text { ways, top of } \\
\text { cooling tower } \\
\text { apron }\end{array}$ & 45 & - & - & & - & Diatoms \\
\hline P2-7 & Detention basin & 21 & 3400 & - & & - & $\begin{array}{l}\text { Diatoms, } \\
\text { blue- } \\
\text { greens, } \\
\text { amoebae }\end{array}$ \\
\hline
\end{tabular}


Table 4-6 (continued)

\begin{tabular}{|c|c|c|c|c|c|c|}
\hline \multirow[b]{2}{*}{$\begin{array}{l}\text { Sample } \\
\text { Number }\end{array}$} & \multirow[b]{2}{*}{ Location } & \multirow[b]{2}{*}{$\begin{array}{l}\text { Temp. } \\
\left({ }^{\circ} \mathrm{C}\right)\end{array}$} & \multicolumn{3}{|c|}{$\begin{array}{l}\frac{\text { Legionella Densities }}{(c e l 1 \mathrm{~s} / \mathrm{mL})} \\
\text { (c) }\end{array}$} & \multirow[b]{2}{*}{$\begin{array}{l}\text { Associated } \\
\text { Biota } \\
\end{array}$} \\
\hline & & & A & $\frac{\text { Legionella }}{\mathrm{B}}$ & Group $\mathrm{C}$ & \\
\hline$P 2-8$ & $\begin{array}{l}\text { Detention basin, } \\
\text { isolated } \\
\text { portion }\end{array}$ & 22 & 40 & 13 & - & I. P. \\
\hline P2-9 & $\begin{array}{l}\text { Ditch near fish } \\
\text { pond }\end{array}$ & 21.5 & 40 & - & 67 & Diatoms \\
\hline P2-10 & Fish pond & 21.5 & 67 & 120 & 190 & $\begin{array}{l}\text { I. P. } \\
\text { (blue- } \\
\text { greens, } \\
\text { diatoms, } \\
\text { nematodes): } \\
\text { live } \\
\text { protozoa }\end{array}$ \\
\hline$P 2-11$ & Detention pond & 20.5 & 440 & 760 & 40 & Fung $i$ \\
\hline$P 2-12$ & $\begin{array}{l}\text { Discharge from } \\
\text { detention pond }\end{array}$ & 20.5 & 150 & 160 & 80 & - \\
\hline P2-13 & $\begin{array}{l}\text { Reservoir at } \\
\text { boat ramp }\end{array}$ & 20 & - & - & 80 & $\begin{array}{l}\text { Mixed } \\
\text { healthy } \\
\text { community }\end{array}$ \\
\hline P2-14 & $\begin{array}{l}\text { Reservoir, among } \\
\text { dead plants }\end{array}$ & 19.5 & - & - & 40 & $\begin{array}{l}\text { I. P., } \\
\text { but much } \\
\text { variety }\end{array}$ \\
\hline P2-15 & Reservoir at dam & 20 & - & - & 40 & Mixed \\
\hline P2-16 & Raw water intake & - & - & - & - & - \\
\hline
\end{tabular}

aThe dash indicates concentrations below the limit of detectability.

binsufficiently preserved. 
Legionella associated with excavation have been reported previously (Tyndall 1983), even though Legionella are aquatic rather than soil organisms.

The relatively higher densities of Legionella in the detention basin, which also supported a large population of amoebae, was interesting in light of reports (Tyndall and Domingue 1982; Fields et a1. 1984) that Legionella may grow in apparent symbiosis with various protozoa, including amoebae. It may be that the populations of Legionella are maintained or are, in fact, amplified in this situation because of the presence of associated protozoans.

FURTHER INVESTIGATION OF A SUSPECTED NEW SPECIES

Further tests of the untypeable Legionella isolate from the Phase I study confirmed and extended the previous results (Table 4-7). The Legionella isolate

Table $4-7$

CHARACTERISTICS OF UNTYPEABLE Legionella ISOLATED FROM PLANT D

Characteristic

Growth on:

CYE

BHI

Blood agar

Gram staina

Gr.-

Catalase

$+$

Reaction with
conjugates
against:

L. pneumophila

L. bozemanii

L. gormanif

L. micdadei

L. dumoffii

L. Iongbeachae

L. jordanis

L. oakridgensis

$a_{G r} .-=\overline{g r a m}$-negative rods with morphology suggestive of Legionella.

bserogroups 1 to 6 . 
from plant-exposed water at plant D [designated "L?" in the Phase I report (Christensen et al. 1983)] did not grow on blood agar or brain heart infusion agar (Table 4-7). This isolate was weakly catalase positive, as is Legionella. but it did not react with antisera prepared against the known species of Legionella. Cooperative studies with personnel at the CDC in Atlanta also confirmed the lack of serologic identity with known Legionella species.

The ONA hybridization studies carried out by 0 r. 0 . Brenner at the COC verified that this Legionella isolate from the Phase I study was a previousiy undiscovered species of Legionella. We have named this new species Legionella cherrit, in honor of Dr. William B. Cherry, for his many contributions to the elucidation of the serologic and, hence, taxonomic relationships within the Legionella genus.

The characterization of $\underline{L}$. cherrif (Brenner 1984) confirmed the suspicions aroused in Phase I that the serologically untypeable Legionella isolate from plant $D$ was a new species. Unlike $L$. oakridgensis, also isolated in the phase I study, L. cherrif is more typical of other members of the genus. In particular, the fatty acid profile and DNA relatedness are not as dissimilar to those of most Legionella species as are those of $\underline{L}$. oakridgensis (Orrison et al. 1983; Brenner 1984).

The possible involvement of $\underline{L}$. cherrit in human disease is unknown. Considering that the original isolates of $\underline{L}$. pneumophila came from pneumonia patients, it is not surprising that of the first seven reported species of Legionella, six were of clinical origin and only one (1.e., L. jordanis) was an environmental isolate. Since the discovery of the first seven Legionella species, however, many additional species have been discovered, most of which are environmental isolates. 
Section 5

INTEGRATION

The preceding sections have described the Phase II study and its results. The purpose of this section is to discuss Phase II in the context of the entire study, and to relate the results to power plants.

This EPRI study was originally undertaken because the power plant environment provides conditions, such as elevated water temperatures, that may favor Legionella growth or infectivity and also provides a potential vehicle for transmission of the organism to man via aerosolized water droplets. Developing an understanding of the organism in relation to power plants was clearly a desirable objective.

Phase I (Christensen et al. 1983) involved a seasonal survey of the density, viability, and infectivity of Legionella at nine power plants. The next step in the study was to have been a more intensive field study at a subset of those plants. As Phase I progressed, however, it became evident that Legionella responses varied in a complex manner, and that controlled experiments in a laboratory setting would probably shed more light on cause-effect relationships than would additional field studies. The plan for Phase II was therefore modified, with emphasis placed on laboratory experiments. The final component of our project, a study of the association of Legionella with downtime procedures at power plants, will be presented in a forthcoming report.

\section{COMPLEXITY OF LABORATORY WORK WITH ENVIRONMENTAL SAMPLES}

The Phase II work has made clear that to study Legionella in relation to aquatic systems, one must confront at least four complicating factors. First, there is a diverse population of organisms at any one time and place, and the composition of this population will vary from place to place and through time at any one place. Second, the unidentified physical and chemical factors presumed to be responsible for this variation will most likely vary spatially and temporally. Third, other organisms may affect the abundance of Legionalla through direct interaction or by means of their effects on the environment. Fourth, the 
infectivity to humans of any one group of Legionella in an environmental sample is not known a priori.

One means of simplifying this complex situation is to focus on a subset of the Legionella species and serogroups. Much of our work was focused on group $A$ Legionella, consisting of four serogroups of $\underline{L}$. pneumophila. This group causes more than $85 \%$ of the diagnosed human legionellosis cases and also encompasses $67 \%$ of the infectious isolates from the Phase I study (Christensen et al. 1983).

SIGNIF ICANCE OF THE PERSISTENTLY INFECTIOUS ENVIRONMENTAL ISOLATE

Density and infectivity are the two major parameters of concern in attempting to control Legionella populations. The Phase II study focused primarily on density, because the ability to control densities is almost a prerequisite to investigating infectivity. Nonetheless, Phase II produced some significant results relative to infectivity.

The highly virulent environmental isolate of $\underline{L}$. pneumophila used in the guinea pig calibration study is unusual in its persistent maintenance of virulence in the laboratory. Laboratory cultures generally lose their infectivity in serial passage on laboratory media. The inoculum size needed for infection with this isolate is similar to that found for clinical isolates (Wong et al. 1981). This indicates that the virulence level of our high virulence L. pneumophila, which was isolated directly from the environment, is similar to that of Legionella obtained from patients with legionellosis.

The maintenance of virulence in our environmental isolate is interesting in other respects. The presence of this isolate in the environment could be a public health concern. There are continuing occurrences of legionellosis associated with the same serogroup of $\underline{L}$. pneumophila in the county from which the isolate was obtained. The continued existence of virulence in culture implies that the mammalian environment is not necessary for the isolate to maintain its infective ability. Finally, such persistently virulent cultures offer promise for future research aimed at determining the environmental and/or physiological basis of Legionella's ability to cause infection. Some specific combination of environmental parameters may select for, or at least allow persistence of, such organisms in aquatic habitats.

A) though changes in virulence can be realized by laboratory manipulation [i.e., repeated growth of Legionella in successive living hosts (Wong et al. 1981)], 
the underlying molecular mechanisms responsible for these changes in laboratory Legionella cultures are unknown. Consequently, an understanding of the factors that produce virulence in environmental populations is at present unattainable. For the present, controlling Legionella densities may be a more readily attainable goal than that of controlling the infectivity of the population.

\section{Legione11a IN THE POWER PLANT ENVIRONMENT}

Phase II was primarily a laboratory study. From this study we have determined that Legionella can be grown in power plant water in the laboratory, and that its response in that setting is influenced by many factors. These factors-temperature, water quality, other blota, and the nature of the Leglonella population itself--are only partly controllable in the power plant setting. Utilization of the controlled setting and resources of the laboratory will very likely remain the most effective approach to revealing causal relationships, while knowledge of particularly potent sources of Legionella in the power plant environment based on field sampling could indicate situations where precautions are appropriate.

The motivation for these studies was their usefuiness as a first step toward developing methods for controlling the abundance and/or infectivity of Legionella, should such control subsequently be needed. Considering the Phase II results, however, it seems unlikely that the substances influencing Legionella density and infectivity will be identified soon, and it is also unlikely that they will prove to be controllable in the power plant environment. Thus, concentrating on identifying effective biocides might be the most useful course. Increasingly restrictive regulation of chemicals in discharges could, however, reduce the likelihood of success of this approach. The characteristics of Legionella in power plant environments are of practical interest mainly in relation to power plant personnel, whose working environment potentlally overlaps the ecological niche of the organisms. An alternative to options for controlling Legionella in power plant systems would be options for protecting power plant workers from exposure to the organisms. Whether control measures are appropriate or not has not been established. If it is decided that they are needed, the Phase II work will be a useful starting point in their development. 
Section 6

REFERENCES

American Public Health Association (APHA). 1976. Standard Methods for the Examination of Water and Wastewater. APHA, New York, 14th Edition.

Brenner, D. J., A. G. Steigerwalt, and J. E. McDade. 1979. Classification of the Legionnaires' Disease Bacterium: Legionella pneumophila, genus novum, species nova, of the Family Legionellaceae, family nova. Ann. Int. Med. $90: 656-658$.

Brenner, D. J. 1984. Classification of Legionellae, pp. 55-60. IN C. Thornsberry, A. Balows, J. C. Feeley, and W. Jakubowski (eds.), Proceedings, 2nd International Symposium on Legionella, Atlanta, Georgia, June 1983. American Society for Microbiology, Washington, D.C.

Centers for Disease Control (COC). 1978. Isolation of organisms resembling Legionnaries' Disease Bacterium, Georgia. Morbidity and Mortality Weekly Rep. $27: 415$.

Cherry, W. C., B. Pittman, P. P. Harris, G. A. Herbert, B. M. Thomas on, L. Thacker, and R. E. Weaver. 1978. Detection of Legionnaires' Disease Bacteria by direct immunofluorescent staining. J. Clin. Microbiol. 8:329-338.

Christensen, S. W., J. A. Solomon, S. B. Gough, R. L. Tyndall, and C. B. Fllermans. 1983. Legionnaires' disease bacterium in power plant cooling systems: Phase I final report. Prepared for Electric Power Research Institute, Palo Alto, Calif., EA-3153, Research Project 1909-1.

Deubner, D. C., and D. K. Gilliam. 1977. Fever of undetermined etiology after cleaning of steam turbine condensers. Arch. Environ. Health 32:116-120.

Fields, B. S., E. B. Shotts, Jr., J. C. Feeley, G. W. Gorman, and W. T. Martin. 1984. Proliferation of Legionella pneumophila as an intracellular paras ite of the cillated protozoan Tetrahymena pyriformis. pp. 327-328. IN C. Thornsberry, A. Balows, J. C. Feeley, and W. Jakubowski (eds.), Proceedings, 2nd International Symposium on Legionella, Atlanta, Georgia, June 1983. American Soclety for Microbiology, Washington, D.C.

Fliermans, C. B., W. B. Cherry, L. H. Orrison, and L. Thacker. 1979. Isolation of Legionella pneumophila from nonepldemic-related aquatic habitats. Appl. Environ. Microbiol. 37:1239-1242.

Fliermans, C. B., W. B. Cherry, L. H. Orrison, S. J. Smith, D. L. Tison, and D. H. Pope. 1981a. Ecological distribution of Legionella pneumophila. Appl. Environ. Microbiol. 41:9-16.

Fliermans, C. B., R. J. Soracco, and D. H. Pope. 1981b. Measure of Legionella pneumophila activity in situ. Curr. Microbiol. 6:89-94. 
Fraser, D. W., D. C. Deubner, D. L. H111, and D. K. Gilllam. 1979.

Nonpneumonic, short-incubation-period Legionellosis (Pontiac fever) in men who cleaned a steam turbine condenser. Science 205:690-691.

Hutchinson, G. E. 1957. A Treatise on Limnology. Geography, Physics and Chemistry, Vol. I. John Wiley \& Sons, New York. $1015 \mathrm{pp}$.

McDade, J. E., C. C. Shepa, D. W. Fraser, T. F. Tsai, M. A. Redus, and W. R. Dowdle. 1977. Legionnaires' Disease: Isolation of a bacterium and demonstration of tis role in other respiratory disease. N. Eng. J. Med. $297: 1197-1203$.

Orrison, L. H., W. B. Cherry, R. L. Tynda11, C. B. Fliermans, S. B. Gough, M. A. Lambert, L. K. McDougal, W. F. Bibb, and D. J. Brenner. 1983. Legionella oakridgensis: Unusual new species isolated from cooling tower water. Appl. Environ. Microbiol. 45:536-545.

Parker, B. C., M. A. Ford, H. Gruft, J. O. Folkinham III. 1983. Epidemiology of infection by nontuberculos mycobacteria: (IV) Preferential aerosolization of Mycobacterium intracellularre from natural waters. Am. Rev. Respir. Dis. $128: 652-656$.

Siege1, S. 1956. Nonparametric Statistics for the Behavioral Sciences. McGraw-Hill Co., New York. 312 pp.

Tison, D. L., D. H. Pope, W. B. Cherry, and C. B. Fliermans. 1980. Growth of Legionella pneumophila in association with blue-green algae (cyanobacteria). App1. Environ. Microbio1. 39:456-459.

Tynda11, R. L. 1983. Presence of pathogenic microorganisms in power plant cooling waters: Final report for october 1, 1981, to June 30, 1983.

ORNL/TM-8809 (NUREG/CR-3364). Oak Ridge National Laboratory, Oak Ridge, Tennessee.

Tynda 11, R. L. 1984. Environmental isolation of pathogenic Naegleria. CRC Critical Reviews in Environmental Control 13:195-226.

Tynda11, R. L., and E. L. Domingue. 1982. Cocultivation of Legionella pneumophila and free-living amoebae. Appl. Environ. Microbiol. 44:954-959.

Tynda11, R. L., S. B. Gough, C. B. Fllermans, E. L. Domingue, and C. B. Duncan. 1983. Isolation of a new Legionella species from thermally altered waters. Curr. Microbiol. 9:77-80.

Wadowsky, R. M., and R. B. Yee. 1983. Satellite growth of Legionella pneumophila with an environmental isolate of Flavobacterium breve. Appl. Environ. Microbiol. 46:1447-1449.

Wong, M. C., W. L. Peacock, Jr., R. M. McKinney, and K.-H. Wong. 1981. Legionella pneumophila: Avirulent to virulent conversion through passage in cultured human embryonic lung fibroblasts. Curr. Microbiol. 5:31-34.

Yee, R. B., and R. M. Wadowsky. 1982. Multiplication of Legionella pneumophila in unsterilized tap water. Appl. Environ. Microbiol.43:1330-1334. 
Section 7

GLOSSARY

For the reader's convenience, the following specialized terms are briefly defined here in the context of their use in this report.

Antibody: Any of various serum globulins normally present or produced in response to infection or the administration of suitable antigens that combine specifically with antigens and neutralize toxins, agglutinate bacterla or cells, and precipitate soluble antigens. Specific antibodies to Legionella surface antigens are avallable commercially and permit identification of Legionella bacteria strains.

Epilimnion: The upper region of a thermally stratified lake, characterized by more or less uniformiy warm, circulating, and fairly turbulent water (after Hutchinson 1957, p. 427).

Growth index: The negative exponent of the most dilute serial tenfold dilution of Legionella capable of sustaining growth.

Hypolimnion: The lower region of a thermally stratified lake, characterized by deep, cold, and relatively undisturbed water (after Hutchinson 1957, pp. 427-428).

Intraperitoneal injection: Injection through skin and peritoneum into the abdominal cavity.

Metalimnion: The middle region in a thermally stratified lake, where the temperature gradient between the warm epilimnion and the cold hypolimnion is steep and where a change in water density occurs, causing accumulation of particulate and dissolved materials (see Hutchinson 1957, pp. 428-429).

Negative plant water: Water collected from a power plant where infectious Legionella could not be isolated.

Peritoneum: The smooth, transparent serous membrane lining the cavity of the abdomen of a mammal. It is reflected inward over the abdominal and pelvic viscera.

Polyvalent antibodies: A mixture of individual antibodies capable of interacting with more than one toxin, antigen, or kind of microorganism.

Positive plant water: Water collected from a power plant (e.g., F, G, or H) where infectious Legionella were repeatedly isolated.

Serial dilution: A serles of tenfold dilutions (i.e., 1/10, 1/100, $1 / 1000$, etc.). 
Serogroup: A group of Legionella isolates belonging to the same species yet containing common antigens serologically distinct from other isolates of the same species.

Serologic: Pertaining to tests or reactions using serum.

Serum: The liquid portion of blood remaining after removal of the blood cells and clotting components.

Uncompromised: A term indicating that the health of the test animal is not

impaired by stress, disease, inadequate diet, or other factors that would weaken it. 
APPENDIX TABLES 
RESULTS OF EXPERIMENT ENV-2

\begin{tabular}{|c|c|c|c|}
\hline $\begin{array}{l}\text { VIRULENCE } \\
\text { LEVEL }\end{array}$ & $\begin{array}{l}\text { INCUBATION } \\
\text { TEMPERATURE } \\
\left({ }^{\circ} \mathrm{C}\right) \\
\end{array}$ & $\begin{array}{l}\text { WATER } \\
\text { SOURCE }\end{array}$ & $\begin{array}{l}\text { GROWTH } \\
\text { INDEXX }\end{array}$ \\
\hline \multirow[t]{10}{*}{$\mathrm{HIGH}$} & 32 & DIST ILLED & 5 \\
\hline & & $\begin{array}{l}\text { PLANT } \mathrm{B} \\
\text { PLANT } \mathrm{F}\end{array}$ & $\begin{array}{l}5 \\
2\end{array}$ \\
\hline & & PLANT $G$ & 2 \\
\hline & 37 & DISTILLED & 3 \\
\hline & & PLANT B & 3 \\
\hline & & $\begin{array}{l}\text { PLANT } F \\
\text { PLANT } G\end{array}$ & 1 \\
\hline & 42 & DISTILLED & 1 \\
\hline & & PLANT B & 1 \\
\hline & & PLANT $F$ & 1 \\
\hline & & PLANT $G$ & 2 \\
\hline \multirow[t]{12}{*}{ LOW } & 32 & DISTILLED & 6 \\
\hline & & PLANT B & 5 \\
\hline & & PLANT $F$ & 4 \\
\hline & & PLANT $\mathbf{G}$ & 4 \\
\hline & 37 & DISTILLED & 6 \\
\hline & & PLANT B & 6 \\
\hline & & PLANT $F$ & 3 \\
\hline & & PLANT $G$ & 3 \\
\hline & 42 & DISTILLED & 1 \\
\hline & & PLANT B & 1 \\
\hline & & PLANT $F$ & 1 \\
\hline & & PLANT G & 2 \\
\hline
\end{tabular}

a Negative exponent of the most diulute serial tenfold dilution capable of supporting Legionella growth. 
RESULTS OF EXPERIMENT ENV-3

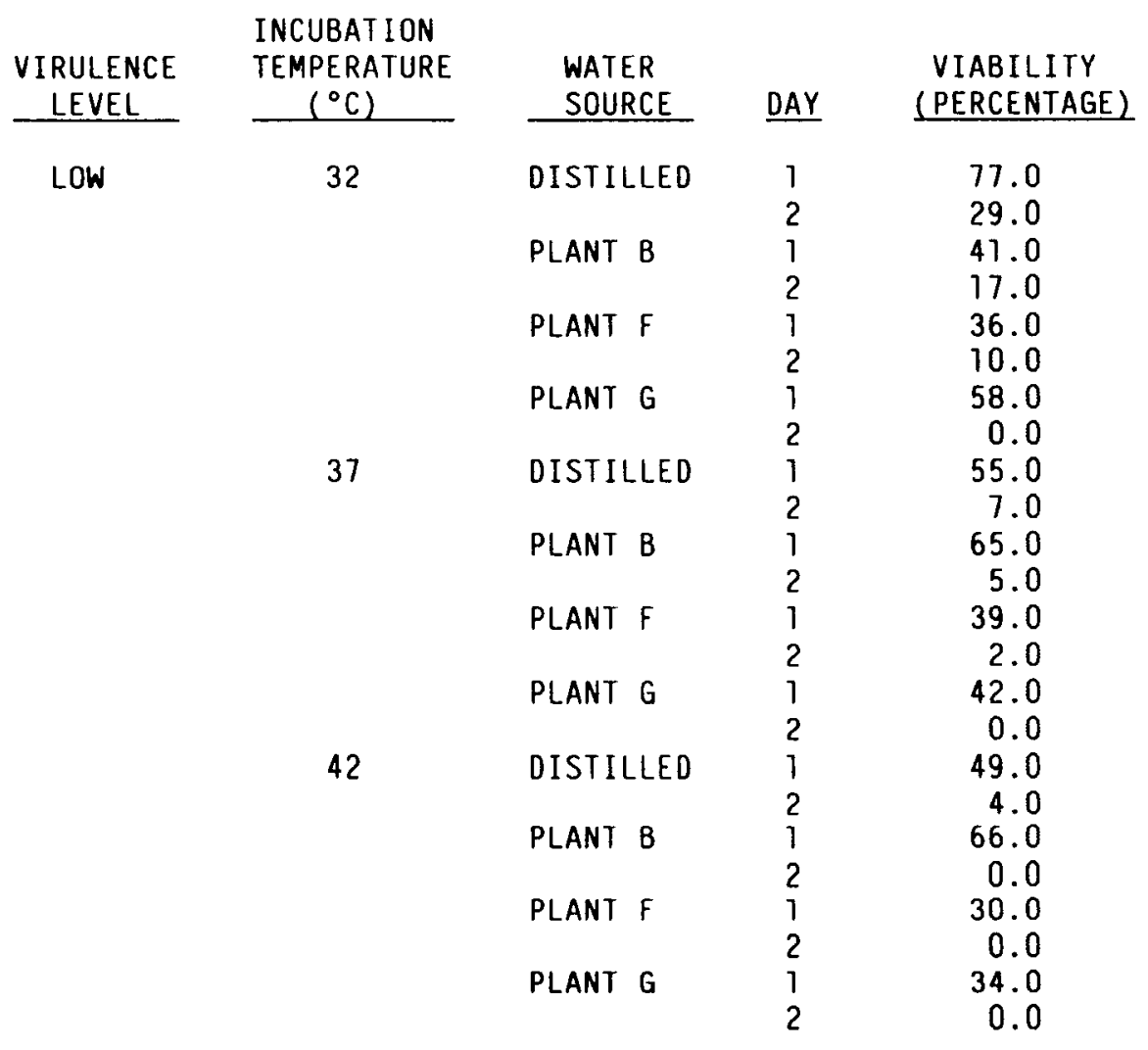


RESULTS OF EXPERIMENT ENV-3

\begin{tabular}{|c|c|c|c|c|}
\hline $\begin{array}{c}\text { VIRULENCE } \\
\text { LEVEL } \\
\end{array}$ & $\begin{array}{l}\text { INCUBATION } \\
\text { TEMPERATURE } \\
\left({ }^{\circ} \mathrm{C}\right) \\
\end{array}$ & $\begin{array}{l}\text { WATER } \\
\text { SOURCE }\end{array}$ & $\underline{D A Y}$ & $\begin{array}{l}\text { VIABILITY } \\
\text { (PERCENTAGE) }\end{array}$ \\
\hline \multirow[t]{22}{*}{$\mathrm{HIGH}$} & 32 & DISTILLED & 1 & \\
\hline & & & 2 & 15.0 \\
\hline & & PLANT B & $\begin{array}{l}1 \\
2\end{array}$ & $60^{\circ} 0$ \\
\hline & & PLANT $F$ & 1 & \\
\hline & & & 2 & 42.0 \\
\hline & & PLANT G & 1 & \\
\hline & & & 2 & 2.0 \\
\hline & 37 & DISTILLED & 1 & $70^{\circ}$ \\
\hline & & PLANT B & 1 & \\
\hline & & & 2 & 36.0 \\
\hline & & PLANT $F$ & 1 & \\
\hline & & & 2 & 37.0 \\
\hline & & PLANT $G$ & 1 & \\
\hline & & & 2 & 13.0 \\
\hline & 42 & DISTILLED & 1 & . \\
\hline & & & 2 & ${ }^{\circ}$ \\
\hline & & PLANT B & 1 & . \\
\hline & & & 2 & ${ }^{\circ}$ \\
\hline & & PLANT $F$ & 1 & . \\
\hline & & & 2 & . \\
\hline & & PLANT G & 1 & . \\
\hline & & & 2 & . \\
\hline
\end{tabular}


RESULTS OF EXPERIMENT ENV-4

TEMPERATURE $\left({ }^{\circ} \mathrm{C}\right)$

32

37

42

32

37

42

32

37

42

DAY POLYA POLYB POLYC TOTAL PLANT B

$\begin{array}{rrrrr}0 & 12 & 4 & 16 & 32 \\ 4 & 36 & 160 & 60 & 256 \\ 7 & 22 & 30 & 8 & 60\end{array}$

$\begin{array}{lllll}0 & 12 & 4 & 16 & 32\end{array}$

$\begin{array}{rrrrr}4 & 12 & 82 & 180 & 274\end{array}$

$\begin{array}{lllll}7 & 180 & 270 & 56 & 506\end{array}$

$\begin{array}{lllll}0 & 12 & 4 & 16 & 32\end{array}$

$\begin{array}{rrrrr}4 & 44 & 96 & 6500 & 6640\end{array}$

$\begin{array}{lllll}7 & 140 & 260 & 8600 & 9000\end{array}$

PLANT F

$\begin{array}{rrrrrr}32 & & & & \\ & 0 & 27 & 110 & 10 & 147 \\ & 1 & 93 & 250 & 10 & 353 \\ & 4 & 40 & 310 & 10 & 360 \\ & 6 & 250 & 230 & 26 & 506 \\ & 12 & 150 & 180 & 31 & 361 \\ & 0 & 27 & 110 & 10 & 147 \\ & 12 & 120 & 67 & 13 & 200 \\ & 1 & 170 & 21 & 27 & 218 \\ & 4 & 200 & 110 & 80 & 390 \\ & 6 & 63 & 80 & 64 & 207 \\ & 12 & 27 & 110 & 10 & 147 \\ & 0 & 57 & 53 & 10 & 130 \\ & 12 & 67 & 330 & 527 \\ & 1 & 130 & 27 & 487 \\ & 4 & 230 & 230 & 360 & 4200\end{array}$

PLANT G

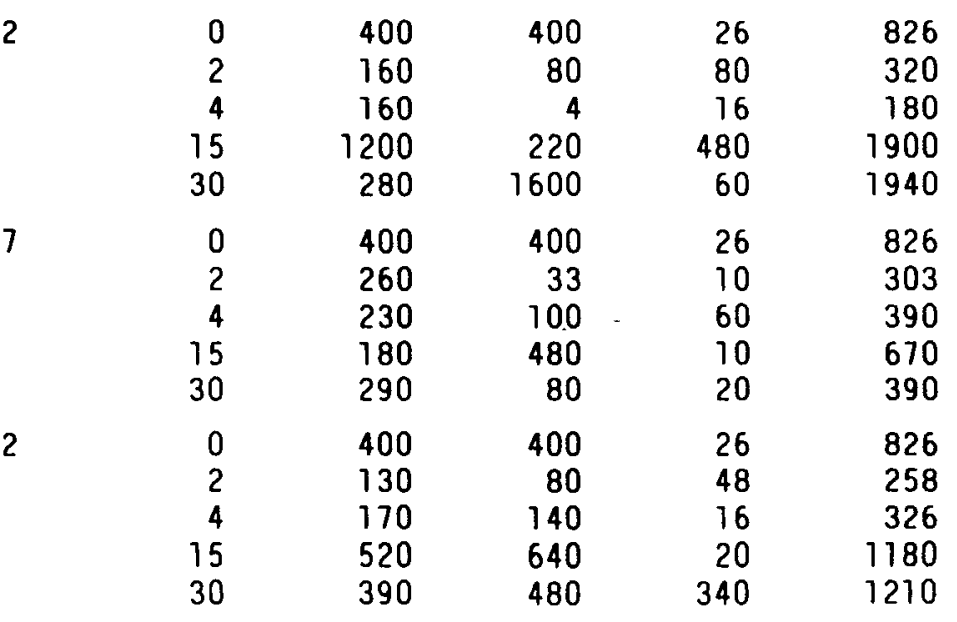




\section{RESULTS OF EXPERIMENT ENV-5}

\begin{tabular}{|c|c|c|c|c|c|c|c|c|}
\hline Legionella & WATER & & TEMPERAIURE & & & ELLLS/mL & & \\
\hline SOURCE & SOURCE & TREATMENT & $\left(^{\circ} \mathrm{C}\right)$ & $\underline{D A Y}$ & POLYA & POLY B & POLYC & IOTAL \\
\hline B & B & UNPROCESSEO & 32 & 0 & 84 & 16 & 8 & 108 \\
\hline & & & & 7 & 330 & 87 & 13 & 430 \\
\hline & & & & & 190 & 40 & 7 & 237 \\
\hline & & & & 14 & 260 & 210 & 0 & 471 \\
\hline & & & & & 190 & 40 & 7 & 237 \\
\hline B & B & UNPROCESSED & 45 & 0 & 84 & 16 & 8 & 108 \\
\hline & & & & 7 & 300 & 13 & 13 & 326 \\
\hline & & & & & 240 & 20 & 0 & 261 \\
\hline & & & & 14 & 53 & 20 & 0 & 74 \\
\hline & & & & & 150 & 27 & 13 & 190 \\
\hline B & B & RESUSPENDEU & 32 & 0 & 84 & 16 & 8 & 108 \\
\hline & & & & 7 & 1900 & 260 & 20 & 2180 \\
\hline & & & & & 2200 & 270 & 7 & 2477 \\
\hline & & & & 14 & 2700 & 970 & 450 & 4120 \\
\hline & & & & & 2200 & 270 & 7 & 2477 \\
\hline B & B & RESUSPENOEO & 45 & 0 & 84 & 16 & 8 & 108 \\
\hline & & & & 7 & 190 & 13 & 7 & 210 \\
\hline & & & & & 490 & 13 & 40 & 543 \\
\hline & & & & 14 & 0 & 0 & 0 & 3 \\
\hline & & & & & 240 & 53 & 0 & 294 \\
\hline 8 & $\mathrm{~F}$ & EXCHANGEU & 32 & 0 & 84 & 16 & 8 & 108 \\
\hline & & & & 7 & 380 & 40 & 7 & 427 \\
\hline & & & & & 270 & 66 & 26 & 362 \\
\hline & & & & 14 & 270 & 80 & 13 & 363 \\
\hline & & & & & 1100 & 370 & 80 & 1550 \\
\hline B & $\mathrm{F}$ & EXCHANGEU & 45 & 0 & 84 & 16 & 8 & 108 \\
\hline & & & & 7 & 80 & 87 & 33 & 200 \\
\hline & & & & & 53 & 27 & 7 & 87 \\
\hline & & & & 14 & 7 & 0 & 7 & 14 \\
\hline & & & & & 47 & 13 & 33 & 93 \\
\hline
\end{tabular}


RESULTS OF EXPERIMENT ENV-5 (continued)

\begin{tabular}{|c|c|c|c|c|c|c|c|c|}
\hline Legionella & WATER & & TEMPERAIURE & & & CELLS/m & & \\
\hline SOURCE & SOURCE & TREATMENT & $\left({ }^{\circ} \mathrm{C}\right)$ & $\underline{D A Y}$ & POLYA & $\underline{P O L Y B}$ & POLY C & TOTAL $^{\circ}$ \\
\hline $\mathrm{F}$ & $\mathrm{F}$ & UNPROCESSED & 32 & 0 & 1600 & 64 & 20 & 1684 \\
\hline & & & & 7 & 690 & 110 & 53 & 853 \\
\hline & & & & & 1000 & 7 & 27 & 1034 \\
\hline & & & & 14 & 270 & 87 & 7 & 304 \\
\hline & & & & & 0 & 7 & 27 & 35 \\
\hline $\mathrm{F}$ & $\mathrm{F}$ & UNPROCESSEO & 45 & 0 & 1600 & 64 & 20 & 1684 \\
\hline & & & & 7 & 1200 & 120 & 20 & 1340 \\
\hline & & & & & 1500 & 150 & 7 & 1657 \\
\hline & & & & 14 & 1600 & 100 & 13 & 1713 \\
\hline & & & & & 2200 & 100 & 130 & 2430 \\
\hline $\mathrm{F}$ & $\mathrm{F}$ & RESUSPENDED & 32 & 0 & 1600 & 64 & 20 & 1684 \\
\hline & & & & 7 & 200 & 200 & 130 & 530 \\
\hline & & & & & 370 & 180 & 130 & 620 \\
\hline & & & & 14 & 230 & 1800 & 150 & 2180 \\
\hline & & & & & 280 & 2700 & 250 & 3230 \\
\hline $\mathrm{F}$ & $\mathrm{F}$ & RESUSPENDED & 45 & 0 & 1600 & 64 & 20 & 1684 \\
\hline & & & & 7 & 850 & 60 & 20 & 930 \\
\hline & & & & & 520 & 40 & 27 & 587 \\
\hline & & & & 14 & 620 & 130 & 13 & 763 \\
\hline & & & & & 32000 & 40 & 110 & 32150 \\
\hline $\mathrm{F}$ & B & EXCHANGED & 32 & 0 & 1600 & 64 & 20 & 1684 \\
\hline & & & & 7 & 700 & 27 & 27 & 754 \\
\hline & & & & & 810 & 73 & 40 & 923 \\
\hline & & & & 14 & 300 & 560 & 93 & 953 \\
\hline & & & & & 660 & 260 & 20 & 940 \\
\hline $\mathrm{F}$ & 8 & EXCHANGED & 45 & 0 & 1600 & 64 & 20 & 1684 \\
\hline & & & & 7 & 790 & 130 & 2100 & 3020 \\
\hline & & & & & 670 & 60 & 1800 & 2530 \\
\hline & & & & 14 & 490 & 60 & 1200 & 1750 \\
\hline & & & & & 820 & 73 & 1500 & 23931 \\
\hline
\end{tabular}

àjotals reflect rounding. 
RESULTS OF EXPERIMENT ENV- 6

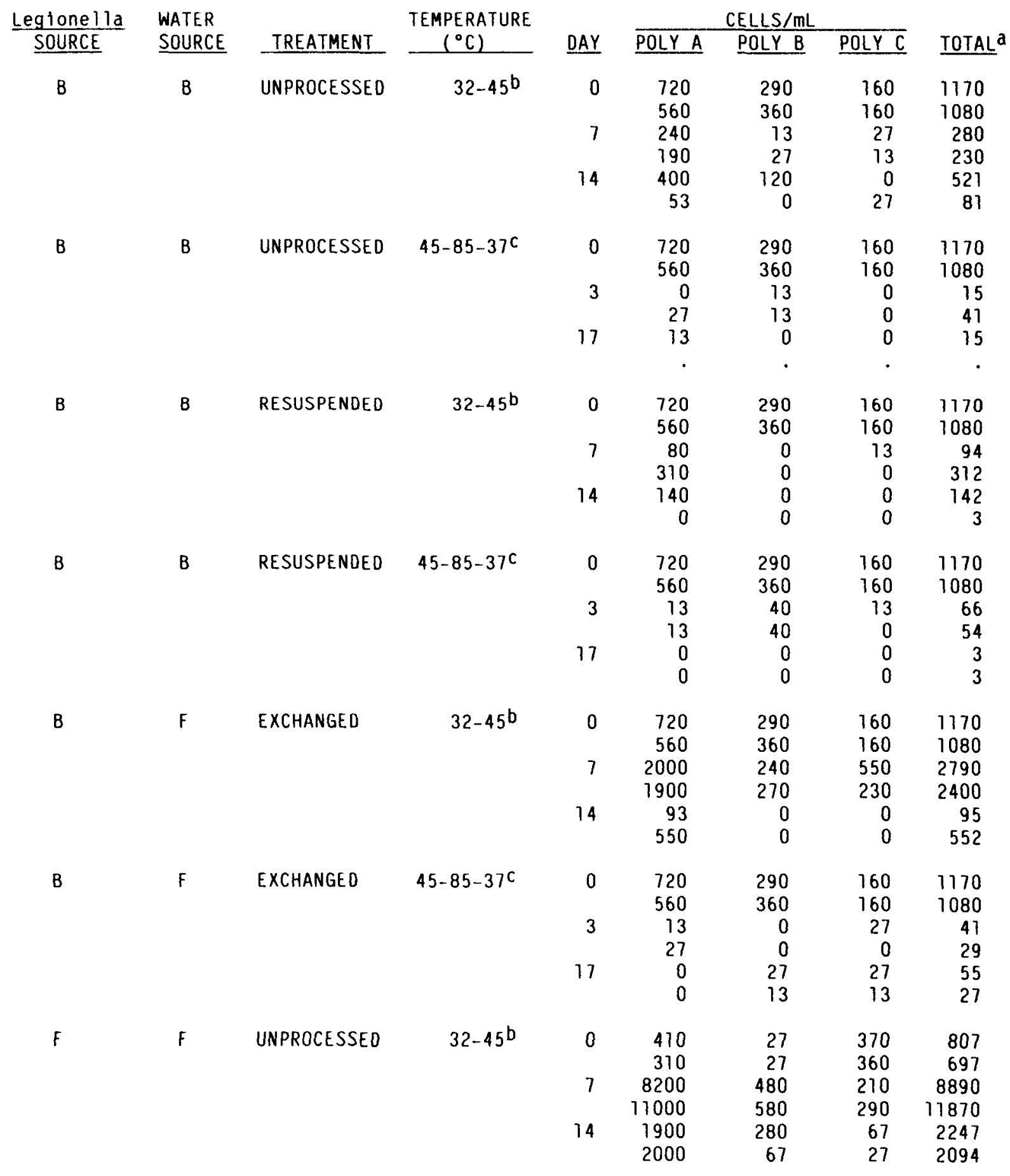

A- 8 
RESULTS OF EXPERIMENT ENV-6 (continued)

\begin{tabular}{|c|c|c|c|c|c|c|c|c|}
\hline Legtonella & WATER & & TEMPERATURE & & & CELLS/m & & \\
\hline SOURCE & SOURCE & -TREATMENT & $\left({ }^{\circ} \mathrm{C}\right)$ & $\underline{\text { DAY }}$ & POLYA & POLY 8 & POLYC & TOTAL $^{a}$ \\
\hline$F$ & F & UNPROCESSED & $45-85-37 c$ & 0 & 410 & 27 & $\begin{array}{l}370 \\
360\end{array}$ & 807 \\
\hline & & & & 3 & $\begin{array}{r}370 \\
0\end{array}$ & $\begin{array}{r}27 \\
0\end{array}$ & $\begin{array}{r}360 \\
0\end{array}$ & $\begin{array}{r}697 \\
3\end{array}$ \\
\hline & & & & & 13 & 0 & 0 & 15 \\
\hline & & & & 17 & 630 & 53 & $\mathbf{0}$ & 684 \\
\hline & & & & & 67 & 40 & 13 & 120 \\
\hline$F$ & $\mathbf{F}$ & RESUSPENDED & $32-45^{b}$ & 0 & 410 & 27 & 370 & 807 \\
\hline & & & & & 310 & 27 & 360 & 697 \\
\hline & & & & 7 & 7400 & 250 & 80 & 7730 \\
\hline & & & & & 7400 & 470 & 120 & 7990 \\
\hline & & & & 14 & 790 & 13 & 13 & 816 \\
\hline & & & & & 430 & 0 & 13 & 444 \\
\hline $\mathrm{F}$ & $F$ & RESUSPENDE D & $45-85-37^{c}$ & 0 & 410 & 27 & 370 & 807 \\
\hline & & & & & 310 & 27 & 360 & 697 \\
\hline & & & & 3 & 13 & 27 & 0 & 41 \\
\hline & & & & & 40 & 40 & 27 & 107 \\
\hline & & & & 17 & 0 & 0 & 0 & 3 \\
\hline & & & & & 13 & 0 & 0 & 15 \\
\hline $\mathrm{F}$ & B & EXCHANGED & $32-45^{b}$ & 0 & 410 & 27 & 370 & 807 \\
\hline & & & & & 310 & 27 & 360 & 697 \\
\hline & & & & 7 & 1900 & 80 & 80 & 2060 \\
\hline & & & & & 2000 & 170 & 67 & 2237 \\
\hline & & & & 14 & 4700 & 160 & 110 & 4970 \\
\hline & & & & & 3900 & 270 & 53 & 4223 \\
\hline $\mathrm{F}$ & B & EXCHANGED & $45-85-37 c$ & 0 & 410 & 27 & 370 & 807 \\
\hline & & & & & 370 & 27 & 360 & 697 \\
\hline & & & & 3 & 600 & 110 & 80 & 790 \\
\hline & & & & & 750 & 200 & 80 & 1030 \\
\hline & & & & 17 & 320 & 53 & 13 & 386 \\
\hline & & & & & 190 & 27 & 27 & 244 \\
\hline
\end{tabular}

\footnotetext{
$\bar{a} \overline{\text { Totals }}$ reflect rounding.

bThe cultures were incubated at $32^{\circ} \mathrm{C}$ for $7 \mathrm{~d}$ and at $45^{\circ} \mathrm{C}$ thereafter.

CThe environmental chamber, inftially set at a temperature of $45^{\circ} \mathrm{C}$, increased to $85^{\circ} \mathrm{C}$ for about $18 \mathrm{~h}$ on day 3 . The cultures were moved to a $37^{\circ} \mathrm{C}$ chamber for the remainder of the experiment.
} 
RESULTS OF EXPERIMENT ENV-7

\begin{tabular}{|c|c|c|c|c|c|c|c|c|}
\hline Legionella & WATER & & TEMPERATURE & & & CELLS/mI & & \\
\hline SOURCE & SOURCE & TREATMENT & $\left({ }^{\circ} \mathrm{C}\right)$ & $\underline{D A Y}$ & $\overline{P O L Y A}$ & POLY 8 & POLY C & TOTAL $^{\mathrm{a}}$ \\
\hline B & B & UNPROCESSED & 32 & 0 & 290 & 27 & 350 & 667 \\
\hline & & & & & 130 & $\begin{array}{l}80 \\
27\end{array}$ & 310 & $\begin{array}{r}520 \\
41\end{array}$ \\
\hline & & & & 7 & $\begin{array}{r}0 \\
13\end{array}$ & $\begin{array}{l}27 \\
13\end{array}$ & $\begin{array}{r}13 \\
0\end{array}$ & $\begin{array}{l}41 \\
27\end{array}$ \\
\hline & & & & 17 & 120 & 0 & 0 & 122 \\
\hline & & & & & 230 & 27 & 0 & 258 \\
\hline B & B & UNPROCESSED & 45 & 0 & 290 & 27 & 350 & 667 \\
\hline & & & & & 130 & 80 & 310 & 520 \\
\hline & & & & 7 & 160 & 0 & 0 & 162 \\
\hline & & & & & 40 & 0 & 0 & 42 \\
\hline & & & & 17 & 0 & 0 & 0 & 3 \\
\hline & & & & & 0 & 0 & 0 & 3 \\
\hline$B$ & B & RESUSPENDED & 32 & 0 & 290 & 27 & 350 & 667 \\
\hline & & & & & 130 & 80 & 310 & 520 \\
\hline & & & & 7 & 13 & 40 & 13 & 66 \\
\hline & & & & & 27 & 0 & 0 & 29 \\
\hline & & & & 17 & 270 & 0 & 0 & 272 \\
\hline & & & & & 110 & 0 & 13 & 124 \\
\hline 8 & B & RESUSPENDED & 45 & 0 & 290 & 27 & 350 & 667 \\
\hline & & & & & 130 & 80 & 310 & 520 \\
\hline & & & & 7 & 27 & 0 & 0 & 29 \\
\hline & & & & & 40 & 0 & 0 & 42 \\
\hline & & & & 17 & 0 & 0 & 0 & 3 \\
\hline & & & & & 13 & 0 & 0 & 15 \\
\hline 8 & $\mathrm{~F}$ & EXCHANGED & 32 & 0 & 290 & 27 & 350 & 667 \\
\hline & & & & & 130 & 80 & 310 & 520 \\
\hline & & & & 7 & 13 & 0 & 13 & 27 \\
\hline & & & & & 0 & 67 & 0 & 69 \\
\hline & & & & 17 & 0 & 910 & 13 & 924 \\
\hline & & & & & 170 & 0 & 40 & 211 \\
\hline 8 & $\mathrm{~F}$ & EXCHANGED & 45 & 0 & 290 & 27 & 350 & 667 \\
\hline & & & & & 130 & 80 & 310 & 520 \\
\hline & & & & 7 & 180 & 13 & 13 & 206 \\
\hline & & & & & 110 & 13 & 13 & 136 \\
\hline & & & & 17 & 480 & 67 & 13 & 560 \\
\hline & & & & & 27 & 13 & 67 & 107 \\
\hline
\end{tabular}


RESULTS OF EXPERIMENT ENV-7 (continued)

\begin{tabular}{|c|c|c|c|c|c|c|c|c|}
\hline Legtonella & WATER & & TEMPERATURE & & & CELLS/mL & & \\
\hline SOURCE & SOURCE & TREATMENT & $\left({ }^{\circ} \mathrm{C}\right)$ & DAY & POLY A & POLY B & $P O L Y C$ & $\underline{\text { TOTAL }}^{\mathrm{a}}$ \\
\hline $\mathrm{F}$ & $\mathrm{F}$ & UNPROCESSED & 32 & 0 & $\begin{array}{l}1700 \\
1500\end{array}$ & $\begin{array}{l}590 \\
630\end{array}$ & $\begin{array}{r}130 \\
93\end{array}$ & $\begin{array}{l}2420 \\
2223\end{array}$ \\
\hline & & & & 7 & 480 & 140 & 0 & 621 \\
\hline & & & & & 50 & 93 & 110 & 253 \\
\hline & & & & 17 & 110 & 27 & 80 & 217 \\
\hline & & & & & 280 & 13 & 13 & 306 \\
\hline $\mathrm{F}$ & $\mathrm{F}$ & UNPROCESSED & 45 & 0 & 1700 & 590 & 130 & 2420 \\
\hline & & & & & 1500 & 630 & 93 & 2.223 \\
\hline & & & & 7 & 40 & 100 & 93 & 233 \\
\hline & & & & & 120 & 0 & 0 & 122 \\
\hline & & & & 17 & 93 & 13 & 93 & 199 \\
\hline & & & & & 170 & 0 & 120 & 291 \\
\hline $\mathrm{F}$ & $\mathrm{F}$ & RESUSPENDED & 32 & 0 & 1700 & 590 & 130 & 2420 \\
\hline & & & & & 1500 & 630 & 93 & 2223 \\
\hline & & & & 7 & 150 & 0 & 0 & 152 \\
\hline & & & & & 27 & 0 & 0 & 29 \\
\hline & & & & 17 & 94 & 60 & 210 & 364 \\
\hline & & & & & 86 & 0 & 27 & 114 \\
\hline$F$ & $\mathrm{~F}$ & RESUSPENDED & 45 & 0 & 1700 & 590 & 130 & 2420 \\
\hline & & & & & 1500 & 630 & 93 & 2223 \\
\hline & & & & 7 & 170 & 13 & 13 & 196 \\
\hline & & & & & 150 & 40 & 0 & 197 \\
\hline & & & & 17 & 570 & 40 & 80 & 690 \\
\hline & & & & & 410 & 27 & 40 & 477 \\
\hline $\mathrm{F}$ & B & EXCHANGED & 32 & 0 & 1700 & 590 & 130 & 2420 \\
\hline & & & & & 1500 & 630 & 93 & 2223 \\
\hline & & & & 7 & 70 & 93 & 13 & 176 \\
\hline & & & & & 13 & 40 & 0 & 54 \\
\hline & & & & 17 & 90 & 20 & 120 & 230 \\
\hline & & & & & 150 & 40 & 120 & 310 \\
\hline $\mathrm{F}$ & 8 & EXCHANGED & 45 & 0 & 1700 & 590 & 130 & 2420 \\
\hline & & & & & 1500 & 630 & 93 & 2223 \\
\hline & & & & 7 & 690 & 40 & 13 & 743 \\
\hline & & & & & 560 & 0 & 13 & 574 \\
\hline & & & & 17 & 940 & 53 & 69 & 1062 \\
\hline & & & & & 1000 & 80 & 80 & 1160 \\
\hline
\end{tabular}

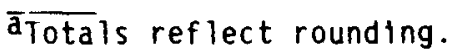


RESULTS OF EXPERIMENT ENV-8

Legionella CONCENTRATION

\begin{tabular}{|c|c|c|c|c|c|c|}
\hline \multirow{2}{*}{$\begin{array}{l}\text { WATER } \\
\text { SOURCE }\end{array}$} & \multirow{2}{*}{$\begin{array}{l}\text { PELLET } \\
\text { PRESENT } \\
\end{array}$} & \multirow[b]{2}{*}{ FILTRATION } & \multirow[b]{2}{*}{ DAY } & \multicolumn{3}{|c|}{ (CELLS/mL) } \\
\hline & & & & $\overline{P O L Y A}$ & POLY B & POLY C \\
\hline \multirow[t]{20}{*}{ B } & NO & NO & 0 & 0 & 0 & 0 \\
\hline & & & 3 & 80 & 53 & 0 \\
\hline & & & 3 & 107 & 0 & 27 \\
\hline & & & 7 & 0 & . & . \\
\hline & & & 7 & 0 & 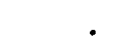 & . \\
\hline & NO & YES & 0 & 27 & 0 & 0 \\
\hline & & & 3 & 31413 & 6320 & 213 \\
\hline & & & 3 & 9707 & 53 & 27 \\
\hline & & & 7 & 0 & . & . \\
\hline & & & 7 & 0 & & \\
\hline & YES & NO & 0 & 373 & 267 & 213 \\
\hline & & & 3 & 6249 & 297 & 200 \\
\hline & & & 3 & 5050 & 320 & 80 \\
\hline & & & 7 & 0 & . & . \\
\hline & & & 7 & 667 & & \\
\hline & YES & YES & 0 & 373 & 267 & 213 \\
\hline & & & 3 & 1680 & 320 & 0 \\
\hline & & & 3 & 907 & 80 & 267 \\
\hline & & & 7 & 0 & . & . \\
\hline & & & 7 & 0 & 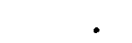 & . \\
\hline \multirow[t]{20}{*}{$F$} & NO & NO & 0 & 0 & 0 & 0 \\
\hline & & & 3 & 7840 & 640 & 107 \\
\hline & & & 3 & 9920 & 827 & 53 \\
\hline & & & 7 & 15147 & . & . \\
\hline & & & 7 & 4387 & 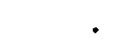 & . \\
\hline & NO & YES & 0 & 27 & 0 & 0 \\
\hline & & & 3 & 0 & 0 & 0 \\
\hline & & & 3 & 3325 & 347 & 0 \\
\hline & & & 7 & 1227 & . & . \\
\hline & & & 7 & 0 & . & \\
\hline & YES & NO & 0 & 373 & 267 & 213 \\
\hline & & & 3 & 2812 & 853 & 267 \\
\hline & & & 3 & 293 & 800 & 53 \\
\hline & & & 7 & 68800 & $\cdot$ & 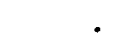 \\
\hline & & & 7 & 5547 & 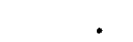 & \\
\hline & YES & YES & 0 & 373 & 267 & 213 \\
\hline & & & 3 & 347 & 187 & 27 \\
\hline & & & 3 & 1920 & 133 & 27 \\
\hline & & & 7 & 11413 & & . \\
\hline & & & 7 & 12640 & 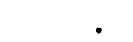 & . \\
\hline
\end{tabular}


RESULTS OF EXPERIMENT ENV-9

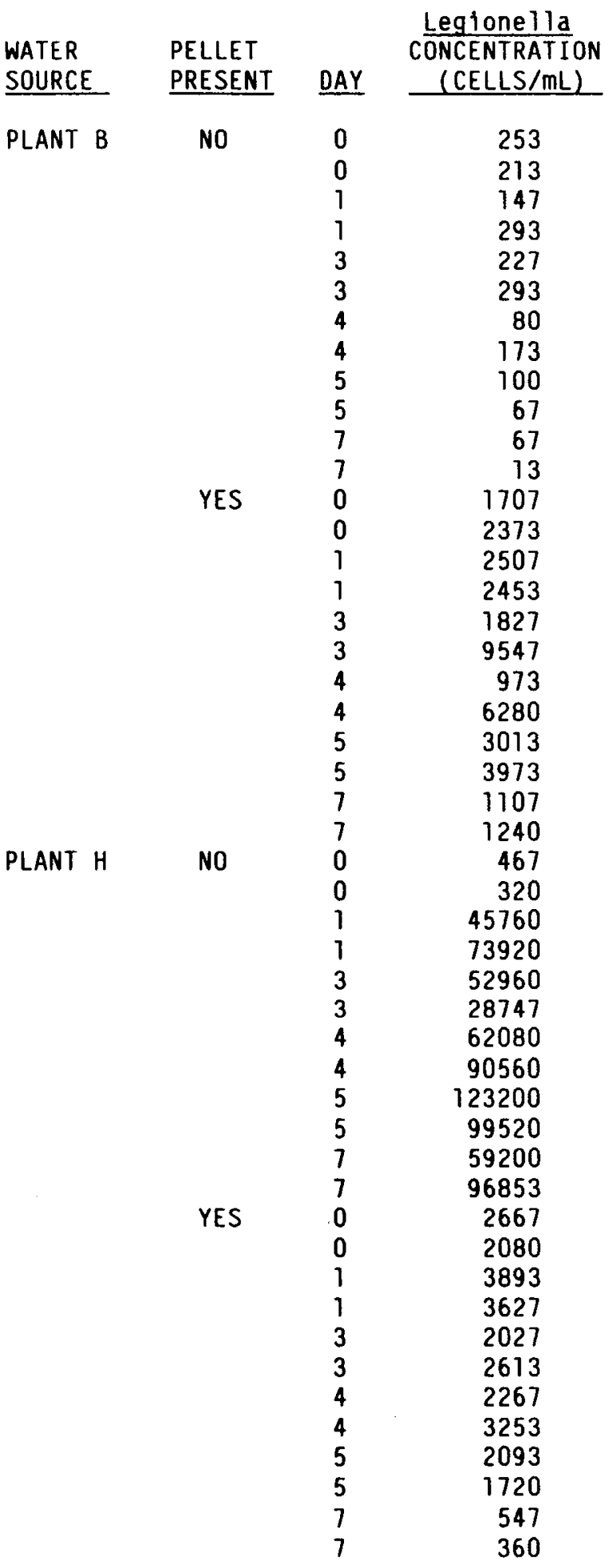


RESULTS OF EXPERIMENT ENV- 10

\begin{tabular}{|c|c|c|c|c|c|c|c|}
\hline \multirow{2}{*}{$\begin{array}{c}\text { WATER } \\
\text { DEPTH } \\
\text { (m) }\end{array}$} & \multirow{2}{*}{$\begin{array}{c}\text { DESIRED } \\
\text { NI TRATE } \\
\text { LEVEL } \\
(\mathrm{mg} / \mathrm{L}) \\
\end{array}$} & \multirow[b]{2}{*}{$\underline{\text { DAY }}$} & \multicolumn{3}{|c|}{ Leajonella DENSITY } & \multirow{2}{*}{$\begin{array}{l}\text { MEASURED } \\
\text { NITRATE } \\
\text { LEVEL } \\
(\mathrm{mg} / \mathrm{L})\end{array}$} & \multirow{2}{*}{$\begin{array}{l}\text { MEASURED } \\
\text { AMMONIUM } \\
\text { LEVEL } \\
(\mathrm{mg} / \mathrm{L})\end{array}$} \\
\hline & & & POLY A & POLY B & POLY C & & \\
\hline 2 & 0 & 0 & 53 & 0 & 0 & 0.00 & 0.02 \\
\hline & & 0 & 80 & 80 & $\begin{array}{r}67 \\
260\end{array}$ & 0.00 & 0.02 \\
\hline & & 3 & 5600 & 160 & 500 & 0.04 & 0.07 \\
\hline & & 7 & 860 & 106 & 26 & 0.23 & 0.07 \\
\hline & & 7 & 2400 & 320 & 80 & 0.54 & 0.06 \\
\hline & 50 & 0 & 53 & 0 & 0 & . & 0.02 \\
\hline & & 0 & 80 & 80 & 67 & & 0.02 \\
\hline & & 3 & 2600 & 134 & 320 & 78.00 & 0.09 \\
\hline & & 3 & 3600 & 240 & 200 & 67.00 & 0.09 \\
\hline & & 7 & 3000 & 160 & 160 & 60.00 & 0.03 \\
\hline & & 7 & 4200 & 80 & 106 & 61.00 & 0.01 \\
\hline 5 & 0 & 0 & 1700 & 40 & 0 & 0.00 & 0.02 \\
\hline & & 0 & 570 & 110 & 13 & 0.00 & 0.02 \\
\hline & & 3 & 4200 & 8600 & 80 & 0.04 & 0.12 \\
\hline & & 3 & 2800 & 500 & 580 & . & 0.14 \\
\hline & & 7 & 1680 & 13000 & 134 & 0.20 & 0.13 \\
\hline & & 7 & 1760 & 1860 & 106 & 0.08 & 0.22 \\
\hline & 50 & 0 & 1100 & 40 & 0 & . & 0.02 \\
\hline & & 0 & 570 & 110 & 13 & . & 0.02 \\
\hline & & 3 & 1500 & 620 & 2 & 71.00 & 0.08 \\
\hline & & 3 & 2800 & 260 & 26 & 70.00 & 0.11 \\
\hline & & 7 & 2400 & 2 & 54 & 90.00 & 0.05 \\
\hline & & 7 & 4200 & 320 & 134 & 78.00 & 0.09 \\
\hline
\end{tabular}


RESULTS OF MEMBRANE CHAMBER STUDY

TREATMENT

RAW WATER

STERILE FILTERED WATER

BACTERIAL BANDS

Legionella CONCENTRATION

DAY POLYA POLYB POLYC

$\begin{array}{rrrr}0 & 833 & 167 & 167 \\ 0 & 2333 & 0 & 0 \\ 1 & 2667 & 0 & 0 \\ 1 & 0 & 0 & 0 \\ 5 & 500 & 0 & 0 \\ 5 & 167 & 0 & 167 \\ 11 & 0 & 0 & 0 \\ 11 & 0 & 0 & 0 \\ 0 & 333 & 0 & 0 \\ 1 & 0 & 0 & 0 \\ 5 & 0 & 0 & 0 \\ 11 & 0 & 0 & 0 \\ 0 & 0 & 0 & 0 \\ 0 & 333 & 0 & 0 \\ 1 & 0 & 0 & 0 \\ 5 & 500 & 0 & 0 \\ 5 & 0 & 0 & 0 \\ 11 & 0 & 0 & 0 \\ 11 & 0 & 0 & 0 \\ 0 & 167 & 0 & 167 \\ 0 & 167 & 0 & 0 \\ 1 & 167 & 0 & 0 \\ 1 & 0 & 0 & 0 \\ 5 & 0 & 167 & 0 \\ 5 & 333 & 0 & 0 \\ 11 & 0 & 0 & 0 \\ 11 & 0 & 0 & 0\end{array}$

